\title{
Exploring African Francophone Doctoral Student Experiences of Student-Faculty Relationship
}

Nathalie Hoblebou Rouamba

Follow this and additional works at: https://researchrepository.wvu.edu/etd

\section{Recommended Citation}

Rouamba, Nathalie Hoblebou, "Exploring African Francophone Doctoral Student Experiences of StudentFaculty Relationship" (2017). Graduate Theses, Dissertations, and Problem Reports. 6535.

https://researchrepository.wvu.edu/etd/6535

This Dissertation is protected by copyright and/or related rights. It has been brought to you by the The Research Repository @ WVU with permission from the rights-holder(s). You are free to use this Dissertation in any way that is permitted by the copyright and related rights legislation that applies to your use. For other uses you must obtain permission from the rights-holder(s) directly, unless additional rights are indicated by a Creative Commons license in the record and/ or on the work itself. This Dissertation has been accepted for inclusion in WVU Graduate Theses, Dissertations, and Problem Reports collection by an authorized administrator of The Research Repository @ WVU.

For more information, please contact researchrepository@mail.wvu.edu. 


\title{
Exploring African Francophone Doctoral Student Experiences of Student-Faculty Relationship
}

\author{
Nathalie Hoblebou Rouamba \\ A Dissertation submitted to the \\ College of Education and Human Services at \\ West Virginia University \\ in partial fulfillment of the requirements for the degree of \\ Interdisciplinary Ph.D. in Education
}

Erin McHenry-Sorber, Ph.D., Chair

Reagan Curtis, Ph.D.

Nathan Sorber, Ph.D.

Heiko Ter Haseborg, Ph.D.

Jennifer Douglas, Ph.D.

Department of Curriculum, Literacy, and Cultural Studies

\author{
Morgantown, West Virginia
}

2017

Keywords: African Francophone doctoral student, advisor, international student, graduate school, language socialization, student-faculty relationship

Copyright @ 2017 Nathalie Rouamba 


\begin{abstract}
Exploring African Francophone Doctoral Student Experiences of Student-Faculty Relationship

Nathalie Hoblebou Rouamba

Graduate student-faculty relationships can impact student program completion, career path, attrition, success, and overall experience. With the increase of African graduate students in the United States, there is a need to understand the relationship dynamics between these students and American faculty. The existing research studies on African students tend to focus on student experience with discrimination, language difficulties, cultural adjustment, financial issues, isolation, and loneliness. This qualitative study explores the experiences of African Francophone doctoral students using a single case study and narrative approach. This research finds African Francophone doctoral student-faculty relationships are multifaceted, and tainted by uneven power in some instances, by linguistic and cultural barriers in others, and by support and encouragement in others.
\end{abstract}


Dedication

To Guieswende, Regis, and Jude. 


\section{Acknowledgements}

"The Lord is my strength and my shield; my heart trusts in him, and he helps me. My heart leaps for joy, and with my song I praise him" (Psalm 28:7).

This study would not have been possible without the support and prayers of many people. I want to first thank my best friend and husband Guieswende Rouamba for following his dreams and coming to the U.S., and for standing by me and believing in me. This dissertation is your reward and a tribute to your love for me.

Special thanks to my sons Regis and Jude for their constant prayers, smiles, and hugs during the difficult times of this dissertation and my studies.

A very special gratitude goes out to my advisor and chair, Dr. Erin McHenry-Sorber. Under her guidance, I embarked on this long and yet rewarding journey. Thank you for your advice, availability, feedback, and keen attention to my situation of international student. I am also grateful to my committee members, Dr. Nathan Sorber and Dr. Heiko Ter Haseborg, for their countless support and feedback. A special thank you to Dr. Jenny Douglas for believing in me and providing me with a graduate assistantship position for several years. A special thank you to Dr. Reagan Curtis for his inspiration, support, great lectures and the opportunity to develop my research skills at the Program Evaluation and Research Center (PERC).

Thank you Dr. Philip Adu and Dr. Joy Martin for your valuable feedback and sharing resources with me.

I am grateful to my parents Victorine and Jacques Ouandaogo for their love, support, encouragement, and for teaching me the importance of persistence and hard work. Thank you for cultivating in me the love to read. Thank you to my brothers and sisters, Claude, Sandrine, 
Gisele, David, Pascal, and Jacqueline Ouandaogo. A special thank you to Gisele Ouandaogo and Sylvie Zigani for their encouragement and support throughout my studies in the U.S.

Thank you to my friends Jacob and Josephine Sanwidi for their infallible friendship, advice, and support.

Thank you to my twin sister from Russia, Natalya Kuznetsova. You are a valuable friend, and a great study buddy and project partner. I enjoyed our exchanges and your words of wisdom.

Thank you to my friends Julie and Brice Gnahore for their incessant support. Dr. Lohi, your hard work is very inspiring.

Thank you to all my wonderful friends, Nadine Ayo-Zabramba, Jean Michel Lops, Yemdaogo and Edwige Tougma, Patoimbasba and Biba Nikiema, and Charles and Hortense Kietega. A special thank you to Nadine, Edwige, Patoimbasba, and Jean Michel for their cheers and prayers.

A special thank you to two amazing persons, Dr. Amy Kuhn and Dr. Constinia Charbonnette, for their continuous support.

Thank you to all the Burkinabe in Lincoln, Nebraska who welcome me when I moved there in 2015.

Thank you to all the faculty at WVU who inspired me: Dr. Janice Spleth, Dr. John Oughton, and Dr. Samuel Stack.

Finally, I must express my very profound gratitude to my participants for sharing their time, and personal stories with me. Without you, this study would not have been possible.

To anyone that I may have forgotten. I apologize. Thank you as well. 


\section{Table of Contents}

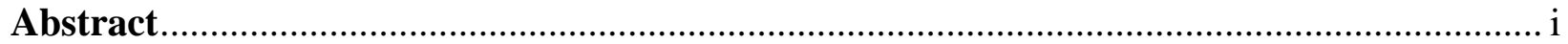

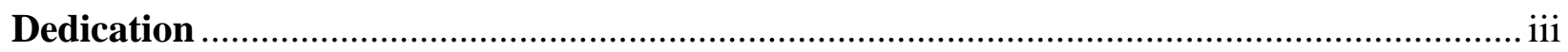

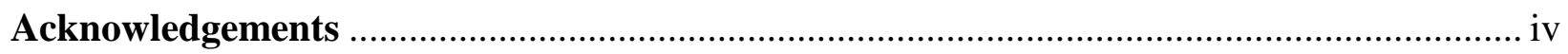

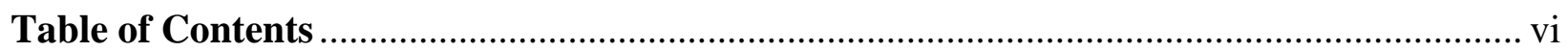

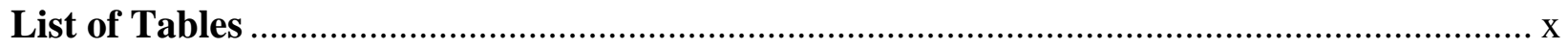

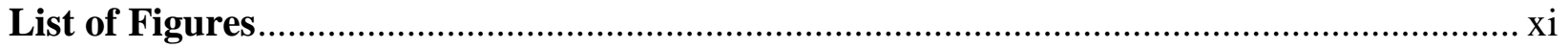

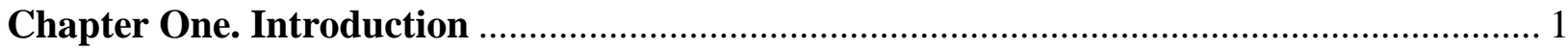

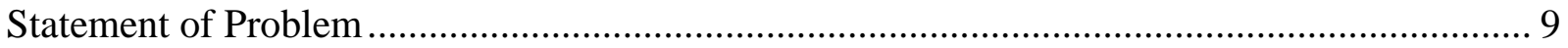

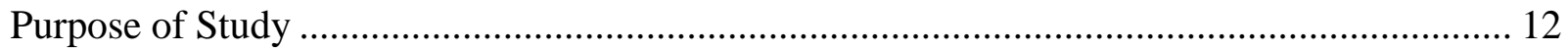

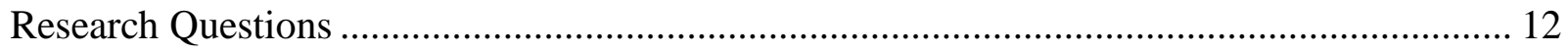

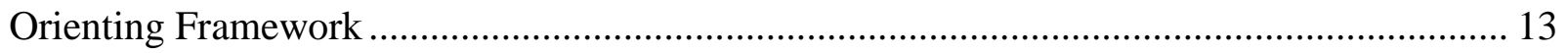

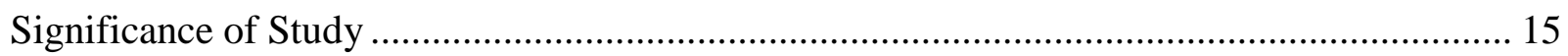

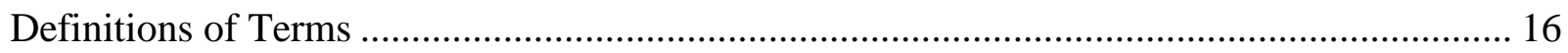

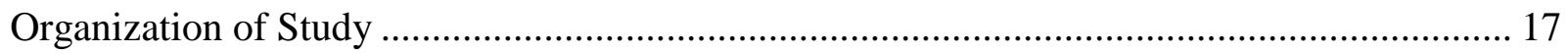

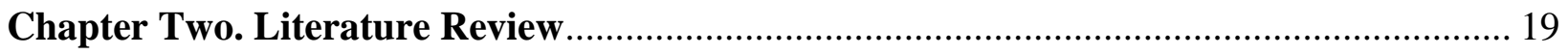

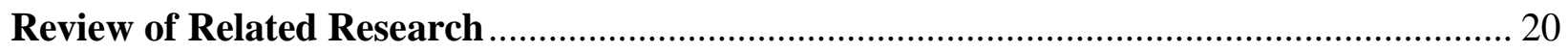

Research on International Graduate Students ............................................................... 20

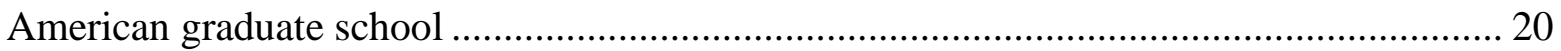

International graduate students ......................................................................... 24

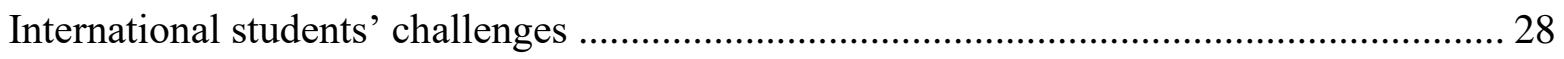

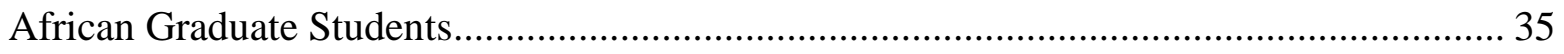

Research on Student-Faculty Relationship ............................................................. 44

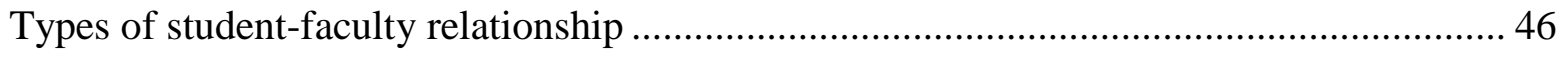

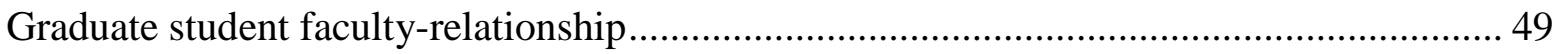




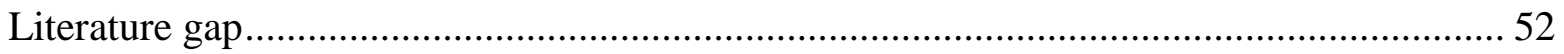

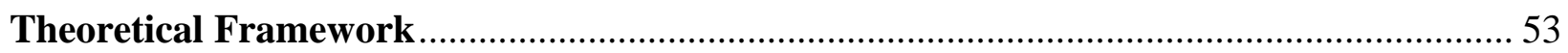

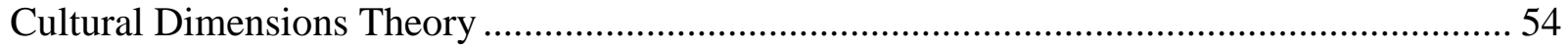

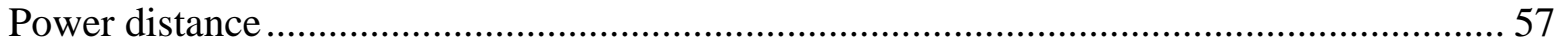

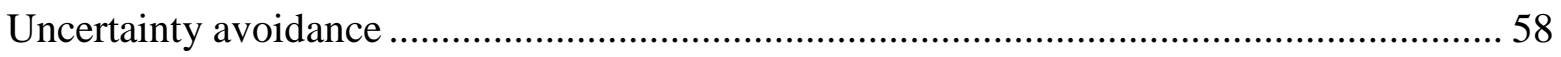

Individualism versus collectivism ..................................................................... 58

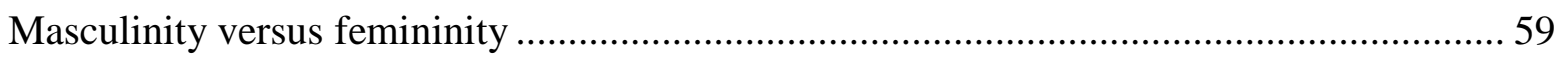

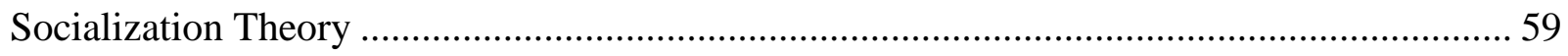

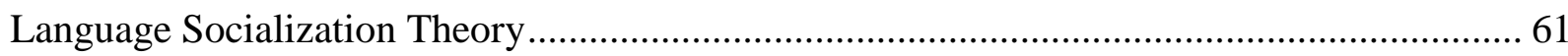

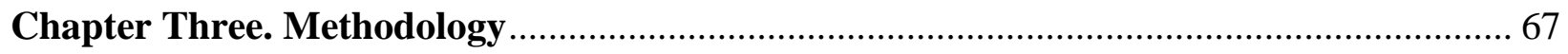

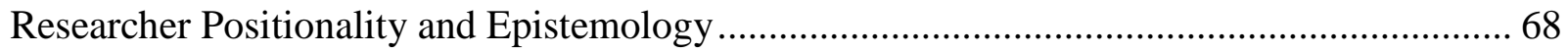

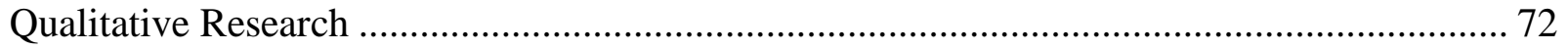

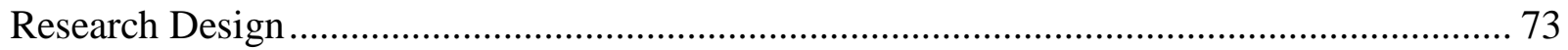

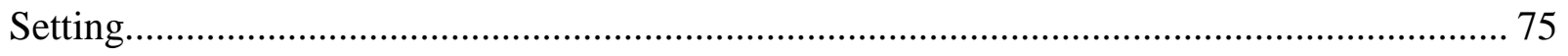

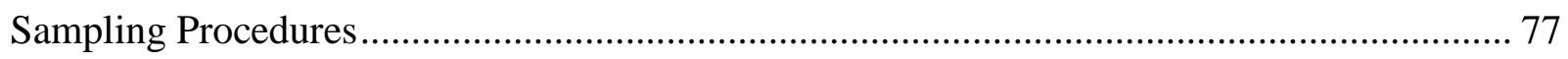

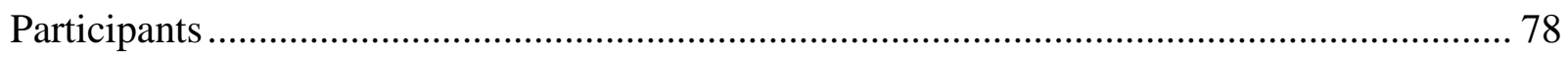

Data Collection and Data Collection Plan........................................................................ 79

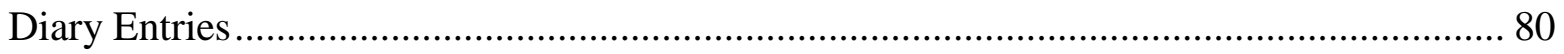

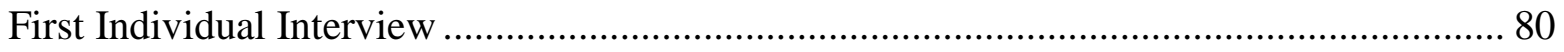

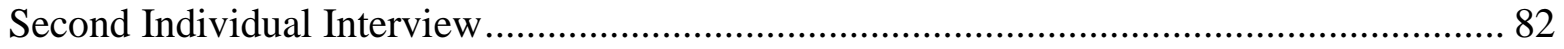

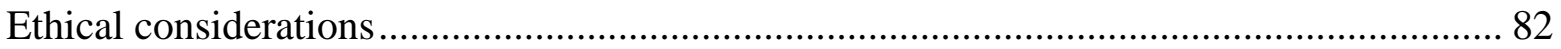

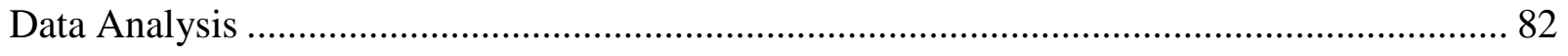

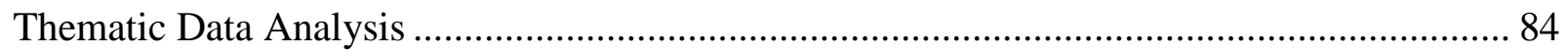

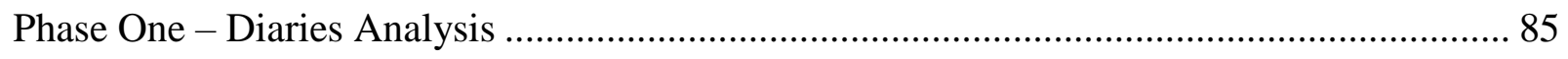

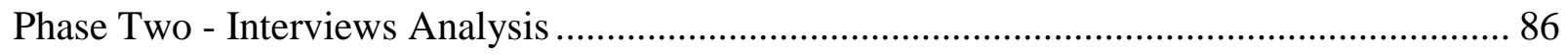




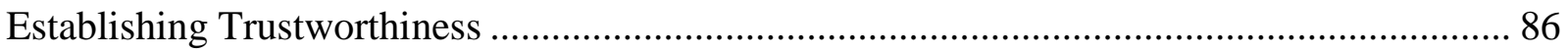

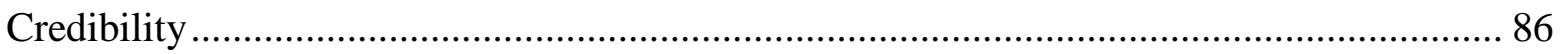

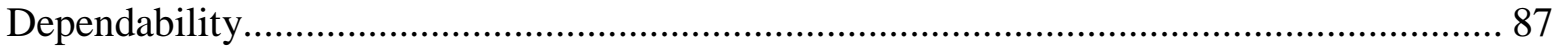

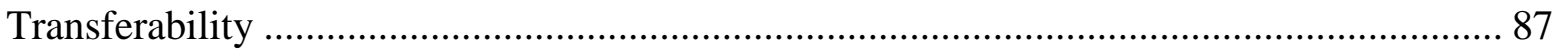

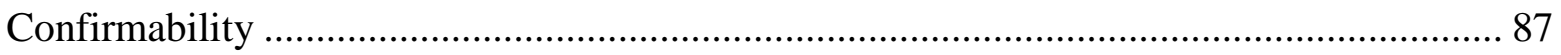

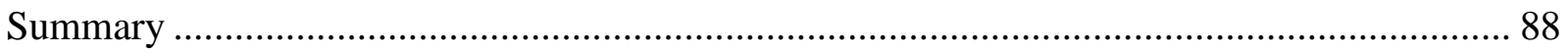

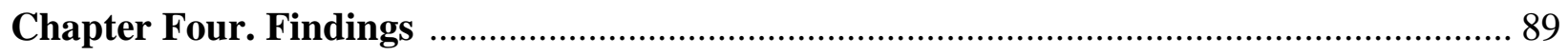

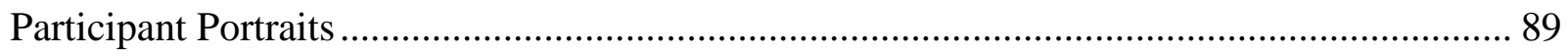

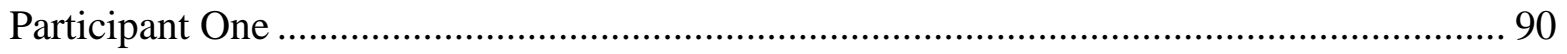

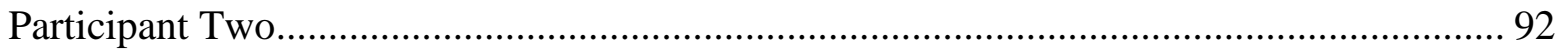

Participant Three

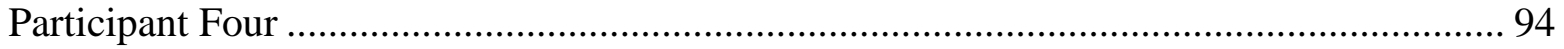

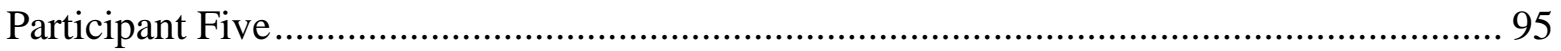

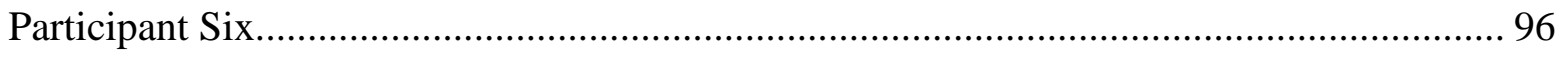

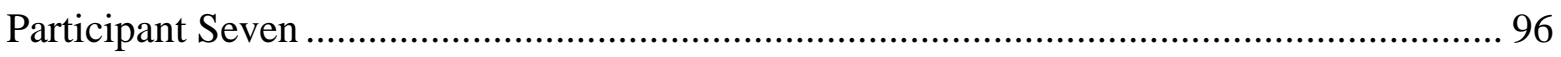

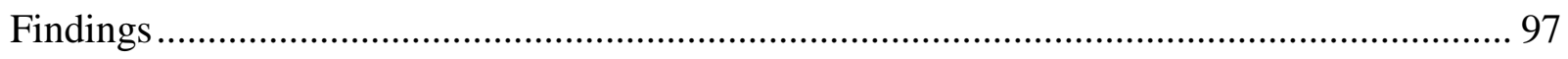

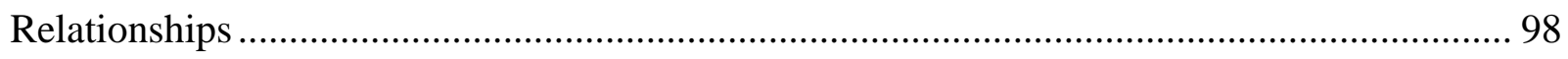

Advisor Relationships................................................................................................... 98

African Francophone Doctoral Students' Perceptions of Relationships .................................. 101

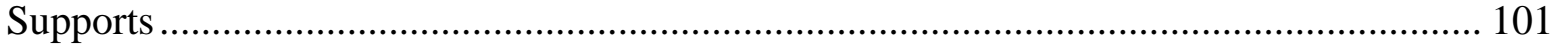

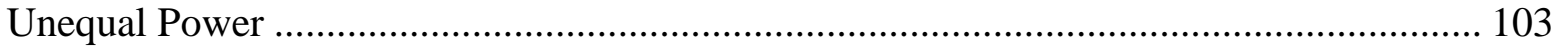

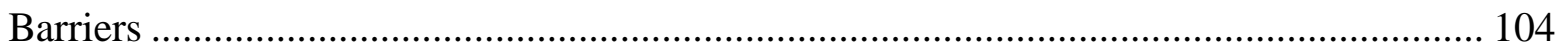

Influences on Student-Faculty Relationships ...................................................................... 105

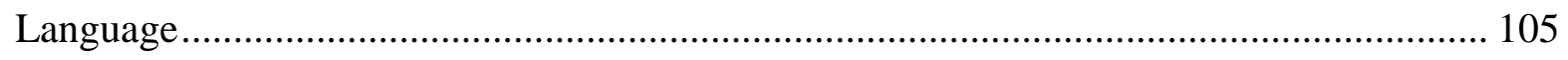

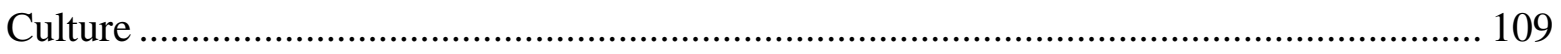




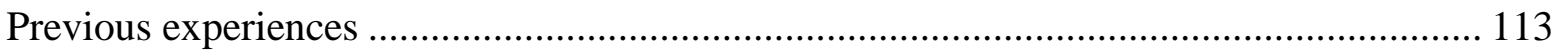

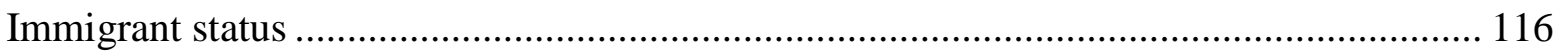

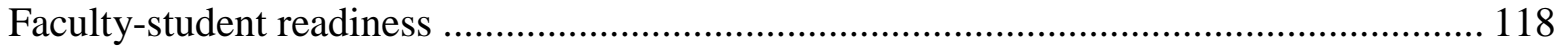

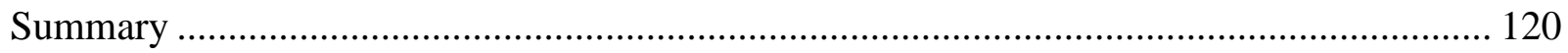

Chapter Five. Discussion, Implications, and Conclusion ........................................ 121

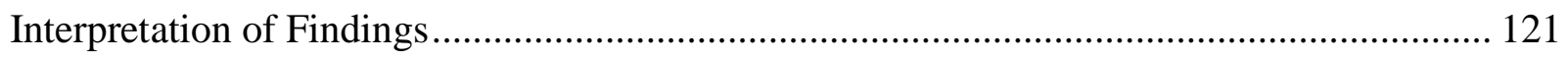

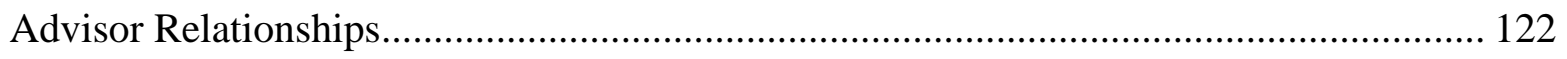

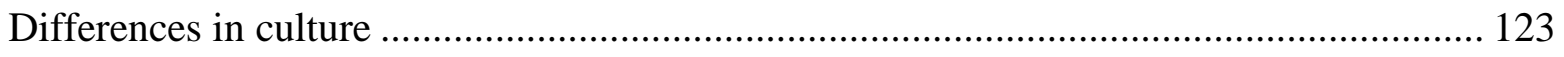

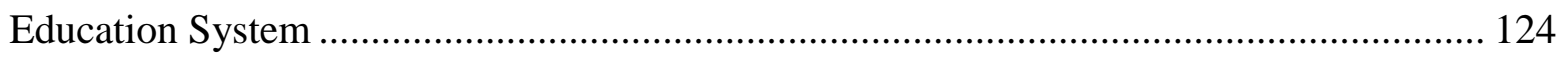

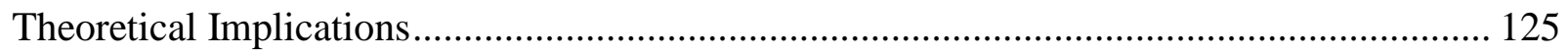

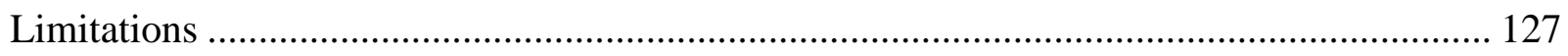

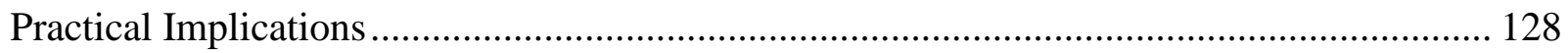

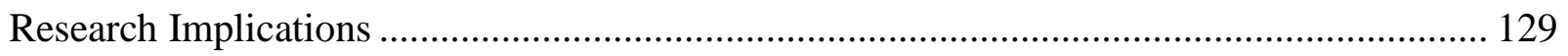

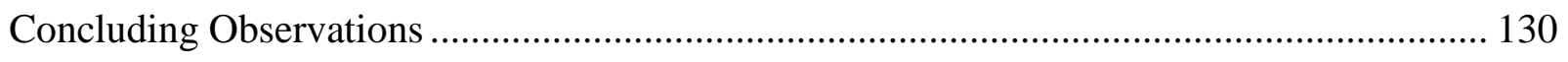

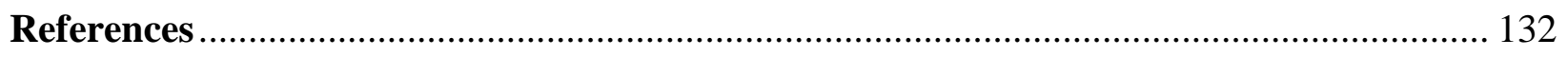

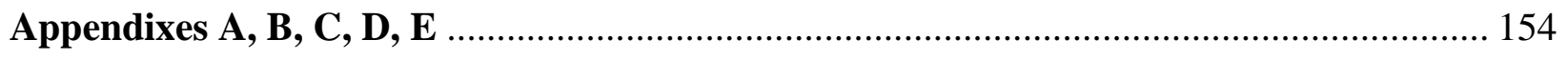

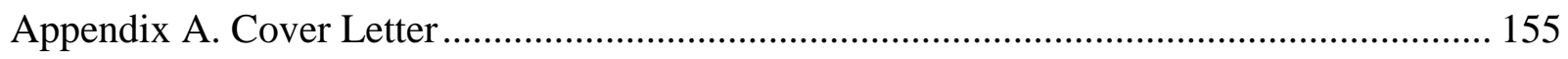

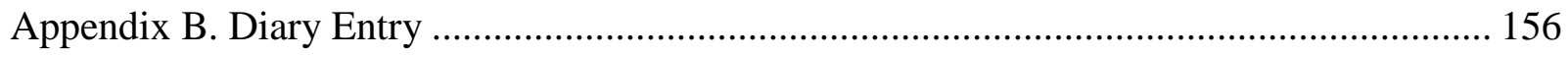

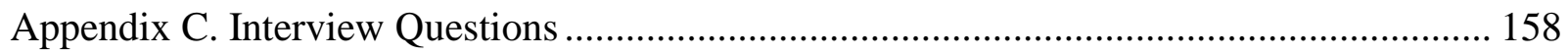

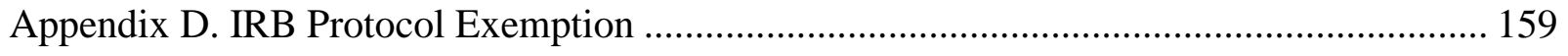

Appendix E. Letter of permission to conduct research ............................................... 161 


\section{List of Tables}

\section{Chapter One. Introduction}

Table 1.1 International Students in United States Universities and Colleges 2010/11 - 2014/15 .. 2

Table 1.2 Description of African Students Presence in the U.S. by Place of Origin................... 3

\section{Chapter Two. Literature review}

Table 2.1 U.S. Colleges and Universities' Compliances with SEVIS Guidelines ..................... 25

Table 2.2 Description of Glasser and Hook III's Expectations for Advising ............................ 48

\section{Chapter Three. Methodology}

Table 3.1 Origin of a Midwest Public University African Students ....................................... 75

Table 3.2 Overview of Participants Gender, Continental Region, and Department................... 79

\section{Chapter Four. Findings}

Table 4.1 Emergent Themes ..................................................................................... 97 


\section{List of Figures}

\section{Chapter Two. Literature Review}

Figure 2.1 Map of Africa with Burkina Faso, Cameroon, Senegal, and Tunisia........................ 37

Figure 2.2 Proposed model of an ideal advisor for international graduate students .................... 52

Figure 2.3 Hofstede's description of cultural dimensions ................................................. 57

Figure 2.4 Illustration of the four stages of socialization (Weidman, Twale, \& Stein, 2001)..... 60

Figure 2.5 Illustration of language socialization (Ochs \& Schieffelin, 2011) ........................... 62

\section{Chapter Three. Methodology}

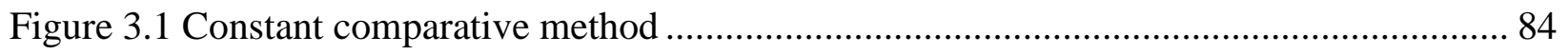




\section{Chapter One. Introduction}

At the core of most critiques of American higher education is the assertion that effective education requires close working relationships between faculty and students. This interaction is seen not only as a means by which the transmission of knowledge and student intellectual growth is best facilitated, but as an educational goal in and of itself.

--Wilson et al. $(1975$, p. 30)

Students travelling abroad to pursue an education is not new. The presence of the first international student in the United States (U.S.) can be traced back to 1784 (Giacchino-Baker \& Baker, 1995; Jenkins, 1983). This number increased to 2,673 in 1904 (Giacchino-Baker \& Baker, 1995) and to 15,000 in 1946 (Jenkins, 1983). Today the number of international students in the U.S. is close to a million (Institute of International Education [IIE] Open Doors, 2015). This growth has been attributed to many reasons, including: the active recruitment by U.S. colleges and universities (IIE Open Doors, 2015); international government scholarships programs and family funds (Agarwal \& Winkler, 1985; IIE Open Doors, 2015); the quality of U.S. higher education (Arthur \& Nunes, 2014); the advancement of career opportunities (Kumi-Yeboah, 2014); American and foreign institutions partnerships (IIE Open Doors, 2015); and the plethora of educational resources and financial support in U.S. higher education (Kumi-Yeboah, 2014). Along these lines, McMahon (1992) used push-pull factors to describe the reasons students leave their home countries' "push" factors to come to the United States' "pull" factors. For example, Sahasrabudhe (2007) found that "the quality of faculty, factors related to the curriculum, infrastructural issues, reservation policies, undergraduate admission process, desire to pursue graduate education and limited opportunities for graduate programs in India" (p. 72) were push factors for Indian students to come to the U.S. Similarly, many African students leave their home 
countries because of the lack of resources, quality of faculty, and uncertainty about the future. Barry (2011) when describing Burkina Faso tertiary education, argued that multiple strikes, academic sessions nullified, campus lockdowns by police, overcrowded classrooms, and quality of education are many of the reasons Burkina Faso students seek better opportunities in other countries. Table 1.1 introduces international students' growth over the last five years in the U.S.

Table 1.1

International Students in United States Universities and Colleges 2010/11 - 2014/15

\begin{tabular}{lllll}
\hline Year & $\begin{array}{l}\text { Total of } \\
\text { international } \\
\text { students }\end{array}$ & $\begin{array}{l}\text { Annual \% } \\
\text { change }\end{array}$ & $\begin{array}{l}\text { Total of } \\
\text { International } \\
\text { graduate students }\end{array}$ & $\begin{array}{l}\text { Annual \% } \\
\text { change }\end{array}$ \\
\hline $2010 / 11$ & 723,277 & 4.7 & 296,574 & 0.9 \\
$2011 / 12$ & 764,495 & 5.7 & 300,430 & 1.3 \\
$2012 / 13$ & 819,644 & 7.2 & 311,204 & 3.6 \\
$2013 / 14$ & 886,052 & 8.1 & 329,854 & 6.0 \\
$2014 / 15$ & 974,926 & 10.0 & 362,228 & 9.8 \\
\hline
\end{tabular}

Note. Open Doors Report on International Educational Exchange 2010-2015.

Other western countries have also experienced increased enrollments of international students in their institutions. In 2014-2015, 436,880 international students were studying in the United Kingdom (Higher Education Statistics Agency [HESA] first statistical release 224, 20142015), and 336,000 in Canada (Canadian Bureau for International Education [CBIE], 2014). Yet, the United States remains the first destination of choice for many international students.

International students are students studying in the U.S. and who hold another country's citizenship. Specifically, the Institute of International Education (2016) defines an international student "as anyone studying at an institution of higher education in the United States on a temporary visa that allows for academic coursework. These include primarily holders of $F$ (student) visas and J (exchange visitor) visas" (http://www.iie.org/Research-andPublications/Open-Doors/FAQ). International students' numbers increase every year (IIE Open Doors, 2015) bringing opportunities and challenges to U.S. colleges and universities. 
International students are known to bring diverse perspectives within the American classroom and financial contributions to U.S. colleges (Mamiseishvili, 2012). In 2014-2015 international students across the U.S. contributed $\$ 30.5$ billion to the U.S. economy (NAFSA Report, 20142015). Currently, more than $37 \%$ of international students are enrolled in graduate school (IIE Open Doors Report, 2014). In addition to bringing diverse perspectives in the classroom, international graduate students engage in teaching, research, and administrative activities in U.S. institutions. These students also increase the number of graduates of American institutions. Carson (2008) found that "One-fifth of all doctorates awarded by American universities go to international students" (p. 1).

International students in the United States are heterogeneous. In 2014-2015, Open Doors reported 33,593 students from Sub-Saharan Africa studying in U.S. universities and colleges. Most students from Sub-Saharan Africa studying in the U.S. come from Ghana, Nigeria, and South Africa. According to UNESCO (2010), Sub-Saharan Africa holds the highest student mobility rates in the world. "The number of African students studying abroad has increased from 2,580 in 1970 to over 1.8 million in 2002" (Africa Statistical Year Book, 2002, as quoted in Maringe \& Carter, 2007, p. 460). With the U.S. providing many opportunities to succeed and make a better living, scholars predict that the U.S. will remain a top destination for Sub-Saharan Africa students (Kigotho, 2015). Table 1.2 describes the country of origin of students from Africa.

Table 1.2

Description of African Students Presence in the U.S. by Place of Origin

\begin{tabular}{lll}
\hline Place of Origin & $2013 / 14$ & $2014 / 15$ \\
\hline East Africa & $\mathbf{7 , 5 4 9}$ & $\mathbf{7 , 5 6 0}$ \\
Burundi & 122 & 165 \\
Djibouti & 7 & 7 \\
Eritrea & 97 & 108
\end{tabular}




\begin{tabular}{|c|c|c|}
\hline Ethiopia & 1,516 & 1,472 \\
\hline Kenya & 3,201 & 3,072 \\
\hline Rwanda & 720 & 800 \\
\hline Seychelles & 16 & 14 \\
\hline Somalia & 15 & 32 \\
\hline South Sudan & 18 & 28 \\
\hline Sudan & 186 & 233 \\
\hline Tanzania & 889 & 867 \\
\hline Uganda & 762 & 762 \\
\hline Central Africa & 2,883 & 3,032 \\
\hline Cameroon & 1,285 & 1,212 \\
\hline Central African Republic & 11 & 13 \\
\hline Chad & 81 & 61 \\
\hline Republic of the Congo & 282 & 288 \\
\hline $\begin{array}{l}\text { Democratic Republic of the } \\
\text { Congo }\end{array}$ & 571 & 755 \\
\hline Equatorial Guinea & 253 & 314 \\
\hline Gabon & 397 & 388 \\
\hline São Tomé and Príncipe & 3 & 1 \\
\hline Southern Africa & 5,683 & 6,043 \\
\hline Angola & 985 & 1,184 \\
\hline Botswana & 228 & 257 \\
\hline Comoros & 27 & 32 \\
\hline Lesotho & 41 & 56 \\
\hline Madagascar & 151 & 122 \\
\hline Malawi & 275 & 272 \\
\hline Mauritius & 221 & 231 \\
\hline Mozambique & 91 & 108 \\
\hline Namibia & 61 & 67 \\
\hline Reunion & 2 & 1 \\
\hline South Africa & 1,716 & 1,838 \\
\hline Swaziland & 177 & 165 \\
\hline Zambia & 502 & 465 \\
\hline Zimbabwe & 1,206 & 1,245 \\
\hline West Africa & 14,998 & 16,958 \\
\hline Benin & 291 & 287 \\
\hline Burkina Faso & 526 & 567 \\
\hline Cape Verde & 69 & 64 \\
\hline Côte d'Ivoire & 1,116 & 1,227 \\
\hline Gambia & 300 & 275 \\
\hline Ghana & 2,914 & 3,099 \\
\hline Guinea & 80 & 109 \\
\hline Guinea-Bissau & 15 & 9 \\
\hline Liberia & 161 & 168 \\
\hline Mali & 315 & 356 \\
\hline Mauritania & 63 & 81 \\
\hline
\end{tabular}




\begin{tabular}{lll} 
Niger & 217 & 199 \\
Nigeria & 7,921 & 9,494 \\
Saint Helena & - & - \\
Senegal & 633 & 633 \\
Sierra Leone & 146 & 152 \\
Togo & 231 & 238 \\
\hline
\end{tabular}

Note. Institute of International Education Open Doors Report 2015 on International Students in the United States.

While international students are far from homogenous, existing literature highlights some common cultural adjustment issues international students experience in their host institutions. Oberg (1960) identified four phases of cultural adjustment: the honeymoon, crisis, recovery, and adjustment phases. The honeymoon phase refers to the excitement and fascination students demonstrated when they newly arrive in the host country. The crisis phase invokes the feelings of disorientation and distress students experience in the face of the new culture. This confusion and the challenges of not always knowing how to react can lead to hostile attitudes toward the new country and culture. The recovery phase characterizes the attitudes students adopt to survive in the new environment and culture. At this level, international students demonstrate a better understanding of the new culture, acknowledging the differences between host and country of origin languages and cultures. The adjustment phase describes the adjustment to the new environment and culture. At this stage, students show more flexibility and are opened to new ideas. However, researchers acknowledge students may not experience similarly or in the same order the cultural adjustment phases (Adler, 1975; Church, 1982; Irwin, 2007) as described by Oberg (1960). Huxur et al. (1996) explored how international students adapt to their new institutions in the U.S. and Canada. Using their personal experiences, the authors described the social loss, emotional distress, and isolation they experience in their new institutions. 
For many international students, adaptation to a new environment also includes a language adaptation. Commonly, it is assumed that once international students adjust to language difficulties, weather, food, and cultural differences they should do well in their studies and social interactions. While this is certainly true to some extent, some difficulties may arise from their cross-cultural experience (Jones, 2008). A large amount of international students experience daily the joy and excitement of studying in a different country and a new environment, but struggle being in a culturally and linguistically different context (Antwi \& Ziyati, 1993; Gardner, 2008; Lipson, 2008).

To better support international students in their learning and success, Huxur et al. (1996) recommended institutions provide a before and an after orientation (e.g., address resources available, discuss teaching and learning format, and interpersonal interactions as viewed in this context) for these students. In consequence, to thoroughly understand international students' experiences in U.S. higher education, it may not be sufficient to address only their academic challenges, adjustment and transition issues, or success stories in the U.S. We start to understand international students in U.S institutions by recognizing all their personal, social, cultural, and academic facets.

The literature demonstrates similar challenges international students from non-western countries experience. Though African students experience similar acculturation issues like other international students from different continents, their transition may differ because of personality, culture, or level of preparedness to sojourn in the host institution (Hull, 1978; Omotosho, 2005). Specifically, research studies on African students in U.S. institutions revealed that discrimination, feeling of loneliness, depression, language barrier, communication issues, homesickness, and cultural difficulties interfere with students' adjustment and social and 
academic achievement (Adelegan \& Parks, 1985; Antwi \& Ziyati, 1993; Blake, 2006; Crosson, 2010; Hanassah, 2006; Omotosho, 2005; Vukeh, 1985; Wang, 2007).

Student-faculty relationships are crucial to the student college experience (Astin, 1993; Pascarella \& Terenzini, 2005; Tinto, 1993); and can impact the quality of graduate experiences (Gardner, 2007; Lechuga, 2011); and attrition rates (Golde, 2000). Academic relationships between faculty and students can be formal (in a classroom setting) and informal (outside of a classroom setting), with both having an important impact on student outcomes, including academic achievement, student satisfaction and development (Lamport, 1993; Terenzini \& Pascarella, 1980; Pascarella \& Terenzini, 1991, 2005). Some of the factors influencing studentfaculty relationships include gender (Patton, 2009; Sax, Bryant, \& Harper, 2005) and race (Cole, 2004; Einarson \& Clarkberg, 2010). Pertaining to student-faculty interaction in relation to gender, Patton (2009) found that African-American female students appreciate having a samerace and same-gender mentor with whom they can identify. "Respondents reported that an African American female mentor had a deeper understanding of the issues present in the academy and could understand many of the challenges that participants faced because they had experienced similar situations" (Patton, 2009, p. 523). Another study by Sax, Bryant, and Harper (2005) revealed different outcomes based on different gender relations. For example, male students show higher attainment politically and socially than female students as a result of their interactions with faculty. In the matter of student-faculty interaction in relation to race, Einarson and Clarkberg (2010) found that African-American and Latino students engaged more with faculty outside the classroom than White and Asian American students. This result is inconsistent with Chang's (2005) study, which revealed that Latino students demonstrated low 
interactions with faculty outside of the classroom. Perhaps, individual attributes, faculty availability, different institutions, and other reasons can explain these contradictory results.

Rice et al.'s (2009) mixed methods case study of international student satisfaction $(n=367)$ with graduate advising relationships revealed that while the majority of participants were satisfied with their advisors, a large minority were dissatisfied. Furthermore, the qualitative data provided details of student discontents with their advisors, which is categorized in four themes:

(a) perceptions of poor advisement that consisted of inaccessibility, lack of guidance, poor feedback, and excessive demands; (b) interpersonal relationship issues, including advisors being impersonal, unsupportive, disrespectful, and abusive; (c) perceived mismatch of research interests; and (d) lack of financial support that seemed to contribute to perceptions about the advising relationship. (Rice et al., 2009, p. 385)

In Adrian-Taylor, Noels, and Tischler's (2007) survey research of interpersonal conflict between international graduate students and faculty supervisors, $34 \%$ percent of faculty supervisors $(\mathrm{n}=$ $53)$ and $22 \%$ percent of international students $(n=55)$ reported having experienced a conflict in their relationships. Some of the reasons for these conflicts were international students' poor English skills, and the different expectations between faculty and students (reported by faculty), and lack of openness, and feedback from the faculty (reported by students). While previous studies have addressed international students and specifically, African students' experiences in the U.S., rarely research studies explored African student viewpoints in relation to studentfaculty relationship. Furthermore, studies addressing African Francophone doctoral student experiences in the U.S. are scarce. These students tend to be assimilated to the larger population of international students, neglecting their unique backgrounds, cultural perspectives, linguistic 
differences, and needs (Bista \& Foster, 2011; Choudaha, 2015; Crosson, 2010; Nguyen, 2013).

Providing a voice to this population of students may help better understand African Francophone doctoral student experiences in American institutions.

\section{Statement of Problem}

The increase of international graduate students on U.S. campuses has contributed to diversifying American graduate schools. With a diverse population, there is a greater chance that U.S.-born faculty will interact, advise, mentor, and collaborate with students from different ethnic, cultural, and religious backgrounds. Thomas, Willis, and Davis (2007) posited that White faculty may have little understanding of academic and non-academic experiences of ethnic minority graduate students or do not have experience working with diverse students or in diverse environments. Faculty come to understand that dealing with international graduate students requires a different approach, and may necessitate a different training to better understand and support these students (Saul, 2016). International students do not form a homogenous group. Their perceptions of teaching, learning, and social interactions may differ in relation to their cultures and previous experiences (Jones, 2008; Omotosho, 2005). Existing literature suggests African students adjust differently to their new environment than other international students (Warren \& Constantine, 2007). Furthermore, African students from different regions may have different challenges. For example, Vukeh's (1985) study on African students' communication issues suggested African Francophone students experience more communication issues than African Anglophone students. A study of two teacher candidates from Burkina Faso and Mali also revealed that these students were accustomed to teacher-centered teaching and learning styles (Park, Rinke, \& Mawhinney, 2011). It makes sense, then, scholars suggest faculty show more understanding (Omotosho, 2005) and empathy toward international students. Such 
considerations, when incorporated, can encourage effective relationships, better support in integrating students in academic departments and institutions, and positive graduate experiences.

Little is known about the influence of African Francophone doctoral students' previous experiences with faculty in home country on their graduate experience in the U.S.; more, no existing study examines solely African Francophone doctoral students' perspectives in regard to student-faculty relationships in U.S. institutions. This study can provide an insight into the challenges of African Francophone doctoral students and benefit faculty, American students, campus staff, and policymakers. Understanding African Francophone doctoral student perceptions of student-faculty relationship from a cross-cultural viewpoint could help enhance student experience and success. A good amount of research has addressed African students' experiences in their host institutions (Adelegan \& Parks, 1985; Antwi \& Ziyati, 1993; Blake, 2006, 2012; Constantine et al., 2005; Crosson 2010; Lobnibe, 2013; Omotosho,2005, Vukeh, 1985; Park, Rinke, \& Mawhinney 2011; Pruitt, 1978). Additionally, studies have highlighted the struggles African students go through in home countries when deciding to study abroad, apply for a college in the U.S., and postulate for a visa. Researchers also acknowledge that culture impacts international students' experiences in the host country (Hull, 1978; Crosson, 2010; Wang, 2006). It is important then to have a good idea of the meaning these students give to student-faculty relationship, teaching and learning, and how these influence their experiences in their programs and institutions.

An exploration of previous research on cross-cultural perceptions of student-faculty relationship revealed no related studies. Limited research has been conducted on international students' viewpoints of learning, and the impact of cultures on student learning experiences (Antwi \& Ziyati, 1993; Crosson, 2010; Jones, 2008; Omotosho, 2005). The limited research on 
Francophone African students in the U.S. may be related to their previous low enrollment rate. Yet, this should not be a barrier to explore and describe these students' experiences. International students come with viewpoints engrained in their previous experiences (Jones, 2008), which can cause confusion about students' role and expectations (Constantine et al., 2005) in departments or when interacting with faculty. The in-depth examination of African Francophone doctoral students' experiences in American higher education can provide insights into their challenges in the U.S. with respect to student-faculty relationship and enable self-analysis of personal beliefs. "As we have seen, there is some kind of continuity in any case since every experience affects for better or worse the attitudes which help decide the quality of further experiences, by setting up certain preference and aversion, and making it easier or harder to act for this or that end" (Dewey, Boydston, \& Cahn, 2008, p. 20). One key recommendation made by advocates of quality in higher education is: "all institutions should establish routine ways to hear students' voices, consult with them, explore their opinions, and document the nature and quality of their experience as learners" (American College Personnel Association (ACPA) \& National Association of Student Personnel Administrators (NASPA), 2004, p. 33). Thus, this study gives a voice to African Francophone doctoral students studying in a Midwestern American institution.

Previous studies on African international students focus on students from African English-speaking countries (Constantine et al., 2005; Omotosho, 2005) and West African undergraduate students (Crosson, 2010). The fewer studies that included African Francophone students did not focus in depth on interpersonal relationship experiences (Crosson, 2010; Park, Rinke, \& Mawhinney, 2011). The present study sought to broaden the knowledge on international graduate student-faculty interactions by exploring these interactions from a crosscultural perspective with a specific focus on African Francophone countries. Three reasons led to 
the choice of these Francophone (or non-English speaking) countries: the scarcity of research on students from African Francophone countries, the researcher's background (come from Burkina Faso, West Africa), and "although the cultural values [and educational system] may be similar the experiences and excitements of graduate school are not the same" (Antwi \& Ziyati, 1993, p. 5) for individual students.

\section{Purpose of Study}

Implementing a single-case study approach, this qualitative study sought to examine and describe African Francophone doctoral students' relationship experiences with faculty in a U.S. research institution. Little research exists that explains a cross-cultural understanding of African Francophone doctoral student-faculty relationships. Equally important, scholars stressed the relation between a poor quality of socialization and doctoral student attrition (Clark \& Corcoran, 1986; Council of Graduate Schools, 2004; Golde, 1998; Gardner, 2007). If numerous studies have addressed graduate student socialization, few studies have focused on African Francophone doctoral students and how their culture and language may influence their socialization experience at one department or university. Faculty advisors play a crucial in the experiences of doctoral students. Their influences go from teaching, supervising graduate assistants, advising, mentoring, to overseeing doctoral student dissertations (Gardner, 2010). Therefore, this study was designed with the hope to fill the gap in the literature.

\section{Research Questions}

The primary research question for this study was: What are African Francophone doctoral students' relationship experiences with faculty in a United States research institution? The subsidiary research questions contributed to the overarching research question and were: 
1. How do African Francophone doctoral students at a Midwestern research institution perceive their relationships with faculty?

2. What factors influence these relationship experiences?

The study sought to explore and describe the experiences of African Francophone doctoral students while engaged in interpersonal relationship with faculty. Understanding how African Francophone graduate students interact with faculty and what challenges may arise from these relationships may help support effective relationships that impact both students and faculty in graduate education.

\section{Orienting Framework}

There are three theoretical lenses that enabled me to fully explore the socio-culturallinguistic influences of African Francophone doctoral student experiences: cultural dimension theory (Hofstede, 1980), socialization of graduate and professional students (Weidman, Twale, \& Stein, 2001), and language socialization (Ochs \& Schieffelin, 2011). Each theory is summarized in the paragraphs below.

Hofstede's (1980) cultural dimension theory stresses the importance of national cultures on individuals' values and relationship dynamics. An individual is a product of a culture (Gay, 1994), and the way one behaves, reacts to others, and sees the world relate to his/her culture (DuPraw \& Axner, 1997; Pedersen, 1991) and previous experiences. With the increase of international students' enrollment in the U.S., individuals from different cultures are called to interact with each other. These interactions have at times led to misunderstanding and conflicts because of different values, cultural differences (Crosson, 2010), and ways people observe or experience the same situation. 
Language socialization (Ochs \& Schieffelin, 2011; Schieffelin \& Ochs, 1986) occurs when learners are socialized into the use of language where they are actively involved and through language in order to understand and internalize their community's beliefs, values, and way of life. In order to become a member of the new environment, neophytes ought to learn the linguistic structures and the appropriate way to use the language. They do so in graduate school by interacting with faculty, staff, and their peers.

Socialization is the process through which individuals learn the values, skills, norms, expectations, and attitudes of a society, institution, or organization to be able to perform their roles acceptably (Bragg, 1976; Weidman, Twale, \& Stein, 2001). Braggs (1976) affirmed socialization is a (1) continuous process "whose end product is the acceptable functioning of the individual in his ascribed roles" (p. 6), (2) learning process, where values, skills, attitudes are developed, and (3) social process that "consists of interactions between individuals and groups of individuals. It is a reciprocal process in that changes occur in both the person being socialized and in the person or group doing the socializing (the socializing agent)" (p. 7). In regard to graduate school, socialization occurs when the newcomers internalize the norms and behaviors of one institution and department through the assistance of a socializing agent (faculty or peers). In accordance with Bragg (1976), socialization happens in three ways: (1) the interaction of students with the structures of the educational setting, (2) the interaction between students and faculty members, and (3) the interaction among students in the same educational program (p. 14). The second point "the interaction between students and faculty members" discussed by Bragg (1976) is the emphasis of the present study. Bragg (1976) stated, "the faculty members are the primary socializing agents for the neophyte professional" (p. 19). They "transmit their attitudes, values, and behavioral norms both formally--through the structures they establish and 
through the courses they teach--and informally--through individual advising and supervising of study and through social activities” (Bragg, 1976, p. 19-20).

Together, these lenses allowed the researcher to consider students as a whole, recognizing their past experiences, cultural and linguistic backgrounds, and socialization issues, to explore how these factors influence relationship dynamics with faculty. In an intercultural interaction, culture plays a crucial role because it affects how students and faculty negotiate the relationships. In addition, because African Francophone doctoral students come from different educational systems and have French as primary language, the influence of language on their relationships with faculty and overall experience cannot be diminished. The combined frameworks aimed to provide awareness into the lived experiences of African Francophone doctoral students as they journey through the American higher education.

\section{Significance of Study}

This study examined and described seven African Francophone doctoral students' relationship experiences with faculty in a Midwestern research institution. Because studentfaculty relationship is fundamental in graduate school, a wealth of research exist on the matter, including advisor-advisee relationship, mentoring in graduate education, student-faculty relationship and its impact on program completion and student attrition (Adu, 2011; AdrianTaylor, Noels, \& Tischler, 2007; Barnes \& Austin, 2009; Schroeder \& Mynatt, 1993; Wang \& $\mathrm{Li}, 2011$ ). While previous studies have been helpful to understand faculty roles on graduate students' growth, program completion, and sense of belonging, they do not address African Francophone doctoral students' socialization experiences, with a specific focus on the studentfaculty relationship. Therefore, this study contributed to the literature on cross-cultural education 
through a conversation with African Francophone doctoral students and introduced a deeper understanding of students' challenges from their viewpoints.

Furthermore, this study provided an insight on an under-studied group (graduate students from Francophone countries in Africa) in the U.S. This study may help faculty and administrators understand what factors influence African Francophone graduate students' experiences and learning in English speaking institutions. Most importantly this study continued the conversation to better promote quality collaboration between faculty and international graduate students. In an age of globalization and internationalization of higher education it is critical to understand how international graduate student experiences are formed, shaped, and how it affects graduate experience and student success.

\section{Definitions of Terms}

A clarification of key terms related to cross-cultural adaptation, international student, and relationship is necessary. For the purposes of the present study, the following terms are defined as:

Adaptation. Adaptation describes the process by which a student studying outside his/her country of origin adjusts his/her values and beliefs with the new environment's (receiving country) values.

Advisor. An advisor is a faculty member who partners with a graduate student to facilitate the coordination of the student's plan of study and thesis or dissertation research.

Cross-cultural. Cross-culture is when two different cultures are interrelated (Marginson \& Sawir, 2011).

Culture. Culture is a set of beliefs, values, ways of living and behaving particular to a certain group of people (Hofstede, 2001). 
Integration. Integration is when a sojourner is engaged in the host environment and culture.

International student. International student is a student from a country other than the U.S., pursuing an educational degree in one of U.S. universities or colleges.

Relationship. Relationship is used to describe the daily formal or informal rapport between faculty and African Francophone doctoral students, including in the classroom, laboratory, and during advising and mentoring.

African Francophone doctoral student. An African Francophone doctoral student is a student from an African Francophone country (that has French as the main or official language), pursuing a graduate degree in the United States.

\section{Organization of Study}

Chapter One introduces international students and African students and describes studentfaculty relationships. The chapter provides a rationale to explore such a specific group as more African students are travelling overseas to pursue an education. Specifically, the statement of problem, the purpose of study, the research questions, the orienting framework, the significance of study, the definitions of key terms, and the organization of study are presented. Chapter Two begins with relevant research on international graduate students and African graduate students, continues with relevant research on graduate student-faculty relationships, and ends with the theoretical framework perspectives. Chapter Three contains the researcher's positionality and role, the research design, the study's setting, the sampling procedures and participants, the description of data collection, the anticipation of ethical issues, the data analysis process, and ways of establishing credibility and trustworthiness. Chapter Four includes participants’ portraits, presents the findings, and ends with a summary. Chapter Five provides the discussion 
of the findings, limitations, and implications of the study. In addition, the chapter provides recommendations for future research and concluding remarks. 


\section{Chapter Two. Literature Review}

This study explored and described African Francophone doctoral student perceptions of student-faculty relationship. Precisely, this study addressed these questions: What are African Francophone doctoral students' relationship experiences with faculty in a United States research institution? How do African Francophone doctoral students at a Midwestern research institution perceive their relationships with faculty? What factors influence these relationship experiences? The scarcity of research examining African Francophone doctoral students' perceptions regarding student-faculty relationship is emphasized in this chapter, which provides a foundation for contributing to the knowledge base of this work (see Merriam, 1998).

The chapter reviews existing literature on African graduate students' experiences in American universities and their relationships with faculty. The review describes American graduate school and discusses the experiences of students from both faculty and student perspectives. In the absence of additional research exploring African Francophone doctoral students' lived experiences, establishing the challenges these students face in their experiences in the U.S. will be arduous. African Francophone doctoral student perceptions regarding studentfaculty relationships in the United States can provide stakeholders, faculty, and campus staff insights for increasing international student retention, improving student support services and encouraging student success, and establishing an overall positive experience. This chapter also presents a framework for the research utilizing three theories underpinning this study of African Francophone doctoral student perceptions of student-faculty relationship: cultural dimensions theory (Hofstede, 1980, 1981, 1985); socialization of graduate and professional students (Weidman, Twale, \& Stein, 2001); and language socialization (Ochs \& Schieffelin, 2011). 


\section{Review of Related Research}

This literature review presented relevant research studies pertinent to African doctoral students' perceptions of student-faculty relationships. The research is divided into two categories: research on African graduate students and research on student-faculty relationships. Each category is further subdivided into smaller sections that thoroughly address the two large categories. On the whole, the literature review revealed an existing gap regarding African Francophone doctoral students' experiences, and African Francophone doctoral students' perceptions of student-faculty relationship from a cross-cultural viewpoint.

\section{Research on International Graduate Students}

International graduate students are a major component of American graduate school. Mamiseishvili (2011) stated, "Internationally diverse student body brings valuable educational, cultural, and economic benefits to U.S colleges and universities" (p. 3). The increase of diversity on American campuses allows a greater contact between international students and American students and faculty, providing more understanding toward people from different groups, and creativity and collaboration in the classroom.

This section introduces studies on graduate school, continues with research on international graduate students and African graduate students' experiences and challenges in the U.S., and concludes with a discussion of research on graduate student-faculty relationship.

\section{American graduate school.}

Some people think grad school will be just like another few years of college: "College was fun, so grad school will be even funner, because I'll be able to buy alcohol legally!” These are typically the same people who don't see anything wrong with the word funner. (Ruben, 2010, p. 2) 
In 2015, the Office of Graduate Education \& Life at West Virginia University invited Adam Ruben for Graduate Student Appreciation Week. Ruben's book, Surviving Your Stupid, Stupid Decision to Go to Grad School, provides a satirical insight in to the experience and challenges of graduate students. Graduate education serves both to develop the new scholarly thinkers as well as to impart the knowledge of scholarly thinkers from one generation to the next (Gardner \& Barnes, 2007). To successfully manage graduate school, a socialization into individual department and graduate school is necessary. Socialization in graduate school is a development "in which a newcomer is made a member of a community — in the case of graduate students, the community of an academic department in a particular discipline" (Golde, 1998, p. 56). In addition, as students evolve through their graduate studies they begin to understand the social expectations of a post-graduate lifestyle (Golde, 1998).

The University of California Berkeley (UC Berkeley) describes graduate school as "an advanced program of study focused on a particular academic discipline or profession" (https://career.berkeley.edu/Grad/GradWhatis). In the book, Thinking Student's Guide to College: 75 Tips for Getting a Better Education, Roberts (2010) argued, "Graduate school is not just advanced undergrad" (p. 141). Moreover, Seligman (2012) stated, it "is like joining a major league baseball team after years in the summer softball league" (p. 26). A graduate program involves: (a) focused studies in a specific discipline with fewer elective possibilities, (b) rigorous evaluation of your work by professors and peers, (c) smaller classes with a large amount of student interaction, (d) work experience through internships, teaching, or research and (e) production of original research (https://career.berkeley.edu/Grad/GradWhatis). While undergraduate and graduate students may have some similar experiences, the literature 
demonstrates that graduate students in general and doctoral students in particular have experiences that are specific to them (Barker, 2011).

Doctoral education across the United States encompasses several common components, including coursework, comprehensive examination, dissertation process (prospectus, research study, and dissertation writing), and public oral defense (Walker et al., 2008). With these stages crucial in a doctoral student's program completion, domestic and international doctoral students agree that student-faculty relationship is one of the most important parts of the doctoral experience (Barker, 2011; Gardner, 2007). To better understand graduate persistence, Tinto (1993) proposed three phases: Transition, Candidacy, and Doctoral Completion. Transition is a crucial stage as new students affiliate with peers and faculty within the department. The Candidacy stage is greatly related to the skills a student developed over the years and the effective exchanges with faculty. The Doctoral Completion stage "covers that period of time from the gaining of candidacy, through the completion of a doctoral research proposal, to the successful completion of the research project and defense of the dissertation" (Tinto, 1993, p. 237). As they progress in their studies, students will specialize and find themselves working more closely with fewer faculty members (advisor, mentor, and dissertation committee members) (Tinto, 1993).

Graduate school is isolating because it is a lonely journey where students are responsible for their own learning and no one is managing their progress (Roberts, 2010). The stress experienced in graduate school combined with emotional and psychological issues can affect student performance and degree completion. To understand the prevalence of depression in graduate school, Peluso, Carleton, and Asmundson (2011) surveyed 292 Canadian Psychology graduate students. The findings revealed that if a graduate student is overburdened or dissatisfied 
with their relationship with their advisor it can lead to symptoms of clinical depression. It is also admitted that the acculturative stress experienced by international students can lead to emotional and psychological issues.

Enrollment and student population. There are two trends describing enrollment in graduate school: first, newly college graduates may decide to enroll immediately to graduate school, while a second choice may be to leave college and find a job or simply take a pause. Many people come back years later to earn a graduate degree. The graduate school admissions requirements differ from the undergraduate. Applicants are required to show a proof of an undergraduate degree completion, a high score of the GRE or any other required test from the chosen program or department, and a high score of Test of English as a Foreign Language (TOEFL) for international students (Doughty, 2004).

The recruitment and enrollment of international graduate students have changed the student body in graduate school. In 2014-2015, there were 362,228 international graduate students enrolled in U.S. institutions. The top three countries sending students to the U.S. are China, India, and South Korea (Open Doors, 2015). These past decades have seen a surge of students from India, Nigeria, Brazil, and Kuwait. Foreign government scholarship programs have expanded the presence of Saudi Arabia, Brazil, Oman, Kuwait, and Iraq students in the U.S. (Open Doors, 20015). Despite the fact that African students' numbers are low compared to other students from other continents, the Open Doors (2015) report acknowledges an increase of these students in the U.S.

While international student home countries offer graduate programs, the fundamentals, requirements, and expectations may differ from the United States education system (Kingston \& Forland, 2008; Lipson, 2008; Yang, Salzman, \& Yang, 2015). American graduate programs were 
primarily designed to serve Americans students. Today with the change of graduate student population, "if a graduate program fails to provide a contemporary context for equipping students in an ever changing world, it stands to reason students will not be committed long term" (Bain, Fedynich, \& Knight, 2011, p. 2).

Researchers have been interested in international graduate students and domestic graduate students' experiences in graduate school for decades (Pedersen, 1991; Sam, 2001; Trice, 2003). Some scholars consider both domestic and international graduate students encounter similar issues in graduate school (Sam, 2001). Other academics, however, argued that international students, in addition to sharing common issues of graduate school with their counterpart Americans, have to cope with language difficulties, discrimination, and cultural adjustment issues (Pedersen, 1991). Constantine et al. (2005) found that racism and discrimination are part of African students' experience in the U.S. Manyika (2000) added that America's history with racism, slavery, and segregation influence Black African student experiences. Resetarits (2012) recounted foreign-born students' struggles from college application and visa obtainment, to living and adjusting in the U.S. International students come from different education systems, which may have a different understanding and tolerance toward academic misconduct. For example, Bretag (2013) affirmed international students are more inclined to commit academic misconduct than American students. If these studies found that international students and African students encounter a lot of challenges in adjusting and integrating U.S. institutions and education system, they also acknowledge these issues can impact student experiences and success in graduate school.

International graduate students. With the internationalization of higher education, it is common today for students to pursue an education outside their home countries. Yet students' 
mobility is nothing new. The colonial and post-colonial era saw a departure of colonized people toward their former settlers' countries to pursue an education and learn from the colonizer (Goodwin, 1993; Woldegiorgis \& Doevenspeck, 2013). The 2013 U.S. Department of Homeland Security (DHS) data report estimates 173 million non-immigrants currently sojourning in the U.S. (Foreman \& Monger, 2014). The DHS categorizes, "nonimmigrants as aliens whose classes of admission are specified in section 101(a)(15) of the Immigration and Nationality Act (INA)" (Foreman \& Monger, 2014).

In September 11, 2001 (also referred to as 9/11), the United Stated experienced a terrorist attack that changed the U.S. forever and its immigration policies. 9/11 affected international students' entry and sojourn in the U.S. and invigorates hate crimes against immigrants, particularly Muslims (March, Zeman, \& Adrian, 2005). The Student and Exchange Visitor Information System (SEVIS), an "implementation of Section 641 of the Illegal Immigration Reform and Immigrant Responsibility Act of 1996 with the Enhanced Border Security and Visa Entry Reform Act of 2002" (March, Zeman, \& Adrian, 2005, p. 7) was created to better monitor foreign students' entry and stay in the U.S. Higher education institutions are now required to comply with the SEVIS guidelines as described in Table 2.1 .

Table 2.1

U.S. Colleges and Universities' Compliances with SEVIS Guidelines

Institutions should report

- When the student arrives on campus

- Failure of a student to enroll

- Full-time enrollment

- When a student drops below a full course load without prior authorization from INS

- Any failure to maintain status or complete the program 
- Change in name or address within 10 days

- Start date of each term

- A student's transfer to another program

- Program extensions

- Off campus employment

- Any other major changes to the student's program of studies

Note. Adapted from March, Zeman, \& Adrian, 2005, pp. 7-8.

The Patriot Act, also known as the 'Uniting and Strengthening America by Providing Appropriate Tools Required to Intercept and Obstruct Terrorism Act of 2001,' proposed by President Bush, and adopted by the U.S. congress, was another reaction to the event of $9 / 11$ and a desire of the U.S. government to prevent terrorism and keep the U.S. safe. Overall, these decisions restrict international student experience in U.S. universities and the American society in general. Nonetheless if the immediate post 9/11 saw a decrease of international students' enrollment in U.S. universities (Bollag, 2004; Hindrawan, 2003), the United States still remains today the top destination for international students.

International students come for many reasons in the U.S., including for quality of education, resources, equal opportunities, and career advancement. Policymakers in higher education have acknowledged the economic and cultural contributions, and diverse perspectives international students bring. Studying in a host country gives both domestic and international students the opportunity to learn, respect, and appreciate others cultures, races, and religions.

Many international students come to pursue a better education and seek equal opportunity in the U.S. A study conducted by Qin and Lykes (2006) sought to understand Chinese women perceptions of studying in the U.S. Participants in the study listed dissatisfaction with homeland, corruption, and gender bias in work places as many of the reasons to pursue an education outside of their country. Le, LaCost, and Wismer (2016) found that international female graduate 
students have positive study experiences in the U.S., which fostered personal growth and sense of belonging. Nonetheless, a student's decision to study in a country other than his home country is not without difficulty. Once in the U.S., international students need to adjust to their new environment including weather, food, language, and culture. They also need to adjust to their campus culture and new education system values. Barletta and Kobayashi (2007) argued that cultural adjustment is the top issue experienced by most international students. The literature recounted difficulties related to cultural shock. Furnham and Bochner (1982) found that international students coming from a culture very different from the host country culture experience higher adjustment difficulties. Further studies however found that students coming from similar cultural background still show some signs of stress (Tsang, 2001). International students experience greater stress when their home country's language is different from the host country's language. These students face exclusive academic issues and communication difficulties (Antwi \& Ziyati, 1993; Trice, 2001; Vukeh, 1985). Many scholars agree that to succeed international students need to master the language (speaking, reading, listening, and comprehension), which can impact their performance and interpersonal interactions (Antwi \& Ziyati, 1993; Lipson, 2008).

If the idea of internationalization started with noble purposes, it has taken a business role today (Habu, 2000). Recent reports (Choudaha, 2011; Reisberg, 2012) suggested that international students are becoming "cash cows" for their host institutions. With many colleges facing budget cuts, foreign students are seen as an immediate solution (Saul, 2016). President Gary Ransdell of Western Kentucky University argues that while it is good to recruit international students and diversify student body, this comes with challenges (Saul, 2016). "It can't be business as usual. We're learning that. There are growing pains" (Saul, 2016, p. n.d.). 
This may suggest that while efforts are made to recruit international students, their integration and support do not always reflect the discourse of multi-cultural campuses promoted by American institutions (Antwi \& Ziyati, 1993). Glass and Braskamp (2012) believe "the growing presence of international students, while introducing new challenges, also creates new opportunities to strengthen higher education's academic mission, where international students contribute to the learning and development of all students" (Inside Higher Ed, 2012).

On top of the adjustment difficulties, students may be confronted by the host country's rejection. Hanassah (2006) found that students from Africa and the Middle East experience more discrimination than their counterparts from Europe. The author, however, found that students are more exposed to discrimination off campus than on campus. To understand American students' acceptance of local and foreign students, Mehta, Ruby, and Letts (1996) asked 207 undergraduate American students to read jobs summaries of American, French, Indian, Chinese, and Kenyan student applicants and rate candidates by job success, likability, and personal adjustment. The results revealed that American students have unjustified attitudes toward foreign students weighing in their likeness of foreigners. In regards to student ethnic background, American students for example "judged newcomers from Kenya less favorably than they judged those from France or from Kansas City” (p. 14). The literature on international students specifically highlights several challenges.

International students' challenges. Lipson (2008) summarized international student challenges in three categories: (1) mastering English, (2) expressing their own viewpoints in papers, class discussions, and research, and (3) academic honesty. Galloway and Jenkins (2005) also identified three main issues: financial support, support service programs, and English proficiency. Other studies concurred international students face language difficulties (Liu, 2011; 
Wu, Garza, \& Guzman, 2015), cultural, academic (Ejiofo, 2010; Omotosho, 2005; Wu, Garza, \& Guzman, 2015), and financial problems (Galloway \& Jenkins, 2005), and discrimination (Hanassab, 2006; Lee \& Rice, 2007). A recurrent challenge highlighted in the literature is language difficulties, which can interfere with student learning and communication. While all international students go through an adjustment period, the challenges they face are experienced differently and in various degree. In this study, international graduate student challenges can be summarized into five main categories: academic, psychological and emotional, financial, cultural, and linguistic.

Academic. Many international graduate students encountered academic problems caused by the different education system (Kingston \& Forland, 2008; Lipson, 2008; Yang, Salzman, \& Yang, 2015). Research has shown that students have different understandings of learning that impact their experience and classroom dynamic (Jones, 2008). Compared to others classrooms around the world, American classrooms "tend to reflect more of a Socratic ideal, where teacher and student interact a great deal in pursuit of knowledge" (Anderson \& Powell, 1991). The United States' education system provides opportunities for students and faculty to interrelate. In the classroom, students are expected to voice and support their own opinions during class discussions. Participation is even highly recommended in graduate school, where all graduate students are required to contribute while learning from their classmates and experienced faculty. On the opposite, many non-western students come from an authoritarian education system where there is a large gap between students and professors (Wang, 2008). A large amount of international graduate students are not used to talking in a classroom and have relied on their professors' directions for many years. Furthermore, the language barrier may slow these students' decisions to share their opinions. Wang and Li (2011) stated that a large minority of 
international students in the U.S. considers their faculty supervisors as the authority figure, causing them not to challenge their decisions even when they disagree with them. It is usual to find international students expecting their faculty-supervisors or advisors to tell them explicitly what to do and what not to do (Wang \& Li, 2011). For example, Essandoh (1995) recounted a situation where a student was not available for the meeting time the advisor has set. The student deliberately chose to miss the meeting instead of communicating with the advisor. Because African Francophone doctoral students come from a different education system, it is crucial for them to adjust to and understand the host country education system requirements and expectations as fast as possible to succeed (Lipson, 2008). Many international graduate students admitted having to adjust to the classroom and learning styles in the U.S. (He, 2012). A key part of graduate school is reading and writing, yet it can be the top challenge for international graduate students. Several studies have looked at writing in academia in relation to stress and anxiety. Karakaya and Ülper (2011) affirmed that "student[s] with writing anxiety find all the stages of writing process extremely demanding and challenging" (p.703). A large majority of international students are more familiar with lectures and classrooms where participation and classroom discussions are limited. It is a big shift when having to speak daily, discuss and support opinions, take critics, and write long papers.

Psychological and emotional. International students experience emotional and psychological stresses impacting their social interactions, well-being, and academic achievement (Han et al., 2013). A study conducted by Han et al. (2013) among 130 international students from China, studying at Yale University, revealed that a large number of students experience depression (45\%) and anxiety (29\%). The authors found that the top four causes of Chinese international student depression are academic stress, social isolation, cultural shock, and 
language difficulties. Building on previous research studies on international students' anxieties, Yang, Salzman, and Yang (2015) examined international graduate student adjustment experiences in Hawaii. Among the findings reported are communications difficulties, academic issues, financial issues, and relationships with faculty. While the authors did not elaborate on specific factors impacting student-faculty interaction, it recognized the importance of studentfaculty interaction as discussed in other studies (Adrian-Taylor, Noels, \& Tischler, 2007; Rice et al., 2009) and the impact of these relationships on both faculty and students. Researchers stress the need to understand factors influencing students' learning and create appropriate student support programs.

The importance of social support on international students' success and overall experience is emphasized in the literature (He, 2012; Summer, Poyrazli, \& Grahame, 2008). To understand the relationship between social support and academic success, He (2012) examined international graduate students studying in a mid-Atlantic research university. The findings revealed social support is important in students' experiences. More, different levels of support can impact differently international graduate student academic achievement in the U.S. Another study by Summer, Poyrazli, and Grahame (2008) examined international student experience with depression and anxiety. It is suggested that the level and quality of support received by international students influence their level of anxiety or depression. With the increase of international student enrollment in the U.S., understanding the challenges they face may help create programs to better support their success (He, 2012; Summer, Poyrazli, \& Grahame, 2008; Yang, Salzman, \& Yang, 2015) and maintain a psychological and emotional balance.

Financial. Many international students face financial issues while studying in the U.S. (Nguyen, 2013; Trice, 2003; Yang, Salzman, \& Yang, 2015). If the countries of origin 
governments sponsor many international graduate students, a large majority of international graduate students rely on university teaching, research, or administrative assistantships. The burden doubles down when a student brings a spouse and children. According to He (2012) international students are among the poorest groups of people. Many international graduate students are attracted to U.S. higher education because of the quality of education, but mostly the availability of resources and financial support. Yet, not all students will or can receive financial assistance. Researchers believed financial burdens can cause stress and anxiety to international students affecting their experience (Trice, 2003). International graduate students on F1 visas are not allowed to work outside of their registered institution according to the immigration policies. Because of their full time status, international graduate students with an assistantship can only work 20 hours per week. Without any other financial aid, family and country of origin government assistance, these students are compelled to live on the tied assistantship paycheck. These restrictions have become a burden and source of financial stress for many international graduate students.

Cultural. Culture has played an important role in students' adjustment in host institutions. Looking at the literature, culture has not been an easy term to describe. For the purpose of this study, I used Hofstede's (1980) definition of culture. Hofstede (1991) described culture as "the collective programming of the mind which distinguishes the members of one group or category of people from another" (p. 5). International students differ from their American counterparts. Even among international students, differences are noticeable based on country of origin and culture. Culture is important because it impacts individuals' perspectives, beliefs, values, and behaviors. 
Researchers stated that cultural adjustment is experienced differently by students depending on how well they prepared before moving in to the host institutions (Smith, n.d.). Nevertheless, anticipated situations can still distress international students. Lee and Rice (2007) interviewed 24 international students from 15 countries around the world on their experiences studying in a host country. Overall, students reported negative experiences related to their race and culture. The study however showed differences when countries are narrowed regionally. Students from Asia, India, Latin American, and the Middle East experienced more racial discrimination while their counterparts from Europe did not experience discrimination related to their race or culture. The study also reported problems experienced in relationship with faculty and campus staff. For many African students transitioning in the U.S. (which has a long history of slavery and racial discrimination), the experience of race and discrimination can be challenging because of their previous positive experience in home countries, where being African and black is accepted and the norm (Bagley \& Young, 1988). Nonetheless, "being confronted by a new culture can be a positive and enlightening experience, which leads to a deepened awareness of self and the appreciation of different cultures" (Newsome \& Cooper, 2016, pp. 196-197). An important concept related to culture is language. Many scholars discussed the issue of language and how it can shape an individual's identity and understanding of the world (Boroditsky, 2011; Deutscher, 2010).

Linguistic. International graduate students from non-English speaking countries (even English speaking countries) recognize the need to adjust to the host country's language (accent, cultural cues, and speed). Scholars believe it is crucial for international students to be proficient in English to adapt to and succeed in the American education system (Andrade \& Evan, 2009; Antwi \& Ziyati, 1993; Huntley, 1993; Lipson, 2008). Though international graduate students are 
required to show a successful test score of TOEFL or IELTS (International English Language Testing Service) and GRE, the literature demonstrates that a high score on the TOEFL does not always indicate a student's ability to speak and interact (Trice, 2003). In addition, admission guidelines differ from institution to institution, which has led to the admission of international students with a TOEFL score below the score stipulated (550) in NAFSA guidelines (GiacchinoBaker \& Baker, 1995). Huntley (1993) claims that to do well, international graduate students must understand lectures, faculty, and peers; express their own opinions during classroom discussions; read assigned readings and write papers. To understand the challenges international graduate students have and the resources used to cope with the challenges, Kuo (2011) examined international graduate students at Auburn University. Participants confessed experiencing cultural challenges, which is divided into language difficulties, and food choice. A language deficiency may impact students' engagement, self-confidence, and participation in the classroom. Language proficiency is related to academic success and social interaction (Andrade \& Evan, 2009). Many international students feel that faculty and classmates judge them based on their capability to express themselves. A participant in Antwi and Ziyati's (1993) study supported this claim "Here, what I notice is that people correlate your intellectual ability with your language proficiency and capability" (p.11). A language barrier can be a challenge for both international graduate students and faculty. The language barrier can also impact how well international graduate students perform in the classroom and communicate with faculty and peers.

Comparable to other international graduate students in the U.S., African Francophone students may experience communication issues, cultural shock, cultural adjustment, academic 
challenges, emotional and psychological distress, and financial burdens that can impact their integration, learning, and interaction with faculty.

African Graduate Students. The presence of Africans in the U.S. dates back to several centuries. For more than three centuries Africans were moved to the U.S. to work as slaves in the sugar cane and cotton fields (Takougang, 1995). In the $20^{\text {th }}$ century, Takougang and Tidjani (2009) suggested that the increase of Africans in the U.S. may be caused by the change of perceptions and political and economic issues in their individual home countries. According to the authors, most African immigrants came to the U.S. in the 1960s-1970s with the hope to get an education and return to their home countries to contribute to the countries' emancipation. Nowadays, most Africans enter the U.S. with the hope to get an education, make a better living, and possibly remain in the U.S. McMahon's (1992) push-pull factors model also describes many of the reasons African students may leave their countries to seek better opportunities, including the degradation of the education system, particularly the problems encountered in higher education.

"Africa is a multi-ethnic and multi-linguistic continent" (Omotosho, 2010, p. 5) with more than 50 individual countries and a population estimated at 1.166 billion (World Population Review, 2015). The colonization of Africa has increased the different historical and development experience of each country. If today all African countries are independent, their developments are still tied to the former colonies in term of financial support, and education system models. West Africa is located between the Sahara Desert and the Gulf of Guinea (The Free Dictionary) and is comprised of the following countries: Benin, Burkina Faso, Cameroon, Côte d'Ivoire, Equatorial Guinea, Gambia, Ghana, Guinea, Guinea-Bissau, Liberia, Mali, Mauritania, Niger, Nigeria, Senegal, Sierra Leone, and Togo (Vukeh, 1985). Other sources have included or 
excluded the following countries: Cameroon, Cape Verde, and Sao Tome and Principe to the Western region (Population Reference Bureau, 2014). Central Africa included Burundi, the Central African Republic, Chad, the Democratic Republic of the Congo, and Rwanda. North Africa incorporated Algeria, Egypt, Libya, Morocco, Sudan, Tunisia, and Western Sahara. There is no consistency in the number of African Francophone countries because of the place given to French language in relation to local language. In these countries, French is either used as the official language, the main language, or the language of education, and administration (Manning, 1999). The present study focuses on five countries ${ }^{1}$, which four are described below.

Burkina Faso. Burkina Faso, also known as Upper Volta, is a landlocked country in West Africa with a land area of 105,869 square miles (Shelley, 2013) and a population estimated at 18,105,570 in 2015 (World Bank, 2016). The country is bordered in the northwest by Mali, the northeast by Niger, the east and southeast by Benin, and the south by Ghana, Togo, and Côte d'Ivoire (Shelley, 2013). Burkina Faso was colonized in the 1890s by France and received its independence in 1960. The World Bank report (2016) estimated Burkina Faso’s GDP at \$12.257 billion in 2014.

Cameroon. Cameroon is located in Central Africa and bordered by Nigeria, Chad, the Central African Republic, Gabon, Equatorial Guinea, and the Republic of Congo. Former French colony, Cameroon gained its independence in 1960. The population of Cameroon was estimated at 23,344,179 in 2015 (World Bank, 2016). Before the 1970s, Cameroon was divided between French Cameroon and British Cameroon. Today, French and English are both the official languages. In 2015, Cameroon's GDP was at $\$ 28.416$ billion.

\footnotetext{
${ }^{1}$ Participant Two believes her experience can be valuable to other international students. Yet, she requested her country and some details of her studies will not be disclosed.
} 
Senegal. The Republic of Senegal is a country located in West Africa with a population of 15,129.273 (World Bank, 2016). Senegal shares borders with Mauritania, Mali, Guinea, and Guinea-Bissau. After a century under French colonization, Senegal gained its independence in 1960. Senegal's GDP was estimated at \$13.61 billion in 2015.

Tunisia. Tunisia is situated in the northern parts of Africa, with a population of $11,107,800$ in 2015 (World Bank, 2016) and an area of 64,000 square miles. The country is bordered by Algeria on the west and Libya on the south. Former French colony, Tunisia became independent in 1956. In 2015, Tunisia’s GDP was reported at $\$ 43.015$ billion (World Bank, 2015).

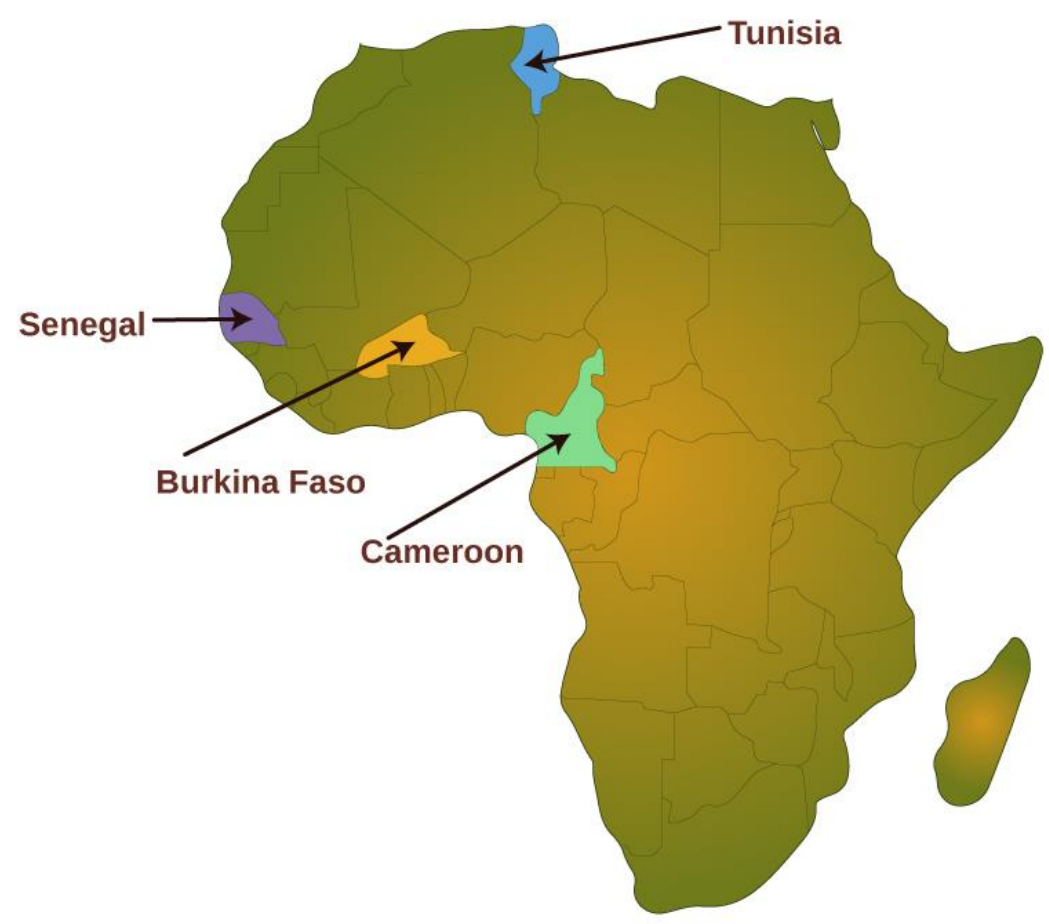

Figure 2.1. Map of Africa with Burkina Faso, Cameroon, Senegal, and Tunisia.

Education remains a challenge at all levels in these countries. While France introduced its education model in the colonies, the goal of education during the colonization period was to 
spread French ideology and culture (Woldegiorgis \& Doevenspeck, 2013). Higher education was not well developed in French colonies. Contrary, to respond to the French Assimilation idea, a limited number of Africans in French colonies were sent to study in France (Woldegiorgis \& Doevenspeck, 2013). This approach has slowed the development of higher education in Francophone countries and increased the gap between the few educated Africans and a large uneducated Africans. Prior to European education, teaching and learning in Africa "was embedded in the cultural setting of the time without having formally established institutions that deal with the production and dissemination of knowledge" (Woldegiorgis \& Doevenspeck, 2013, p. 36). Today, education holds an even more important place in African countries. It is the gateway for many to rise from poverty, make a better living, and contribute to the country's economic and political sectors. While many African Francophone higher education systems lack resources and funding, and have large class sizes, Africans recognize the role of higher education in the development of a country.

Generally, African Francophone education system follows the French education system model. Students spend six years of primary education, which is crowned by the "certificat d'étude primaires élémentaires' (CEPE). The certificate gives an entrance to students to seven years of secondary school, which is sanctioned by two obligatory exams. The 'brevet d'études du premier cycle' (BEPC) is an exam after four years of secondary school, and is necessary to move to the next level. The 'baccalauréat' (BAC) is the culmination of the seven years and an entrance diploma for the university. Higher education encompasses universities, colleges, and technical and vocational schools or 'grandes écoles'. Many African countries also have private and religious schools and universities. During the colonization, education was reserved to an elite group, and they were educated to serve the purpose of the colonizers. Today, higher education 
has extended in many African countries with the creation of public and private colleges and universities, expanding higher education access to a larger population (Woldegiorgis \& Doevenspeck, 2013).

If the role of higher education is uniformly recognized in the development of a country, and was promoted after the independences in the 1950s-1960s to increase social and economic stability and decrease poverty; today, higher education is becoming a cause of concern for many Sub-Sahara African countries (Ngara, 1995). There is a gap between the curricula, production of graduates, and the employment demands (Ogom, 2007). For example, over 40\% of 1999/2000 Ghanaian graduates from Social Sciences and Arts were unemployed because of the incongruity between their education and required skills in the job market (Ogom, 2007). Ogom (2007) stated, Although skilled graduates are desperately needed in Sub-Saharan Africa, the employment opportunities of those being churned from the current higher education system are limited because they lack the requisite skills for immediate absorption into the workforce. In Burkina Faso, for example, the national university's annual pool of over 1000 graduates that typically consists of lawyers, economists, and journalists cannot be easily absorbed into the national workforce (Hoffman, 1996) and the situation is even worse in the Republic of Benin where there is a flagrant overproduction of tertiary diplomas without cognizance of the economy's ability to absorb them (World Bank, 1994) (p. n.d.)

Scholars argue the primary problem of tertiary education in developing countries is engrained in the lack of resources (ACHE, 2001 as cited in Ogom, 2007). African scholars believe the negligence of higher education is linked to International Monetary Fund (IMF) and World Bank policies on promoting primary education in negligence of higher education. For example, for 
many African countries to be able to keep receiving financial assistance from the IMF and World Bank, they must decrease the funding for higher education (Ogom, 2007). The lack of support from national governments and international non-governmental organizations, low salary, and large class sizes, are many of the causes of "brain-drain" of qualified Africans toward Europe and America (Ogom, 2007). Faculty and students' unions have been voicing in vain their concerns. To remediate to Sub-Sahara African higher education crisis, the African Union in 2006 encouraged a regional collaboration and urged making higher education a priority. Such promotion has led to the creation of the "New Partnership for Africa's Development (NEPAD), 10-year partnership program of the Association of African Universities, Association of Commonwealth Universities and the South African University Vice Chancellors Association" (Ogom, 2007, p. n.d.). While many African countries are taking actions to improve higher education, there are still some existentialist questions of higher education they do not consider. Ogom (2007) when citing Bollag (2004) affirmed:

In its current form, design and content, it [higher education] is of limited relevance in the context of rapid social and economic changes in the region and bears little connections to the local economy and society. Modeled after European higher education, it has evolved from educating only a few highly qualified students into mass systems of lower quality (p. n.d.)

In Being an African Student: Stories of Opportunity and Determination, Omotosho (2005) describes what it means to be an African student in U.S. campuses and the specific challenges African students encounter in their receiving countries. If being in the U.S. represents a great opportunity for most African students, the adjustment to the new environment remains a challenge. The existing research studies discussed the experiences of both African undergraduate 
and graduate students in the U.S. and emphasized the challenges experienced in U.S. higher education, including homesickness, lack of preparedness, racial discrimination, cultural adjustment, isolation, language difficulties, academic problems, depression, and financial issues (Antwi \& Ziyati, 1993; Constantine et al., 2005; Crosson, 2010; Essandoh, 1995; Lee \& Opio, 2011; Lee \& Rice, 2007; Manyika, 2001; Nebedum-Ezeh, 1997; Omotosho, 2005; Pruitt, 1978). This section specifically discusses discrimination and cultural issues relevant to African students' experiences.

Discrimination. African students affirmed being discriminated in their host institutions. Several scholars addressed international students' challenges from a new-racism perspective (Lee \& Opio, 2011; Lee \& Rice, 2007). New-racism is a concept coined by Martin Barker in 1981 in light of the racism manifested toward African-Caribbean and South Asians in the United Kingdom. New-racism is a prejudice against individuals from different cultures (Barker, 1981). To understand African student athletes' experiences, Lee and Opio (2011) examined White and Black African students in the U.S. The findings indicated that Black African students were discriminated while White African students were not. Lee and Opio (2011) claimed that discrimination can impact African students' experiences and create acculturative stress. Although students reported being discriminated by White faculty or White students, the literature revealed situations where Black African students face discrimination by other international students from Asia or African Americans students (Blake, 2006; Constantine et al., 2005). Equally important, Lee and Rice (2007) found that international students' discrimination goes beyond racial problems. Students may also be discriminated against because of their accent and place of origin. These various experiences can impact African students' adjustment and create emotional distress. 
Social and cultures differences. To explore and understand the cultural impact on the experience of students, Crosson (2010) used interviews to gather data from ten West African undergraduate students pursuing their associate degree in Georgia. The results showed that West African students "appeared to attempt to conform and/or promote harmony in the situations they encountered" (Crosson, 2010, p. 114). Two students from Togo and Senegal recognized being less outspoken than American students because of the influence of their culture. The student from Togo supported the claim that back in Togo, "students are not encouraged to express their thoughts so openly. They might be thinking of something important or something might be hurting them inside, but they are taught not to openly talk about it with others. Or if they are [in] school and they sometimes have a question, they may not ask the question" (Crosson, 2010, p. 88). In Western culture, "talking is powerfully associated with notion of individuality, freedom, equality, democracy, reason, intelligence and honesty" (Kim \& Markus, 2005, p. 182). Previous studies have noted African students' desire to participate in classroom discussion, but are reluctant because of the perceived attitude of faculty and classmates. In Antwi and Ziyati's (1993) study, participants recounted:

They had been cut and diminished academically because their professors considered it a waste of time trying to help international students who are not proficient in spoken English because the assumption is that they are not going to do well because of their low intellectual ability (p. 11)

Many African students have kept silent in their courses because of fear of lack of understanding by faculty and peers, and the lack of mastering of cultural cues and slang used in classroom or informal conversation (Antwi \& Ziyati, 1993). These studies showed that culture plays a crucial role in learning, social interactions, and individuals' worldviews and attitudes. 
Being in a different cultural context enables African students to challenge their own values, recognize the similarities and differences in both cultures and adapt (Crosson, 2010). Mkhize and Frizelle (2000) revealed that "Black students sometimes find themselves torn between two worlds - on the one hand, they live in the world that values connections and attachments to family and community whilst, on the other hand, they have to spend their educational (and later, work) lives in a world that values independence and competition against others in order to succeed" (p. 6). African students enter their host institutions with different worldviews, social values, and expectations that may clash with the values of the host country and institution and effect their adjustment and experience (Constantine et al., 2005; Nebedum-Ezeh, 1997). To comply to the new environment values, many African students in the U.S. may have to make decisions that do not always align with their primary values (Young, 2003), causing identity conflict and bringing more confusion. Nwadiora (1996) found that Nigerian students' acculturation issues can be related to identity. The author assumed that Africans in the U.S. prefer to be acknowledged as Africans, and they struggle to adapt to American values while maintaining their previous culture and values. With the history of slavery and racism in the U.S., African sojourners experiences in the U.S. cannot be disconnected from African American experiences, leading to a challenge to identify with or deny African American identities. The research suggests U.S. faculty reflect on their perceptions of international students and own biases and learn about African students' cultures, challenges, and experiences to better support them (Constantine et al., 2005; Omotosho, 2005). A better preparation in home country and adequate support once in the U.S. can also ease the stress of the students and facilitate their integration (Nebedum-Ezeh, 1997). 


\section{Research on Student-Faculty Relationship}

Hartnett (1976) in Scholars in the Making, reported five dimensions that doctoral students found important in their doctoral experience:

(1) The nature and quality of student relations with faculty; (2) the extent to which the department can be regarded as a true 'community'; (3) the degree of faculty attention to and concern for teaching; (4) procedures and philosophy related to the evaluation of graduate student performance; and (5) the rigidity and/or flexibility of the formal curriculum requirements. (p. 59)

As noted in previous studies, and pointed by Hartnett (1976), student-faculty relationship is considered a critical aspect in doctoral student experience. If students' relationship experiences with faculty are generally positive, there are other cases where negative relationships are noted (Adrian-Taylor, Noels, \& Tischler, 2007; Bargar \& Mayo-Chamberlain, 1983; Rice et al., 2009). Early research studies have focused on the impact of student-faculty relationship on students' experiences and satisfaction with college education (Astin, 1993; Endo \& Harpel, 1982; Tinto, 1993). Researchers agree that student-faculty interaction is crucial and has an impact on student development and academic growth (Astin, 1993; Pascarella \& Terenzini, 2005). More, Pascarella and Terenzini (1977) argued that different types of student-faculty interaction influence first year college student attrition. In a later study, however, Pascarella and Terenzini (1991) made clear that not all interactions have the same effect on student experiences and outcomes. Interactions, which focused on academic matters or career goals, have a significant influence on first year college attrition than interactions, which centered on personal issues. The literature identified two types of interaction: formal (in a classroom setting) and informal (outside of a classroom setting), with both having an important impact on student outcomes (Lamport, 1993; Pascarella 
\& Terenzini, 2005). Research also showed that frequent interactions with faculty outside of the classroom have significant effects on students' outcomes (Wilson et al., 1975). Results of Cox and Orehovec's (2007) one-year long study at a residential college indicated five types of student-faculty interaction along a continuum outside of the classroom: disengagement, incidental contact, functional interaction, personal interaction, and mentoring. If several research studies emphasized the importance of student-faculty relationship outside of the classroom, Cox and Orehovec (2007) however reported that faculty and students have limited interaction outside of the classroom. The fifth type of interaction, mentoring, is the ideal interaction, where a faculty is invested in supporting and guiding a student. It is accepted that outside interactions between student and faculty positively influence student retention (Pascarella \& Terenzini, 1977). Consequently, Tinto (1987) observed, "Institutions with low rates of student retention are those in which students generally report low rates of student-faculty contact. Conversely, institutions with high rates of retention are most frequently those which are marked by relatively high rates of such interactions" (p. 66). While these studies focus on undergraduate students, it can be used as basis to understand and discuss student-faculty relationship in graduate school.

Student-faculty relationships are more encouraged in graduate education where a higher level of interactions with faculty is required whether for work collaboration, classroom instruction, or thesis or dissertation writing. Relationships impact individuals in all levels of life. Landsford et al. (2005) found that good quality relationships positively influence individual wellbeing. On the other hand, the author reported a negative relationship can impact individual wellbeing, leading to depression and anxiety. A relationship has a beginning, middle, and an end (Reis, Collins, \& Berscheid, 2000). Both faculty and doctoral students are called to interact daily in the classroom, laboratory, and during advising/mentoring sessions. Several studies explained 
the ideal faculty from a student standpoint. An ideal faculty is described as "a person who guides students, motivates and encourages them, gives students confidence, has a tendency to build more positive relationships with students and a person who has earned respect from students" (Telli, Brok, \& Cakirogly, 2008. p.123). On the other hand, Telli, Brok and Cakirogly (2008) found that the contrary of an ideal teacher is "a person who is disorganized, has lack of attention to students, gives lots of critic, is suspicious about students' work and who behaves inconsistently" (p.123). These conceptions relate to student perceptions of the faculty member's ability to engage in positive relationships.

Research pertaining to graduate student-faculty interactions indicates an impact on attrition, professional growth, program completion, and graduate school experience. Schroeder and Mynatt (1993) even noted that graduate students "consider their relations with faculty members to be one of the most important factors in determining the quality of their educational experience', (p.556). Furthermore, studies suggested that graduate advising relationship impact student attrition (Ferrer de Valero, 2001; Golde, 2000).

Types of student-faculty relationship. The most frequent student-faculty relationships described in the literature are advising and mentoring. Based on an historical analysis of advising, Adu (2011) pointed out undergraduate advising has evolved from the basic assistance in course enrollment to a more holistic approach, where academic advisors assist students in getting a quality experience out their education. On the other hand, doctoral advising "focuses on guiding students as they journey to become independent scholars" (Adu, 2011, p. 12). The advisor-advisee relationship holds an important role in graduate school. The literature described good and poor relationships with each having an impact on graduate student experiences. Schlosser et al.'s (2003) study demonstrated that doctoral students assess their academic 
satisfaction based on frequent meetings with faculty, faculty's openness, and mutual collaboration. A similar study by Barnes, Williams, and Archer (2010) correlated doctoral students' satisfaction with faculty attributes like caring, and reachable. A good advising relationship impacts student sense of belonging in the program, program completion, attrition, and overall experience (Ferrer de Valero, 2001; Golde, 2000; Zhao, Golde, \& McCormick, 2007). Students associated approachability with faculty friendliness (Britton et al., 2003). In contrast, a poor relationship influences student's attrition and satisfaction (Barnes, Williams, \& Archer, 2010; Ferrer de Valero, 2001; Golde, 2000).

When dealing with students, faculty argued that domestic and international students should be held to the same standards and instructions should not be modified to fit international students' needs. However, faculty who have more experience with international students or travelled around the world may be more inclined to modify their instructions to accommodate international students (Trice, 2000). Understanding students' previous experience, education system, and unique needs can enable faculty to better support student learning (Britton et al., 2003).

In discussing the role of a graduate advisor, Girves and Wemmerus (1988) supported the critical place of the advisor and the impact the advisor carries in graduate student learning and socialization in the graduate program. In Chun-Mei, Golde, and McCormick's (2007) study, one student passionately described the advisor-advisee relationship as follow:

It is impossible to overestimate the significance of the student-advisor relationship. One cannot be too careful about choosing an advisor. This is both a personal and professional relationship that rivals marriage and parenthood in its complexity, variety and ramifications for the rest of one's life (p. 263) 
Glasser and Hook III (2008) went further and recommended seven expectations for advising as described in Table 2.2.

Table 2.2

Description of Glasser and Hook III's Expectations for Advising

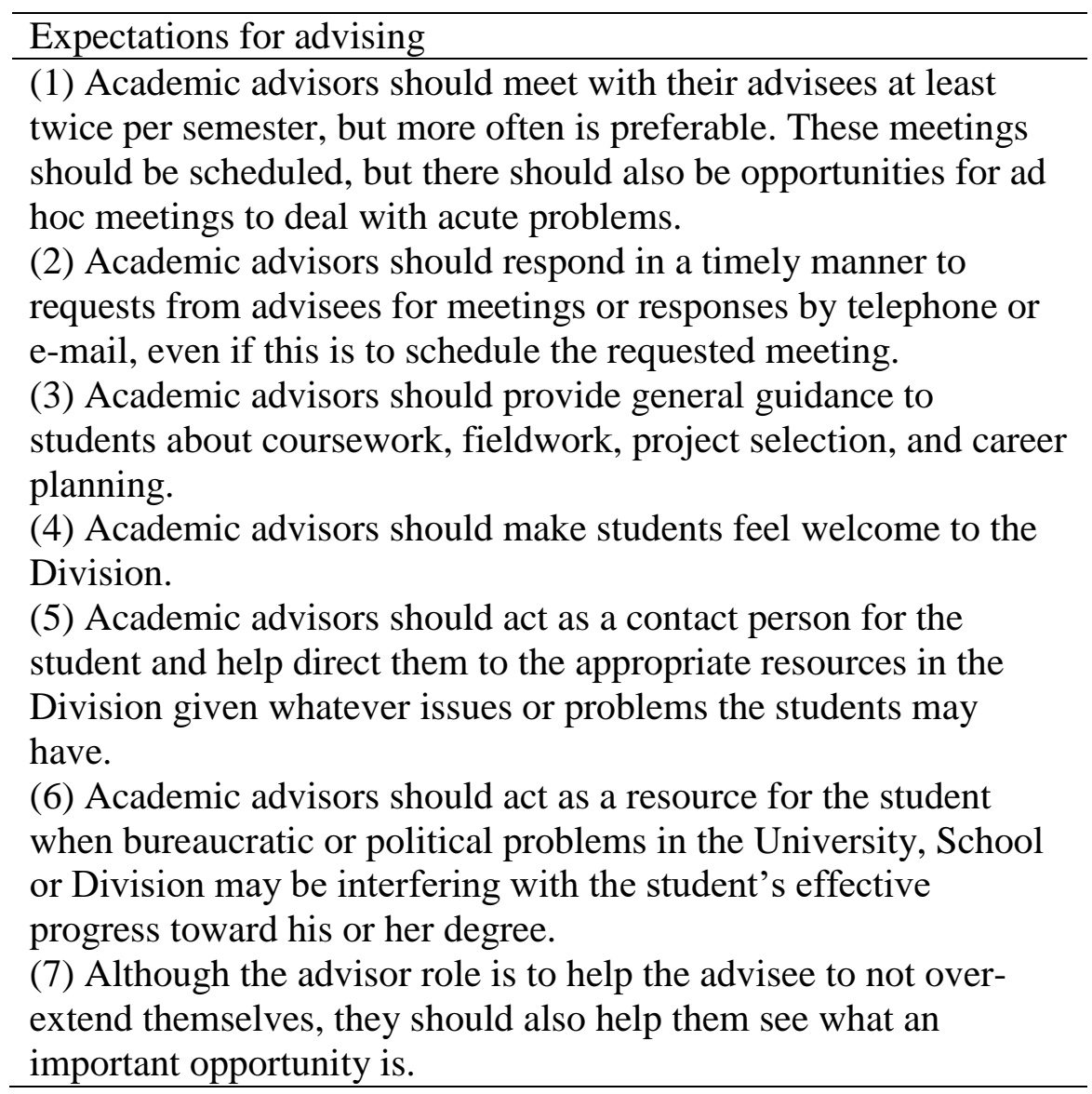

Note. Glasser \& HooK III (2008), p. 337.

The proposed expectations while important, suggest advisors surpass themselves to accommodate and support advisees. An important element the authors did not describe is expectations for advisees. Studies indicated that students and faculty hold different perceptions of their roles and responsibilities (Adu, 2011), which can influence faculty-student work dynamics.

Mentoring on the other hand is described as a "relationship between a more experienced individual (the mentor) with a less experienced individual (the mentee or protégé) (Glasser \& 
Hook III, 2008, p. 335). A mentor is a faculty member "to whom students turned to for advice, to review a paper, or for general support and encouragement" (Nettles \& Millett, 2006, p. 98). While advising and mentoring have been used interchangeably, Glasser and Hook III (2008) argued advisor responsibility is limited compared to mentor who nurtures a personal and professional relationship with the mentee (p. 335). Additionally, mentoring does not need a formal boundary to happen. It is worth mentioning that not all students have a faculty mentor, especially international students.

Graduate student faculty-relationship. The early definition of student-faculty relationship encompasses traditional White student-faculty interaction. As the landscape of U.S. higher education shifted to a more diverse group, it is worth reconsidering the features this diverse group brings and the interaction dynamic between student-faculty. With the increase of international students in U.S. campuses, faculty are likely to interact with students who are racially different from them. Scholars argued that graduate student-faculty relationships are experienced differently depending of student's origin.

Origin and ethnic issues. The literature indicated that students from different ethnic background or different cultures, or countries have different experiences. International graduate students pointed out the different treatment they receive from faculty because of their origin or ethnicity (Antwi \& Ziyati, 1993; Omotosho, 2005). Tompson and Tompson (1996) revealed three aspect faculty found challenging when teaching international students: Faculty affirm international students do not participate in classroom discussion; do not ask questions; and interact with only others international students. On the other hand, the authors reported international students found communication and networking challenging in their transition in U.S. colleges. To resolve these difficulties, Tompson and Tompson (1996) proposed that faculty 
get to know international students enrolled in their courses and initiate small group activities to include everyone. Glass et al. (2015) examine the impact of student-faculty interactions on international students' sense of belonging looking specifically at instances of inclusion and exclusion. They interviewed forty international students studying in two research universities in the U.S. from four subgroups: "Group 1: high academic preparedness, high financial resources; Group 2: high academic preparedness, low financial resources; Group 3: low academic preparedness, high financial resources; and Group 4: low academic preparedness, low financial resources" (p. 356). A large majority of students were pleased in their interactions with faculty. Students acknowledged the efforts made by faculty to accommodate them. A female graduate from Nepal shared,

I had one professor, he was American, but I just loved his class because he knew that I was afraid to talk, and he said, "If you have something and you are not able to say in class, come and talk to me, and maybe we can raise that in the next class, so that if I start the topic, then you might be able to contribute a lot." That kind of stayed in my mind. In his class, I can speak. I can say what I see because he is okay with it. Little things like that even just giving a little bit of care (p. 358)

The authors also found that "significant, meaningful relationships with professors promoted other positive outcomes, such as students' confidence in their capacity to construct knowledge for themselves" (p. 359). International students in the study were also appreciative of the classroom discussion opportunities given by faculty to share their personal experiences and challenge their personal beliefs and way of knowing. To explore how cultural values shape Chinese students' online learning experience in American universities, Wang (2006) applied Hofstede's cultural dimensions' model. The author corroborated previous studies (Crosson, 
2010) and revealed language, cultural values, and education system influence student learning experience. Wang (2006) pointed out that some characteristics given to Chinese students such as being silent and passive learners might be an effect of the Chinese cultural values. However, to be successful, Chinese graduate students have developed strategies to navigate and succeed in online classrooms.

International graduate student-faculty relationship. Previous studies have addressed international student-faculty advising relationship. Adrian-Taylor, Noels, and Tischler (2007) surveyed 55 international graduate students and 53 faculty supervisors to understand the frequency of interpersonal conflict between these two groups. Thirty-four percent of faculty supervisors and twenty-two percent of international students reported a conflict in their relationships. To understand international student perspectives on graduate advising relationships, Rice et al. (2009) surveyed 367 international students. The authors found that most international students were positively satisfied in their relationships with their advisors. Although, there was a great number of students who were satisfied with graduate advising relationship, there was also a large minority who were dissatisfied. This dissatisfaction was described by the advisor "inaccessibility, lack of guidance, poor feedback, and excessive demands" (Rice et al., 2009, p. 385). One student supported this claim that "my advisor has no ambitions for his students whatsoever. He puts zero work into training them" (Rice et al., 2009, p. 385). In Figure 2.2, Rice et al. (2009) proposed a model of an ideal advisor for international graduate students, cautioning however to use it carefully. Rice et al.'s (2009) description of an ideal faculty advisor relates to the findings of Telli, Brok, and Cakirogly (2008). If Telli, Brok, and Cakirogly (2008) provide a broader definition of an ideal faculty, Rice et al. recommended 
faculty to be interculturally competent to better support both domestic and especially international students.

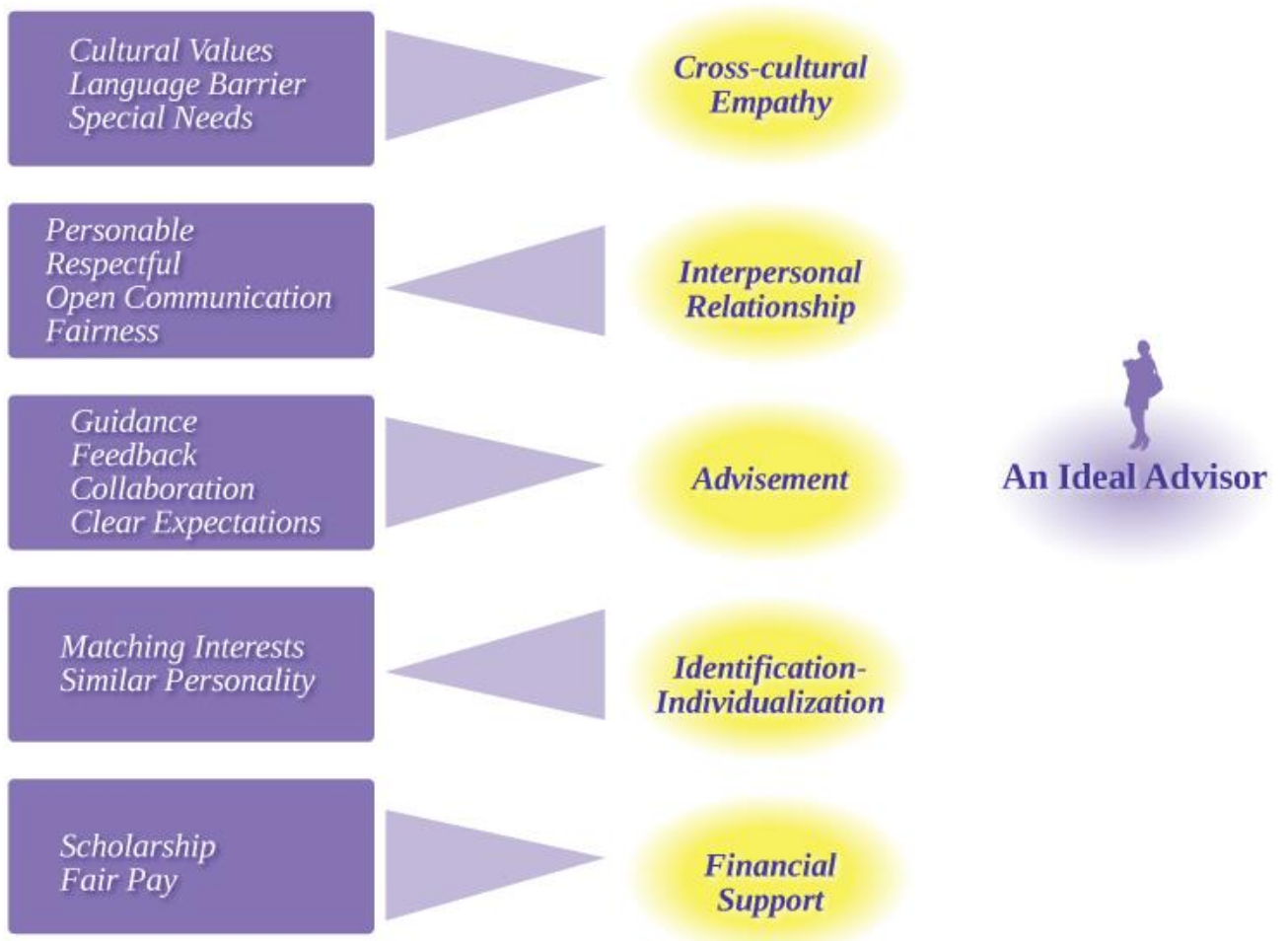

Figure 2.2. Proposed model of an ideal advisor for international graduate students (Rice et al., 2009).

If the suggested model intends to encourage faculty to use a more holistic approach when dealing with international students, the reality may be different and not always enable the ideal support international students are expecting. Advising practice may vary from programs to programs and not all students choose their own advisors. Funding is a real issue for many international students, however faculty may have limited power in providing financial support for all advisees.

Literature gap. The literature on international and African graduate students shows that African students in the U.S., in addition to dealing with language difficulties, homesickness, cultural adjustment, academic problems, financial issues, have to manage and cope with 
discrimination. Although these research studies are connected and provide a better understanding of African students' struggles and adjustment problems, few addressed the impact students' culture, language (Crosson, 2010; Wang, 2006), and previous experiences may have on their adjustment in the new institution and interpersonal relationship. Further, few studies focused on African Francophone countries. Other unanswered questions in the literature pertain to the relationship dynamic of African Francophone doctoral students and faculty. Faculty hold an important role in higher education as instructors, researchers, advisors/mentors, and also as agent of socialization for graduate students. Having an understanding of how African Francophone doctoral student-faculty relationships are formed and shaped may provide a ground to address collaborative and meaningful relationships based on respect of cultural differences. "Looking into the experiences of African students in an American academic setting is indeed a look into forms of negotiations of cultural realities, differences and codes" (Antwi \& Zayati, 1993, pp. 14$15)$.

\section{Theoretical Framework}

A conceptual framework comprised of cultural dimensions theory, socialization of graduate and professional students theory, and language socialization theory guided this study. Cultural Dimensions theory is part of the larger perspective of cross-cultural communication, which highlights the impact of national cultures on the beliefs, values, and attitudes of its members. Language Socialization, on the other hand, started as a reaction to the gap in the literature and is concerned with the interrelation between language and culture in human development. Finally, socialization theory has been widely used in doctoral student research, mainly to understand doctoral students' complex experiences (Gardner, 2007). Though distinct, 
the three theories complement one another providing an understanding of the experiences of African Francophone doctoral students.

\section{Cultural Dimensions Theory}

Extensive work has been done on cultural differences and individual worldviews (Hofstede, 1980; 2001; Kluckhohn, 1951; Kluckhohn \& Strodtbeck, 1961). While previous works have provided ways to compare cultures, they also show that culture can be explored and defined in many ways. The term culture has received many definitions and meanings (in Arts, Science, Sociology, Anthropology, etc.). Fairchild (1967) defined culture as:

A collective name for all behavior patterns socially acquired and transmitted by means of symbols; hence a name for all the distinctive achievements of human groups, including not only such items as language, tool-making, industry, art, science, law, government, morals and religion, but also the material instruments or artifacts in which cultural achievements are embodied and by which intellectual cultural features are given practical effect, such as buildings, tools, machines, communication devices, art objects, (...) (p. 80)

Kluckhohn's (1951) definition often serves as a basis for some theories on culture. For Kluckhohn (1951) "culture consists in patterned ways of thinking, feeling and reacting, acquired and transmitted mainly by symbols, constituting the distinctive achievements of human groups, including their embodiments in artifacts; the essential core of culture consists of traditional (i.e. historically derived and selected) ideas and especially their attached values" (p. 86). To explain culture, Weaver (1986) uses a cultural iceberg analogy divided in two parts: external (which illustrates the visible features of a culture, such as language, arts, music, and food) and internal (which illustrates the invisible features of a culture, such as values, beliefs, and body language). 
Hofstede created a similar model to Weaver's iceberg model, the cultural onion, constituted of a core (values) and three layers (rituals, heroes and symbols). The core of the onion, which is invisible, holds the values of the culture. Individuals act according to their cultural value systems. The first layer stands for rituals, which are for example, greeting symbolic people use daily. The second layer stands for heroes, such as national heroes that have an impact on the country and culture like Nelson Mandela in South Africa. The last layer stands for symbols such as body images (for example facial scarification in Africa). International students come with beliefs and values that dictate their attitudes. The literature pointed out issues international students face because of their different values and worldviews.

National culture influences how people behave in institutions (Sanchez \& Curtis, 2000) or when they interact with each other. Hofstede's model is valuable for understanding African Francophone doctoral students' experiences in American higher education. With students and faculty coming from diverse backgrounds, culture is significant because it affects what both students and faculty bring to the relationship. It influences how students and faculty communicate and react to one another. Culture can also determine the meanings that students and faculty confer on their relationships. In this study, culture is defined as "the collective programming of the mind which distinguishes the members of one group or category of people from another" (Hofstede, 1991, p. 5). Human mental programming, which can be represented by a pyramid, has three levels of uniqueness (Hofstede, 1981). The first level represents the individual personality, which is specific to each individual, and is both inherited and learned. The next level characterizes culture or collective, which is learned and shared by individuals belonging to the same group. And the last level describes human nature, which is universal and shared by all mankind. The learning component of culture provides African Francophone 
doctoral students with a capacity to learn and adapt to the new culture's norms and customs.

"Graduate study in the U.S. is structured in such a way that individuals have to form or belong to some kind of group in order to survive. From class discussions or assignments to research assistantships and forming academic committees, students form alliances with other individuals in order to succeed" (Lobnibe, 2013, p. 206-207). Yet, many international students stay attached to people from the same or similar culture and country (Miller et al., 2009), undermining their fast adaptation, development, and sometimes success.

Geert Hofstede (1980) conducted a large scale study in 1968 and 1972 among International Business Machines (IBM) Corporation's employees to examine cultural differences between 40 nations. The findings recommended four dimensions (power distance, individualism versus collectivism, masculinity versus femininity, and uncertainty avoidance) (See Figure 2.3) to understand the impact of national cultures on individuals' values, believes, and behaviors in multi-cultural workplaces, organizations, or institutions. Later, two more dimensions (long/shortterm orientation and indulgence versus restraint) were added relating to Michael Bond (1987; 1988) and Michael Minkov's (2007) works. With the internationalization of higher education, cross-cultural interactions between students, faculty, and staff from different backgrounds are inevitable. Four views of Hofstede's theory are particularly relevant to the study of African Francophone doctoral students, and include Power Distance, Uncertainty Avoidance, Individualism (as opposed to Collectivism), and Masculinity (as opposed to Femininity). 


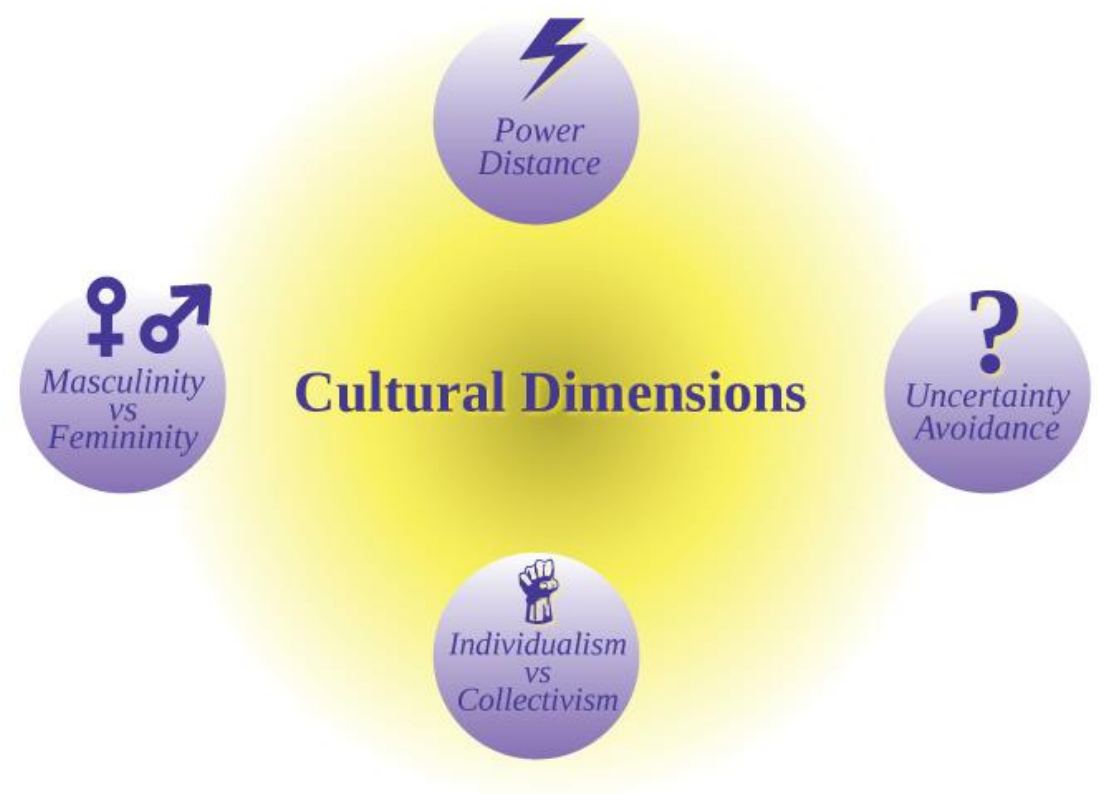

Figure 2.3. Hofstede's description of cultural dimensions.

Power distance. This dimension refers to "the extent to which the members of a society accept that power in institutions and organizations is distributed unequally" (Hofstede, 1985, p. 347). Members of a country rated high in power distance accept the unequal distribution of power, as observed in a parent-child or teacher-student relationship. Most African students come from high Power Distance countries, where students regard faculty as authority figures. With the United States rated low in Power Distance, African francophone doctoral students and faculty may have different understanding of their roles and expectations. The American education system is less guided by power distance, allowing students and faculty to collaborate and learn from one another. Because African francophone doctoral students are not used to engaging informally with faculty or voice openly their ideas in the classroom, they may have difficulties adjusting in this system. For example, Lobnibe (2013) found that female West African graduate students perceived the U.S. classroom atmosphere difficult to relate to because of the 
informality. Another participant in Antwi and Ziyati's (1993) study acknowledged that his education system has not prepared him to voice his opinions or concerns in the classroom.

Uncertainty avoidance. Uncertainty avoidance indicates "the degree to which the members of a society feel uncomfortable with uncertainty and ambiguity, which leads them to support beliefs promising certainty and to maintain institutions protecting conformity" (Hofstede, 1985, pp. 347-348). Students from high uncertainty avoidance cultures are comfortable in structured classes and learning conditions. Once in a culture where uncertainty is tolerated, these students may feel uncomfortable, such as in an American graduate classroom, where faculty do not hold students' hands to help them walk. The unstructured format of some graduate seminars may also leave these students confused.

Individualism versus collectivism. This tenet stands for A preference for a loosely knit social framework in society in which individuals are supposed to take care of themselves and their immediate families only; as opposed to Collectivism, which stands for a preference for a tightly knit social framework in which individuals can expect their relatives, clan, or other in-group to look after them, in exchange for unquestioning loyalty (Hofstede, 1985, p. 348)

Non-western countries are commonly described with collectivist characteristics (Triandis, 1995). Triandis and Berry (2004) described four main characteristics of the collectivist culture as follows: (1) individuals define themselves in relation to the group (family, tribe, religious group, etc.); (2) the interest of the group dominates; (3) the group directs individuals' actions; and (4) individuals stay loyal to the group despite their personal interests. In other words, "I am because we are; without we I am not, and since we are, therefore I am" (Mbiti, 1969, as cited in Nwadiora, 1996, p. 118). The United States is considered an individualist society (Hofstede, 
1980). Personal interests and successes are praised and encouraged. Many African students have experienced and known interdependent relationships all their lives and the transition in a culture that promote competitiveness and ambition may be challenging.

Masculinity versus femininity. This dimension indicates:

A preference for achievement, heroism, assertiveness, and material success; as opposed to Femininity, which stands for a preference for relationships, modesty, caring for the weak, and the quality of life. In a masculine society even the women prefer assertiveness (at least in men); in a feminine society, even the men prefer modesty. (Hofstede, 1985, p. 348)

The United States is a masculine society according to Hofstede's rating score, thus students coming from a feminine society (e.g., Burkina Faso and Senegal) need to adjust to the U.S. norms, which value assertiveness, competition, and success. Students who do not transition successfully may experience psychological and emotional difficulties influencing their graduate experience (Kim, 2001).

Such differences in culture may influence African doctoral students' relationships with faculty. To seek and maintain effective student-faculty relationship, African Francophone doctoral students and faculty must first understand each other and the luggage each one brings in the relationship.

\section{Socialization of Graduate and Professional Students}

Several scholars have used a socialization framework to examine and understand undergraduate student (Pascarella \& Terenzini, 1991, 2005) and graduate student experiences (Gardner, 2007; Thornton \& Nardí, 1975; Weidman, Twale, \& Stein, 2001). Researchers found that the quality of student socialization can impact a student's decision to leave his/her program 
(Gardner, 2007; Golde, 1998). Although there is extensive work on doctoral student socialization, few studies take into consideration the context and specificity of different institutions and disciplines or individual groups. According to Weidman, Twale, and Stein (2001), "Socialization in graduate school refers to the process through which individuals gain the knowledge, skills, and values necessary for successful entry into a professional career requiring an advanced level of specialized knowledge and skills" (p. 5). Building on Thornton and Nardi's (1975) work, Weidman, Twale, and Stein (2001) suggested four stages of socialization: anticipatory, formal, informal, and personal (Figure 2.4).

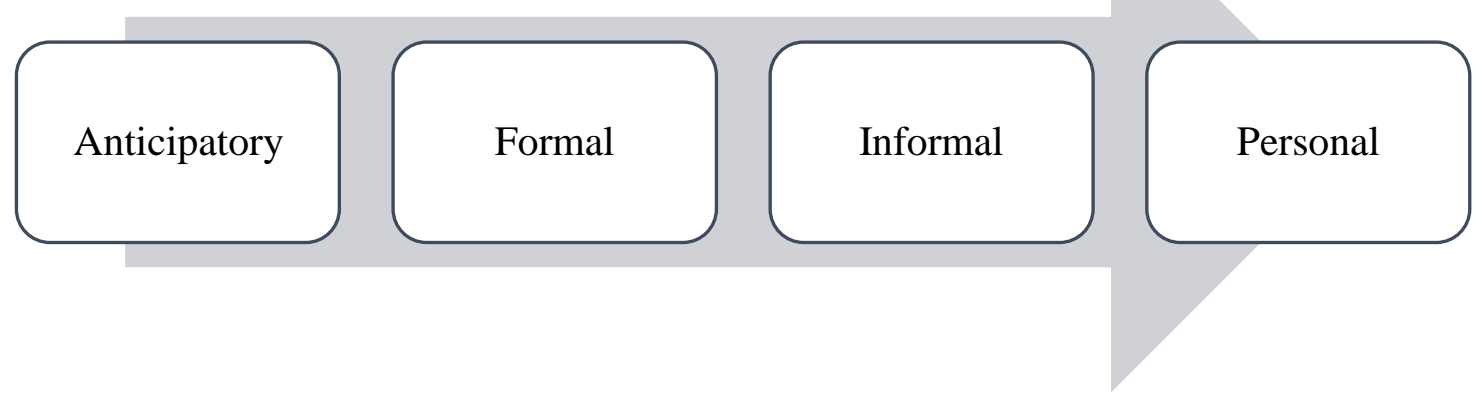

Figure 2.4. Illustration of the four stages of socialization (Weidman, Twale, \& Stein, 2001). In the anticipatory stage, new students enter graduate programs and learn what is expected from them. The formal stage provides students with opportunities to learn role expectations from faculty and older and experienced students during their daily formal and informal interactions. In the informal stage, students continue to learn cues on acceptable behavior. In the personal stage, students reconcile and merge individual and professional images and roles to form a professional identity. Gardner and Mendoza (2010) also highlighted the necessity to socialize doctoral student into teaching, research, and service, important aspects of doctoral experience. Many African Francophone doctoral students come with various motivations and different expectations. As much as institutions and departments assess whether a 
student is a fit in the program, African Francophone doctoral students also want to know if the institution and program are a fit for them. One way students assess their experience is the quality of relationship they have with faculty. Once African Francophone doctoral students enroll in their programs, they are influenced by the department's culture, values, expectations, and views of person-to-person interactions, which may reinforce or weaken their integration and sense of belonging. Understanding students' expectations and attitudes helps understand how they integrate a department and negotiate student-faculty relationship. Faculty play an import role in supporting students throughout the different stages of the doctoral program. Coming from a different education system with different values may be stressful for African Francophone doctoral students. Therefore, looking for and sustaining relationships with faculty may influence the course of doctoral student experience and attrition.

\section{Language Socialization Theory}

Carson (2008) argues that socialization of international graduate students can include "acculturation to the U.S., engagement to the institution, or professional socialization within the discipline” (p. 17). In the present study, Ochs and Shieffelin (2011), and Schieffelin and Ochs' (1986) language socialization framework is combined with two frameworks to better understand African Francophone doctoral students' experiences. "Language socialization arose out of an anthropological conviction that language is a fundamental medium in children's development of social and cultural knowledge and sensibilities (...)" (Ochs \& Schieffelin, 2011, p. 1). Early research conducted by Ochs and Schieffelin showed that language is interlinked to social and cultural context. Language socialization is a dual process of socialization into and through: socialization through language and socialization to use language (Figure 2.5). 


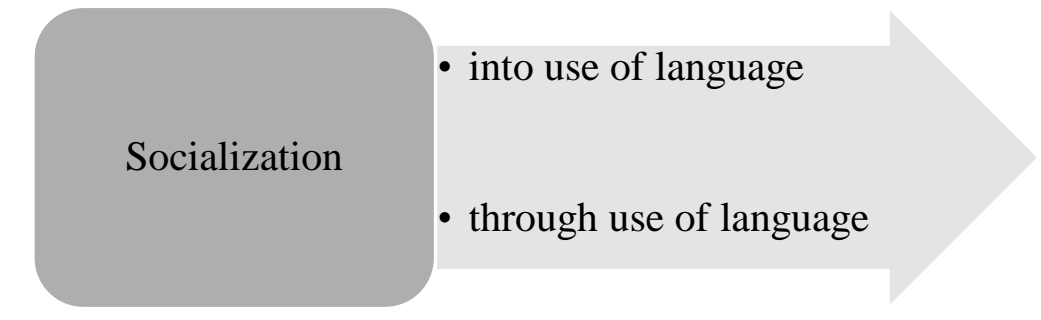

Figure 2.5. Illustration of language socialization (Ochs \& Schieffelin, 2011).

Language here is viewed as a mediating tool of beliefs, perceptions, values, and attitudes of the community. Therefore, it can be assumed that African Francophone doctoral students will not only have a linguistic and cultural barrier in terms of knowing or not knowing the new environment, institution, or department, but even on how they perceive what is important for them or not. Hilliard (1983), as quoted by Robinson and Clardy (2011, p. 106) stated, “A language is not simply a means of communicating in a narrow sense. Psychologically, it is a prime source of cultural identity. It is also a cognitive structuring of the world which is linked to one's worldview, identity, self-concept and self-esteem" (p. 27). The research on international students and African students' linguistic issues, focus on the communication aspect, neglecting the relation between language and culture and their impact on the lack of knowledge of the host environment's values and customs.

United States campuses include students from different languages and cultures. Gardner and Lambert (1972) have developed the concept of "integrativeness" that describes the positive tendency of second language learners toward the target language and culture. Ignoring student first language and cultural background and the parts they play in student identities can be “subtractive" (Valenzuela, 1999), in the sense it suppresses important aspects of students' cultures and forces students to shed part of their identities for a chance of success. Language for these students can become a challenge in adjusting academically and succeeding in their institutions (Zhou, Frey, \& Bang, 2011). Scholars investigated the challenges being culturally 
and linguistically different in American society and campuses (Silbernagel, 2015). Today the United States includes people who speak Spanish, English, Chinese, French, and so forth. Despite the large number of dual language learners, Robinson and Clardy (2011) stated that over $83 \%$ of postsecondary faculty are White and have limited experience managing culturally diverse groups. This issue also translates in to higher education, where lots of faculty are White American. Robinson and Clardy (2011) recommended instructors keep themselves informed on this matter to better support students. The literature highlights the important place of the environment on an individual's linguistic identity. When students' culture and language are not appreciated, it may affect the way they portray themselves and affect their decisions to speak in the classroom. For example, many African students reported not speaking in the classroom because they are judged by their strong accent, or cultural differences (Antwi \& Ziyati, 1993; Omotosho, 2005). Previous studies conducted on Latino students in the U.S. revealed that the negative effect of the environment increases student sense of loss, impacting their academic performance (Irizarry, 2011; Robinson \& Clardy, 2011; Silbernagel, 2015). African Francophone doctoral students have previously been socialized in their countries of origin. Because of that, there might be some acculturative stress because of the dissonance between previous and current beliefs and values. Cultural differences influence students. For example, participants in Zhou, Frey, and Bang's (2011) study reported a willingness to enroll in classes where the instructor could reduce cultural distance. Other students worked supplemental hours to acquire American culture and values. There is an attempt from students, then, to find their equilibrium and adjust to the new environment (Kim, 2001). One issue however, is when students feel depreciated or feel their previous experiences, knowledge, culture are brushed away. This may impact the way they 
see and define themselves in the new environment and their academic performance. As van Lier (2007, p. 58) affirmed:

When our lives change significantly as in the case of learning a new language, [new culture], we need to construct new ways of linking the self to new worlds and words (i.e. forge new identities and new ways of expressing our identities); we also need to develop relationships with new people and strive to establish who we are and wish to become. Thus, while identities are ways of relating the self to the world and are in this sense personally valued constructions, they are socially forged and negotiated through our relations and interactions with other people (as cited in Ushioda, 2010, p. 7)

Both faculty and African Francophone doctoral students bring different identities related to their culture, language, and experience. Fostering effective relationships and a successful integration into the department and institution may require both groups — when interacting with each other in the classroom or during advising sessions - to go beyond the stereotypes, primary impressions, and learn more about each other experience, culture, values, and beliefs and how it influence the person as a whole.

Cross-cultural adaptation theory refers to the individual's ability to adapt to a new culture or environment. Al-Sharideh and Goe (1998) described adjustment as "a transition process that unfolds over time as students learn to cope with the exigencies of the university environment" (p. 2). These demands include learning to communicate effectively with faculty and classmates, understanding students' roles and faculty expectations, and mastering the institution rules and codes of conduct. Scholars recognize international students have different adaptation experiences than their American counterparts. Warren and Constantine (2007) take it further, affirming that Black-African students adjust differently than other international students coming from other 
continents (such as Europe or Asia). The unfamiliarity with the education system and new challenges push students to their boundaries, forcing them to adjust and change. Such processes can be seen in Liu's (2011) writings. Liu (2011), an international graduate student, was a teacher in China before deciding to pursue a degree in Canada. She reported:

As a sojourner, I experienced challenges adjusting psychologically and socially to life in the new country. I suffered symptoms of culture shock such as loss of my identity, lack of confidence, longing for my home country and family, and unwillingness to interact with others. This made me feel confused about my new life in Canada, and I asked myself why I had come. I had family and good friends in China where I was well taken care of, and I did not need to cook after 9:00 p.m. when I returned from my classes. In China I had a respectable job as a teacher, and I was popular with my students. I realized that my new identity as an international graduate student in Canada was not as successful or respectable as my identity in China. In this new society, I lost my sense of achievement and comfort. I began to worry about my situation and felt lost, and I chose to keep to myself in my own world and associated mostly with other Chinese graduate students, something Siu (1952) defines as "in-group tendency" (p. 36) (p. 79)

Liu (2011) recognized that barriers in English skills, the bond to other Chinese students, and timidity undermine a rapid adjustment and mastering of English language, crucial to any social interaction and success in an English-speaking environment. Liu's experience is not unique and has been shared by many other international students. Many international graduate students have English has a second language. Although these students have met the Graduate Record Examination (GRE), Test of English as a Foreign Language (TOEFL), department and university requirements, writing papers and carrying out research in your second language can be 
challenging and may cause some anxiety, which can undermine academic and personal accomplishment. Leaving the safety of familiar places and people for a new environment brings a trial to one identity, but also opportunities to learn and transform as a person (Kim, 2001). "Adapting to a new and unfamiliar culture, then, is more than survival. It is a life-changing journey. It is a process of 'becoming' --personal reinvention, transformation, growth, reaching out beyond the boundaries of our own experience" (Kim, 2001, p. 9).

In sum Cultural Dimensions theory (Hofstede, 1980), Socialization of Graduate and Professional Students (Weidman, Twale, \& Stein, 2001), and Language Socialization (Ochs \& Schieffelin, 2011) can be used together to explain African Francophone doctoral students' experiences and describe the difficulties they experience when negotiating student-faculty relationship. 


\section{Chapter Three. Methodology}

As doctoral student attrition rate is at 50\% (Ferrer de Valero, 2001; Golde, 2000) and the role of advising and mentoring highlighted as an influencing factor, there is a need to focus on student-faculty relationship at the doctorate stage. If doctoral student experience is influenced by the quality of interaction with faculty, it makes sense to explore African Francophone doctoral students' interactions with U.S. faculty as they reflect on their experience in the U.S. education system and come to gain in depth understanding of themselves.

The purpose of this study was to explore and describe the experiences of African Francophone doctoral students using a qualitative method. There is a dearth of research studies that examine African doctoral students' experiences in the U.S. Even less research exists on African Francophone doctoral students' perceptions of student-faculty relationship. Considering the gap in the literature, this single bounded case study sought to examine and describe African Francophone doctoral student experiences when negotiating the academic and social relationship with U.S. faculty in a Midwestern research institution. The aim of this study was also to answer the following central research question: What are African Francophone doctoral students' relationship experiences with faculty in a United States research institution? Subsidiary research questions were:

1. How do African Francophone doctoral students at a Midwestern research institution perceive their relationships with faculty?

2. What factors influence these relationship experiences?

Hofstede's cultural dimensions theory, Weidman, Twale, and Stein's socialization model, and Ochs and Shieffelin's language socialization theory shaped the research questions through the 
lenses of social and cultural differences in education, social interactions, values and beliefs, and expectations in the host institution.

Chapter Three discusses the researcher's positionality and role, the research design, the study's setting, the sampling procedures and participants, the description of data collection, anticipation of ethical issues, data analysis process, and ways of establishing credibility and trustworthiness.

\section{Researcher Positionality and Epistemology}

Research provides a common interspace for researcher and participants, where researcher and participant have an influence on the space (England, 1994). Kezar (2002) stated, "within positionality theory, it is acknowledged that people have multiple overlapping identities. Thus, people make meaning from various aspects of their identity ..." (p. 96). My positionality as a graduate student, African Francophone student, and my interest in student-faculty relationship guided my view and approach to conduct this study. "Identities come into play via our perceptions, not only of others, but of the ways in which we expect others will perceive us. Our own biases shape the research process, serving as checkpoints along the way" (Bourke, 2014, p. 1).

Interpretivism and constructivism have often been used interchangeably (Merriam, 2009). Coming with the belief that relationships are socially and culturally constructed I approach this study from a constructivist perspective. According to Creswell (2009),

Individuals seek understanding of the world in which they live and work...These meanings are varied and multiple, leading the researcher to look for the complexity of views rather than narrowing meanings into a few categories or ideas... Often these subjective meanings are negotiated socially and historically. They are not simply 
imprinted on individuals but are formed through interaction with others (hence social constructivism) and through historical and cultural norms that operate in individuals' lives (p. 8)

Drawing from the philosophy of phenomenology, which emphasizes individuals' experiences and interpretations (Merriam, 1998), I aim to understand African Francophone doctoral student experiences as they share their viewpoints and convey through description the lived experiences (Giorgi, 1985). Race, gender, ethnic, culture, and religion diversify many U.S. colleges and universities. And the way people make sense of their world is deeply influenced by their social and cultural 'programming' (Hofstede, 1980). While African Francophone doctoral students interact daily with faculty, the meaning they give to these relationships may differ from U.S. faculty.

Creswell (2007) explained a qualitative research starts with assumptions or a worldview and leads to the self-reflection of the qualitative researcher. In a qualitative research, the researcher is the main instrument for data collection and analysis. Consequently, the researcher should be able to build truthful relationship with participants, demonstrate sensitivity and understanding, accept uncertainty, and carry a good communication with participants (Merriam, 1998). Truthfully, I have a personal and an educational interest in exploring African Francophone doctoral student-faculty relationship. I had a good experience studying in Burkina Faso. The system has promoted a very competitive environment, where only the best survive and get to the top. My good experience however does not erase the lack of interaction with faculty, resources or infrastructures. I come from a culture and education system where interactions with faculty are limited or non-existent. I remember the long lectures hours and boredom of students mostly those sitting at the end of the classroom, who could not hear the instructor because of 
microphone issues. I interacted more with my peers. My college years at the University of Ouagadougou are marked by many conflicts between student unions and Burkinabe's government. The 1999-2000 university year was nullified because of the strikes and hours of classes students missed. Like many African countries, Burkina Faso's government sees university students as disruptive. Education at all levels in Burkina Faso is under crisis. Most importantly, one can observe sadly the lack of efforts of the government to improve higher education and increase the chance of students and faculty to succeed and contribute to the country's development. In 2009, the newspaper 'l'Observateur' number 740 pointed out the difficult work condition of Burkina Faso faculty compared to their counterparts in West Africa. For example, a 'professeur titulaire' in Burkina Faso earns monthly 354000 CFA Franc BCEAO (around \$575.45 depending of the dollar's rate) compared to 1000000 CFA Franc BCEAO (around \$1625.56) for a faculty in Senegal. With the massification of higher education, many African universities like the University of Ouagadougou in Burkina Faso have difficulties accommodating students and providing them with quality education and resources to succeed. University students have become the voice to seek quality education, justice, and equality for all and a burden for any African government who ignores this segment of the population.

For many years I felt uncomfortable talking to faculty in the U.S. or sharing my opinions in the classroom, or going with the informality between students and faculty. As I moved forward in my education, I came to realize the crucial role faculty play in a student's life and the necessity of maintaining a good relationship with faculty. If I have been fortunate to meet encouraging and helpful people on my road, this is not typical for all international students. I recalled the complaints and frustrations of some of my fellow international graduate students regarding the courses' clarity and expectations, and their challenging rapports with faculty. I 
recalled some of their suggestions to avoid some classes taught by such and such faculty because of the biases they display toward international graduate students. These affirmations got me very interested in understanding the relationship dynamic among international graduate students and their faculty. I also wanted to understand if these challenges were typical to all graduate students or related only to international graduate students. More, the informal conversation I had with African students reinforced my interest and decision to pursue this topic. As a West African Francophone doctoral student, myself, I supposed that African Francophone doctoral students have more challenges interacting with faculty in the U.S. because of the language issue and lack of understanding of the culture, and expectations of their institutions and departments. I could not agree more with Merriam (1998) when stated that these assumptions can influence the researcher. Choosing also to study Francophone students from Francophone Africa can also be a source of bias. The findings of this study could be different if other international students from Africa, Asia, or Europe were studied. Rapports with faculty, specifically faculty-advisor, facultymentor, or faculty-supervisor are intensified in graduate school. Thus, building and reinforcing good relationships is a key element of a positive experience in graduate school.

Because of my background as a West African Francophone graduate student, one may consider that I enter this study with a bias. Yet, my aim is not to prove that African Francophone doctoral students and U.S. faculty do not understand each other or experience difficult relationships but to examine how African Francophone doctoral students construct these relationships and whether their previous experiences influence their present experiences and perceptions. As Spradley (1979) describes,

I want to understand the world from your point of view [African doctoral students]. I want to know what you know in the way you know it. I want to understand the meaning 
of your experience, to walk in your shoes, to feel things as you feel them, to explain things as you explain them. Will you become my teacher and help me understand? (as cited in Kvale \& Brinkmann, 2009, p. 34)

As a West African Francophone doctoral student, it is necessary I constantly acknowledge my position, personal experience, connection with participants and any obstacle I may have to fully understanding African Francophone doctoral student experiences in the U.S.

\section{Qualitative Research}

My research questions asked African Francophone doctoral students to contemplate their lives and experiences in U.S. institutions. I was not looking to reach an objective truth but to understand the uniqueness and overall experiences of students. Furthermore, the study sought to understand the meaning African Francophone doctoral students give to their interactions with faculty (Creswell, 2007; Merriam, 2009). Because this study required participants to examine their values, beliefs, and assumptions, a qualitative methodology was the appropriate approach to understand student reality and collect rich and meaningful data. Patton (1985) argues that qualitative research

...is an effort to understand situations in their uniqueness as part of a particular context and the interactions there. This understanding is an end in itself, so that it is not attempting to predict what may happen in the future necessarily, but to understand the nature of that setting-what it means for participants to be in that setting, what their lives are like, what's going on for them, what her meanings are, what the world looks like in that particular setting-and in the analysis to be able to communicate that faithfully to others who are interested in that setting... The analysis strives for depth of understanding (p. 1) 
A qualitative design approach permits the researcher to inductively explore the meanings African Francophone doctoral students give to their relationships with faculty (Patton, 2002). The objective of the qualitative researcher is to collect rich data that is not quantifiable. Because relationship is a social activity and African Francophone doctoral students studying in the same institution share similar language, values, and different perspectives, an instrumental single case design was used.

\section{Research Design}

An instrumental single case study was used for the present study because of the value of examining in depth a phenomenon through distinct individuals' perspectives and the context that matters to the experiences of participants. Case studies are used when "(a) "how" or "why" questions are being posed, (b) the investigator has little control over events, and (c) the focus is on a contemporary phenomenon within a real-life context" (Yin, 2009, p. 2). Further, a case study is a thorough exploration of a program, an individual(s), event, or activity (Creswell, 1998) and is used when the researcher wants to understand a real-life phenomenon in a natural setting (Yin, 2009). A qualitative study is linked to the philosophy of phenomenology, stressing the importance of experience and interpretation (Merriam, 1998). The qualitative researcher seeks to understand a problem or phenomenon and its interrelations in a context (Stake 1995).

Additionally, Yin (1994) describes a case study as an

empirical inquiry that investigates a contemporary phenomenon within its real life context, especially when the boundaries between phenomenon and context are not clearly evident. In other words, you would use the case study method because you deliberately wanted to cover contextual conditions_-believing that they might be highly pertinent to your phenomenon of study ... The case study inquiry copes with the technically 
distinctive situation in which there will be many more variables of interest than data points ... In this sense, the case study is not either a data collection tactic or merely a design feature alone but a comprehensive research strategy (p. 13)

Case studies have been extensively used in psychology, sociology, political science, anthropology, social work, business, education, nursing, and community planning (Yin, 2009). "The case study method allows investigators to retain the holistic and meaningful characteristics of real-life events-such as individual life cycles, small group behavior, organizational and managerial processes, neighborhood change, school performance, international relations, and the maturation of industries" (Yin, 2009, p. 5).

There are two types of case study design: single-case and multiple-case. A single-case study design allows the researcher to study a phenomenon in-depth that may have been before inaccessible. A single-case design also calls for careful and thorough examination of the case to increase the robustness of the theory. Yin (1994) identified five components of research design that are important for case studies which include a study's questions; its propositions, if any; its unit(s) of analysis; the logic linking the data to the propositions; and the criteria for interpreting the findings (Yin, 1994, p. 20). There are various sorts of case studies: instrumental, collective or multiple, and intrinsic (Stake, 1995; Yin, 2009). An instrumental case study focuses on a single issue of concern, selecting one bounded case to demonstrate it.

This instrumental single case study aimed to understand a real-life phenomenon, which is the experience of African Francophone doctoral students in one bounded system, a Midwestern research university in the U.S. It is representative because it captures the conditions of a common place situation. The researcher combined several strategies (interviews, documents, and audio 
materials) to reach richer insights of African Francophone doctoral students' experiences and perceptions.

\section{Setting}

The present study took place at a Midwestern research university. The rationale for selecting this site was the relative high presence of African students $(n=194)$ and the access to participants. Table 3.1 presented detailed information of students from thirty-three African countries, the country official language(s), and level of students.

The present institution, located in the American Midwest, welcomes a relative large number of African students. In 2015-2016, the institution reported over 190 African students studying there. Open Doors described recent increasing interest of international students to Midwestern colleges and universities.

Table 3.1

Origin of a Midwest Public University African Students

\begin{tabular}{|c|c|c|c|c|}
\hline Place of Origin & Undergraduate & Graduate & Professional & Official Language \\
\hline \multicolumn{5}{|l|}{ Eastern Africa } \\
\hline Kenya & 7 & 7 & 1 & Swahili, English \\
\hline Rwanda & 10 & 4 & 0 & $\begin{array}{l}\text { Kinyarwanda, English, } \\
\text { French }\end{array}$ \\
\hline Somalia & 1 & 0 & 0 & Somali, Arabic \\
\hline South Sudan & 1 & 0 & 0 & English \\
\hline Sudan & 13 & 2 & 0 & Arabic, English \\
\hline Tanzania & 0 & 1 & 0 & Swahili, English \\
\hline Uganda & 2 & 2 & 0 & English, Swahili \\
\hline \multicolumn{5}{|l|}{ Central Africa } \\
\hline Cameroon & 6 & 2 & 0 & English, French \\
\hline Chad & 0 & 1 & 0 & French, Arabic \\
\hline The Republic of the & 2 & 0 & 0 & French \\
\hline \multicolumn{5}{|l|}{ Congo } \\
\hline The Democratic & 6 & 0 & 0 & French \\
\hline \multicolumn{5}{|l|}{ Republic of the } \\
\hline \multicolumn{5}{|l|}{ Congo } \\
\hline \multicolumn{5}{|l|}{ Horn of Africa } \\
\hline Eritrea & 3 & 8 & 0 & None, Tigrinya \\
\hline
\end{tabular}




\begin{tabular}{lllll}
$\begin{array}{l}\text { Ethiopia } \\
\text { Northern Africa }\end{array}$ & 4 & 8 & 0 & Amharic \\
Algeria & 0 & 1 & 0 & Arabic \\
Egypt & 4 & 10 & 0 & Arabic \\
Libya & 1 & 2 & 0 & Arabic \\
$\begin{array}{l}\text { Morocco } \\
\text { Tunisia }\end{array}$ & 1 & 2 & 0 & Arabic \\
$\begin{array}{l}\text { Southern Africa } \\
\text { Botswana }\end{array}$ & 0 & 1 & 0 & Arabic \\
Malawi & 0 & 1 & 0 & English, Tswana \\
Mozambique & 1 & 1 & 0 & English, Chewa \\
South Africa & 0 & 1 & 0 & Portuguese \\
& 0 & 4 & 0 & English, Afrikaans, \\
Zambia & 0 & 4 & 0 & Xhosa, Zulu \\
$\begin{array}{l}\text { Zimbabwe } \\
\text { Western Africa }\end{array}$ & 6 & 2 & 0 & English \\
Benin & 5 & 2 & 0 & \\
Burkina Faso & 5 & 7 & 0 & French \\
Côte d'Ivoire & 2 & 1 & 0 & French \\
Ghana & 3 & 12 & 0 & French \\
Guinea-Bissau & 1 & 1 & 0 & English \\
Liberia & 1 & 0 & 0 & Portuguese \\
Nigeria & 3 & 4 & 1 & English \\
Sierra Leone & 1 & 0 & 0 & English \\
Togo & 10 & 2 & 0 & English, Bengali \\
Total = 194 & $\mathbf{9 9}$ & $\mathbf{9 3}$ & $\mathbf{2}$ & French \\
\hline Not & & & \\
\hline
\end{tabular}

Note. Midwest Public University Fact Book 2015-2016.

The institution studied is an educational institution of international stature and classified within the Carnegie "Doctoral Universities: Highest Research Activity" category. Located in the Midwest of the United States, this institution was a land-grant university and a member of the Association of Public and Land-grant Universities (APLU). It was accredited by the Higher Learning Commission (HLC) of the North Central Association of Colleges and Schools. The institution registers annually over 25,000 students with 5000 graduate and professional students. The university hosted over 2,000 international students (Institution Research, Fall 2015), about 1000 of which were graduate and professional international students (Dunker, 2014). These students come from over 100 different countries. The top places of origin of students are China, Malaysia, India, Oman, and Brazil (Institution Research, Fall 2015). Participants were recruited 
after the researcher received the approval of the West Virginia University (WVU) Institutional Review Board (IRB) and the target institution approval to comply with human subject research requirements.

\section{Sampling Procedures}

Snowball sampling was used to recruit participants. This specific sampling is defined as "a technique for finding research subjects. One subject gives the researcher the name of another subject, who in turn provides the name of a third, and so on" (Vogt, 1999, p. 268). Snowball sampling, also referred to as a chain referral sampling was appropriate to select participants for this study because of their limited number in the institution. Because international graduate students often know each other, it was easy for current participants to recruit friends or contacts for the study. A linear snowball sampling was used. While this technique allowed the researcher to have access to participants, the researcher did not have control over which participants, existing participants referred to or the information they shared with each other. Another issue with the snowball sampling is that participants may tend to recommend people who have same traits, interests, and/or majors with them. The researcher used a gatekeeper, who was a full-time employee and a graduate student at the institution. The gatekeeper is from West Africa and was working and studying in the institution at the time of the study. The part of the gatekeeper was to identify participants and introduce them to the researcher. He did not take part in the study. His only role was to be an entry point to the institution and population. In addition to snowball sampling, a purposeful sampling was used. African Francophone graduate students were intentionally selected "because they can purposefully inform an understanding of the research problem and central phenomena in the study" (Creswell, 2007, p. 125). This sampling allowed me to gather data and information from a specific group that another group cannot provide. 


\section{Participants}

A qualitative researcher is interested in richer and meaningful data and not the quantity of data (Gay, Geoffry, \& Peter, 2009) or generalization of information (Creswell, 2013), causing sample size to be smaller than the sample size in quantitative studies. Scholars argue several reasons can influence the choice of a sample size in qualitative research, yet the concept of saturation is considered often as a main guiding principle (Mason, 2010). Saturation was fulfilled in this study, when participants addressed recurrent themes.

Creswell (2013) commented, "one general guideline for sample size in qualitative research is not only to study a few sites or individuals but also to collect extensive detail about each site or individual studied" (p. 157). The study centered on seven participants who came from five African countries, including: Central, North, and West Africa countries: Burkina Faso, Cameroon, country X [decided to remain anonymous], Senegal, and Tunisia. The choice of these countries was based on participants' accessibility at the time of the study, the researcher's background (the researcher comes from Burkina Faso), the gap in the literature, and the quest to understand African graduate student experiences in U.S. campuses. Although African graduate students share a similar French education system and somewhat similar historic (colonization) and cultural values, each country still has local languages and a specific national culture, which can have a unique influence on a student experience and perception of student-faculty relationship.

Both male and female students were included. Participants were at least 19 years old, on F1 or J1 student visas, all doctoral students, had been in the U.S. for more than a year and had previously been exposed to their respective countries' higher education systems. The relative small number of participants did not prevent the collect of rich data. 
Table 3.2

Overview of Participants Gender, Continental Region, and Department

\begin{tabular}{llll}
\hline Participants & Gender & Continental Region & Department \\
\hline One & Female & West Africa & Education \\
Two & Female & Central Africa & Education \\
Three & Male & West Africa & History \\
Four & Male & West Africa & English \\
Five & Male & North Africa & History \\
Six & Male & West Africa & Economics \& \\
& & & Statistics \\
Seven & Male & Central Africa & Statistics \\
\hline
\end{tabular}

Data Collection and Data Collection Plan

Creswell (2007) compared the data collection in a qualitative study to a "series of interrelated activities aimed at gathering good information to answer emerging questions" (p. 117). To reach a good case study, Yin (2009) suggested using multiple sources of evidence. This study included several data sources: diary, two distinct individual interviews, and audio recordings. The data collection occurred in two phases: phase one was diary writing and collection; phase two consisted of individual interviews. Once I received the approval from the Institutional Review Board (IRB), the gatekeeper provided several participants' names, email addresses, and telephone numbers. The researcher sent an introductory email to participants providing them with information on the study and an invitation to participate in the study. The seven participants who came forth were provided with additional information and consent forms. Once I received students' consent to participate, I sent the diary entry instructions and questions. After participants completed the diaries, the researcher conducted the first phase of data analysis. For the next step, I scheduled the interview date, time, and location. Diaries and individual interviews were gathered across five weeks.

The two-fold data collection took place in Spring 2017. The diary entry included seven participants (see Table 3.2), occurred over two and a half weeks, and allowed participants to 
reflect on their experiences as international student in the U.S. The interview included the same participants. However, one participant could not participate in the interviews. Both the diary entries and individual interviews were conducted in English. All participants were comfortable engaging in English with the researcher. Though participants come from a French language background, one could argue for the richness of the data when diaries and interviews are conducted in participants' first language, but the time constraints and potential translation of the data from French to English guided the choice of the researcher to conduct the diaries and interviews fully in English. Furthermore, because the phenomenon is experienced in English, conducting the diaries and interviews in English could allow the researcher to better capture the participants' experiences in this specific context.

Diary Entries. Diary entries can serve as preliminary information and a source of emergent questions to guide interviews. The intent of this diary was to provide participants an opportunity and a time to reflect on their experiences in the U.S. and country of origin, and share the experiences they had/have with faculty, specifically their graduate advisor. The rationale for using diaries to support the interviews in this study is participants can have plenty of time to reflect and describe and share their stories. Diary method has been used in qualitative research and several disciplines like Nursing (Li \& Bray, 2007). Several researchers have previously used dairies to support individual or group interviews (Li \& Bray, 2007). In the present study, participants were given several open-ended questions pertaining to their experiences in their department and with faculty (Appendix B). Two to three questions were sent every other day to give participants an opportunity to ponder and share their experiences.

First Individual Interview. An individual interview was conducted with six participants. The interview did not last more than one-hour. The semi-structured interview format used in this 
study "enables participants to express and explore their experiences, thoughts, and viewpoints creatively" (Knowles, 2007, p. 139). According to Patton (2002):

We interview people to find out from them those things we cannot directly observe... we cannot observe feelings, thoughts, and intentions. We cannot observe behaviors that took place at some previous point in time. We cannot observe situations that preclude the presence of an observer. We cannot observe how people have organized the world and the meanings they attach to what goes on in the world. We have to ask people questions about those things. The purpose of interviewing, then, is to allow us to enter into the other person's perspective (pp. 340-341)

Furthermore, the semi-structured interview format tends to give flexibility to the researcher, allowing him/her to orient the conversation based on what is happening and said on site. Questions can be created or removed in the protocol based on the answers given by the interviewee during the interview. The advantage of conducting semi-structured interviews for this study is the opportunity to have a two-way communication between interviewer and participant. Another advantage is that the interviewer can prompt and ask follow-up questions. I mainly chose this data gathering format because of the chance it gives to be connected with participants and to give them a voice to openly share their experiences.

The interview involved a series of open-ended questions. When discussing good questions to ask in a qualitative interview, Patton (2015) recommended six types of questions, including questions related to (1) experience ad behavior, (2) opinions and values, (3) feelings, (4) knowledge about a situation, (5) sensory, and (6) background/demographic. Appendix C describes the interview protocol I used. After each interview I went through the audiotape and interview notes and assessed if I needed further information. As a qualitative researcher and a 
graduate student from Burkina Faso, West Africa, I was cognizant of the experiences of international student and the temptation I may have to guide the conversation through my own experience. Nonetheless, I permitted my participants to share their experiences and prompted them when only needed.

Second Individual Interview. The second interview was used as a member check. All six participants were contacted and only one participant came forth. The phone conversation lasted between 10-12 minutes long between the researcher and the participant. The researcher asked few questions regarding participant's responses in diaries and interviews for clarity purposes. The member checking was very helpful and confirmed findings.

Ethical considerations. Keeping in mind the rights and privacy of my participants. I was determined to foresee any problems that may stand up while conducting the study (Creswell, 2009). To do so I complied to the CITI training and submitted an application for IRB approval. An approval of the West Virginia University (WVU) and target institution were received in regard to the application proposed by the researcher. A cover letter was provided to participants informing them of the study purpose and intent, the intended use of the data collected, and the voluntary choice to participate or withdraw at any time of the study without consequences. The participants were also ensured orally and in written format of the confidential character of their

answers and identity. Copies of both institutions' approvals (Appendix D and Appendix E) were sent to each institution for record purposes.

\section{Data Analysis}

Nieuwenhuis (2007) explained "...qualitative data analysis tends to be an ongoing and iterative process, implying that data collection, processing, analysis and reporting are intertwined, and not necessarily a successive process" (pp. 99-100). The data analysis process 
"involves consolidating, reducing, and interpreting what people have said and what the researcher has seen and read — it is the process of making meaning" (Merriam, 2009, pp.175176). Yin (2009) goes further, suggesting to start analyzing the data with the questions in the case study protocol (p. 128). While my intent was not to do a grounded theory study, I utilized the constant comparative method of data analysis to understand African Francophone doctoral student lived experiences in the U.S. If this method was first recommended (Glaser and Strauss, 1967) for developing grounded theory, research has shown that "the constant comparative method of data analysis is inductive and comparative and so has been widely used throughout qualitative research without building a grounded theory” (Merriam, 2009, p. 175). In citing Glaser and Strauss (1967), Fram (2013) affirms the constant comparative analysis method "is an iterative and inductive process of reducing the data through constant recoding" (p. 3). The method necessitates an in-depth reading of the data, a coding and recoding process that leads to the identification of themes (Thomas, 2009). According to Thomas (2011) "the basic principle governing the process of constant comparison is that you emerge with themes that capture or summarize the essence (or essences) of your data" (p. 171). For the data analysis, the following steps (Thomas, 2011, see figure 3.1) were followed:

Step 1. Organize data (raw data files, working data files).

Step 2. Read individually each diary or interview transcript (from working data files) going line by line and underlining the sections that may be relevant to my research questions.

Step 3. Read through each diary or interview transcript a second time to make sure I am not missing important ideas. Mark any "temporary construct" or frequent ideas found in the text (Thomas, 2011, p. 172). 
Step 4. Read the diaries or interviews again using the temporary constructs as a reference, abandon the ones that are not reinforced and come up with "second-order constructs" (Thomas, 2011, p. 127). Thomas (2011) argues that these second-order constructs "should make a good job of summarizing the important themes" (p.172) in the data. Step 5. Go through the diaries or interviews once more refining the second-order constructs. Once satisfied with these constructs, label them themes. "These themes, or categories, are the essential building blocks of...analysis" (Thomas, 2011, p. 172). Step 6. Map themes using good quotations to illustrate them.

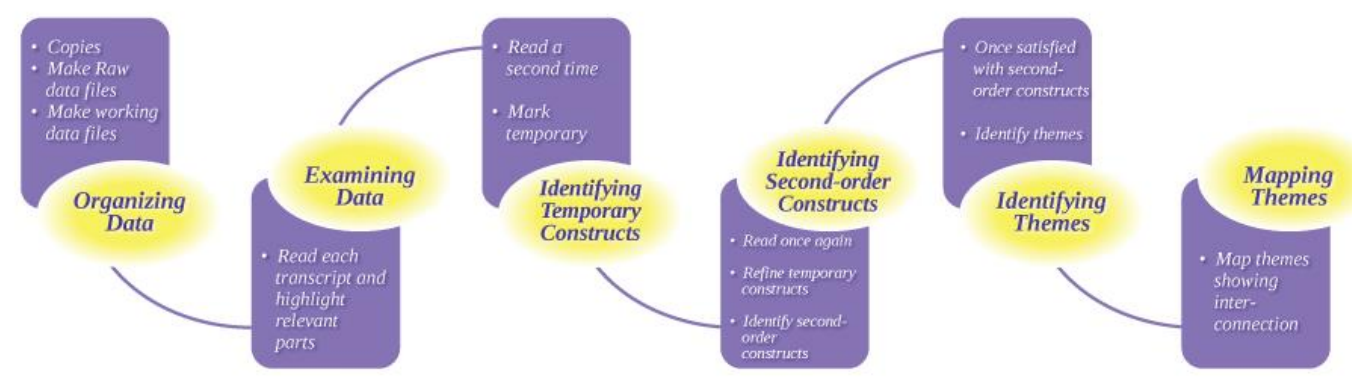

Figure 3.1. Constant comparative method: Using Thomas' (2011) model as a means of data analysis.

\section{Thematic Data Analysis}

For each participant, the researcher collected data from a diary entry and an individual interview. To understand and describe African Francophone doctoral students perceived experiences of student-faculty relationship I utilized values coding to code the diaries and interview transcripts. Since my research questions asked African Francophone doctoral students to assess their beliefs and values because of the shift in cultural, education, and linguistic 
systems; value coding was appropriate to code the data. "Values coding is the application of codes onto qualitative data that reflect a participant's values, attitudes, and beliefs, representing his or her perspectives or worldview" (Goble \& Wolf, 1993; LeCompte \& Preissle, 1993, in Saldana, 2009, p. 89).

A code can be a word or a phrase that recapitulates the data (Saldana, 2009) When coding, the qualitative researcher uses personal judgment which is tainted by her bias (Sipe \& Ghiso, 2004 in Saldana, 2009). Knowing what to code and what to leave out is not a new issue for novice qualitative researchers. Some scholars (Strauss, 1987, in Saldana 2009) believed everything in the data should be coded while other argued that only relevant part of the data should be coded (Seidman, 2006 in Saldana, 2009). Saldana (2009) recommended novices to qualitative research to code "anything and everything that was collected" (p. 15).

All collected data for this study was manually coded. While the manual process was tedious and time consuming, "there is something about manipulating qualitative data on paper and writing codes in pencil that give you more control over and ownership of the work" (Saldana, 2009, p. 22). The data analysis included two phases and is described as follows.

\section{Phase One - Diaries Analysis}

The first phase of analysis focused on diary entries. The dairy entry (Appendix B) included a series of open-ended questions. The diaries were collected over two and a half weeks. Participants informed the researcher of their busy schedules constraining the researcher to send several reminders and assure they completed the diaries.

A constant comparative method was utilized for the diaries analysis. I read each diary in its entirety several times, and spent time marking relevant points to the study. The themes started to emerge from the data including education system barriers, faculty preparedness, language 
obstacles, differences in culture, sense of freedom, sense of self-acceptance, discrimination, and relationship between student-faculty. During the diary analysis, it became apparent there were two groups of students: those who experience little difficulty and those who struggled. The interviews provided the researcher an opportunity to further examine the emergent themes in the diaries and explore these two groups.

\section{Phase Two - Interviews Analysis}

The second phase of data analysis included interview transcripts. The interviews were conducted using semi-structured format with open-ended questions. Participants were prompted to talk about relationship experiences, and factors influencing these relationships. I collected six audios with the longest audio at 57 minutes and 54 seconds and shortest at 31 minutes and 50 seconds. I first listened to each audio file and transcribed verbatim the researcher and participants' conversations. Next I read each transcript several times and noted relevant portions in regard to the research questions and framework. The multiple readings allowed the researcher to note recurrent ideas across diaries and interview transcripts. Themes found in the diaries were combined with the emergent themes in the interviews or dropped. The final themes included (1) advisor relationships, (2) supports, (3) unequal power, (4) barriers, (5) language, (6) culture, (7)

previous experiences, (8) immigrant status, and (9) faculty-student readiness. Table 4.1 provides details on the themes in relation to research questions.

\section{Establishing Trustworthiness}

To ensure trustworthiness in the study, several strategies were used.

Credibility. In order to certify that my report is true to participant responses I used member checks or respondent validation (Merriam, 2009). According to Maxwell (2005) "this is the single most important way of ruling out the possibility of misinterpreting the meaning of 
what participants say and do and the perspective they have on what is going on, as well as being an important way of identifying your own biases and misunderstanding of what you observed" (p. 111). I conducted a second interview that was used as member check with two participants. This strategy allowed participants to check the preliminary analysis for any misinterpretation. Peer examination (Merriam, 2009) is another approach used in this study. The frequent discussion I had with faculty and peers provided me with feedback to address my biases and polish my research questions, data collection, and data analysis. As a West African graduate student it is necessary to constantly acknowledge my position, personal experience, connection with participants and any obstacles it can cause to my full understanding of African Francophone doctoral students' experiences in the U.S.

Dependability. Another effort to ensure trustworthiness in the study occurred with the use of triangulation (Merriam, 2009). The use of individual interviews and diaries strengthens the study (Patton, 2002), allowing me to check participant responses across the two types of data collected.

Transferability. Yin (2009) stated that generalization is not an automatic process. Transferability as discussed here refers to the degree to which the findings of the present study can be generalized or transferred to other similar institutions. For Yin (2009), a theory can be tested by challenging the current findings in one or several institutions where the researcher thinks the same findings should occur. "Once such direct replications have been made, the results might be accepted as providing strong support for the theory" (Yin, 2009, p. 44).

Confirmability. Case study research calls for the use of multiple sources of evidence leading to a triangulation of data to confirm information (Yin, 2009). Additionally, as a researcher I have revealed my interests in this study and interpretations when discussing the 
findings and conclusion. Stake (1995) affirmed that researchers should reveal their standpoints in the interpretation. Yet, as a researcher I attempted throughout the study to conduct, transcribe, and report precise data and information, giving in-depth information from African Francophone doctoral students' perspectives.

\section{Summary}

Chapter Three dealt with the methodology. In addition to discussing her positionality and role, the researcher covered the following points: the research design, the research site, the sampling procedures, the participant selection, the data collection, the ethical issues, data analysis, and the creditability and trustworthiness of the data. Chapter Four presents the findings of the research, and Chapter 5 ties these themes to the framework and existing literature, and provide implications for future research and practice. 


\section{Chapter Four. Findings}

The purpose of this study was to explore and describe the experiences of African Francophone doctoral students and their academic relationships with faculty. Seven African Francophone doctoral students who studied in a Midwestern research institution participated in the study. The study aimed to answer an overarching question: What are African Francophone doctoral students' relationship experiences with faculty in a United States research institution? The research also investigated two subsidiary research questions:

1. How do African Francophone doctoral students at a Midwestern research institution perceive their relationships with faculty?

2. What factors influence these relationship experiences?

Chapter four presents the findings of the data analysis. Especially, it introduced the participants, reported the emergent themes, and provided a summary of the chapter.

\section{Participant Portraits}

Participants in the study were diverse and came from Central, North, and West Africa. There were two female and five male students. The age range was between 35 and 45 years old. Five of the seven participants came in the U.S. under the Fulbright Foreign Student Program. The Fulbright Program, established in 1946 by J. William Fulbright and supported by the U.S. Department of States and Bureau of Educational and Cultural Affairs, offers funding to both foreign and national professionals, scholars, students, and teachers to further teaching and research. One hope of this program is that the foreign Fulbright fellows will take back home their knowledge of the U.S. culture, and the academic skills acquired to empower their countries (iie.org). While these five participants recognized making the decision to pursue a degree in the 
U.S. and applying for a Fulbright fellowship, the choice of this specific institution was made by the Institute of International Education (IIE) officer.

The two remaining participants reported that this institution was the first or only one to give them an admission. Participant Six wrote: "[Name of institution] was the only school which gave me an admission to their Ph.D. program.” Participant Seven shared that based on his research on American universities he knew this institution would be the easiest to get in. For this reason, he wrote: "I did not try to spend my money in applications." When I prompted the participants about how they felt about this lack of choice, the first participant reported that at first he was happy because "When you first arrive in the U.S. you do not know the system and you just want to be accepted in a university. And having one institution admit and provide you with an assistantship for your studies, you do not have a reason to complain, mainly if you have been rejected by other institutions in the past." Despite this lack of choice, he explained that after studying in the U.S. for a while and knowing more about the system and universities, he thought that maybe a different institution would have been a better fit for him.

Participant One. Participant One is a tall female graduate student from Burkina Faso, West Africa, pursuing a doctorate degree in education. She came in the U.S. via the Fulbright scholarship. She has been in the United States for more than five years and describes herself as a goal oriented person who is focused on her goals and objectives. She appears to be a very joyful person and smiled and laughed a lot. She lost both her parents at a young age and was raised by her older brother, which gave her a different approach to education and life. She stated: "I was more focused on school and had little connection with partying like other young girls and boys do in my country. My concern was just about studying, finishing my degree and get[ting] a job to be independent." Education meant a lot to her because she believed being educated gave her a 
voice and the power to stand for herself and do the things she wants to do. Initially, Participant One explained she left her country for the U.S. because she was frustrated and needed to "breathe a fresh air," she also shared that she left to, "get [an] education in America because of the quality of their degrees and also the opportunities this will offer to me on the job market worldwide." She is married and lives in the U.S. with her husband and two children. During the interview, Participant One shared her concerns and pointed out the difficulties in finding childcare for her children and the potential for negative outcomes given these troubles. She asserted that these obstacles couponed any academic challenges she experienced in her program. She wrote:

I am a mom with two kids and an international student. And studying and managing a family is not easy particularly in this country here where you know that you need to pay for day care to send your baby there or find someone who would take care of the baby so that you can have the peace of mind to study. So this is something I am experiencing right now my baby doesn't have day care so I need to rely on friends to help me take care of him and it is affecting a lot my studies.

Participant One said if she was unable to find childcare, she would have to miss class, negatively affecting her grades.

Participant One also complained about social relationships in the U.S. She described the difference between the U.S. and her home country in these terms:

When I came here, uhm, the first thing I notice maybe about people is that there were not, I found them not that happy, uhm, well it looks like everybody was too serious. Let me put it this way: too serious, not like in my environment where people laugh really loud and they chat in the streets. 
This cultural difference, she explained, made relationships difficult. She described her perceptions of people in the U.S. as reserved, focused on themselves, and hesitant to develop friendships. If they do stop to talk with you, the conversation tends to be superficial. "It is going to be just about the weather,' or 'Oh, today is a nice day. Isn't it?'” She continued, "I had a hard time making friends in this country, even up to now I can say that I have only one of two friends and if I say friend it is not like friends in Africa, people with whom I can do everything or tell everything new. It is still some sort of friendship with reserve."

Participant Two. Participant Two is a female doctoral student education major from Central Africa. She was in her last year of a doctoral program and described herself as a firm person, dedicated, and thoughtful. She commented: "I put a lot of work and effort in everything I do" She had been in the U.S. for over five years and was living at the time of the study with her husband and children. She is a Fulbright fellow. I noticed Participant Two had a strong personality and was not shy to share her experiences and concerns. She confirmed my assumptions stating,

When I think strongly about anything I tend to make sure my voice is heard about that issue, and this is one of the reasons I started my doctoral studies in education because I thought that if I pursue my studies in education at the doctorate level, not only would I be able to learn better but I would also be able to impact more people in my life as an educator.

Participant Two criticized the assumptions of many Americans on Black Africans. She shared in her interview:

When I go shopping or interact with people in public places because I have an accent that clearly shows that I am not from here one time I had somebody assumed that I don't 
know how to read and I have nothing against refugees or I am not better than refugees but the fact that they see a black person from Sub-Saharan Africa in this city some people assume that it's a refugee person who come from rural areas some place in Africa and who does not know anything. So that can hurt and sometimes at the same time I know they mean well and they want to help.

Participant Three. Participant Three is a 45-year-old male doctorate student from Burkina Faso, West Africa, majoring in History. He appears confident in his answers and attitudes. He calls himself an 'Americanist' because of his deep interest in American language, culture, and civilization. His background is in American Literature and Civilization. Participant Three was a Fulbright fellow at the time of the study. He is married and his wife and children were living in Burkina Faso when the study was conducted. Participant Three reported that because of this situation, he spent most of his time studying, on campus, or sleeping. He had been in the U.S. for almost three years. Participant Three believes he was having an enriching experience in the U.S. However, he pointed out that some of the challenges he faced in the U.S. came from his home country. He explained: "I remembered some of the news I got from home stressed me out to the point of like I needed to do a huge effort to move over some of the pain in order to be able to finally assist my family." He recounted the time his wife called him from his home country to tell him his father-in-law passed away. He said: "I imagine my wife alone there back home her father passed away her husband is not around to support her she was all alone; it's not easy." When discussing education, Participant Three recognizes the importance of being educated. He explained:

Being educated is having the opportunity to confront or to share other people experiences and share your experience with them this is the only way you can enrich yourself because 
it is not just degrees but it is how the system can improve you or how the system can change you average student so you can participate in communicative way so it is not just learning by role related in a specific way as a teacher or a professor do but it's how much you can impact your environment with what you receive from the system.

Participant Four. Participant Four is a tall male graduate from Senegal, West Africa. He earned a Ph.D. in English several years ago from this institution and was now back in Senegal teaching. He came under the Fulbright fellowship to continue his education in the U.S. When I reached out to him to hear his story and understand his experience in the U.S., he agreed to share his story. The different time zone and his busy schedule made the exchange a little bit chaotic. Participant Four wrote in his diary:

I decided to apply for a Fulbright fellowship to complete my Ph.D. in the USA for many reasons. First, it would enable me to have access to any document I needed. Second, I would have the chance to take courses in postcolonial studies and literary criticism that were not available at my university. Third, I would be able to focus on my studies and research without being distracted by the numerous socio-cultural constraints of the Senegalese society. Fourth, It was so hard to complete a Ph.D. in English less than 6 years at my University given the large number of students and the scarcity of Associate professors who are the only ones supervising Ph.D. dissertations.

Education holds an important place in Participant Four's family. He recounted in his diary: “My father was a civil servant who dedicated himself to the education of his children. My mother, though she was a housewife, valued education." Participant Four discussed the competitiveness of the Senegalese education system, which he believes is partially caused by free education. He commented in his diary: "Throughout their cursus [school cycle], Senegalese students compete 
and are ranked. That type of competition environment could at times be traumatic as, for example, only 20 percent of candidates would succeed in entering mid school.”

Participant Five. Participant Five is a male graduate student from Tunisia, North Africa. $\mathrm{He}$ is a Ph.D. candidate in history and a teaching assistant in the Department of History. He had been living in the U.S for seven years. He previously earned a bachelor degree in History and English from a Tunisian university. He first came under the Fulbright fellowship in the U.S. to complete a master's degree. Participant Five reported he spend most of his time reading, exploring, and researching. During the interview he shared a prejudiced situation he encountered when he was writing for his university's newspaper. He told:

I used to write for the university newspaper called [newspaper's name]. I used to write some articles about different topics but I feel like there was one particular reader each time I write something he will just go online, go on the internet and comment section. $\mathrm{He}$ will just start attacking my person because he knows that I am from Tunisia and that I am a Muslim and so he just leaves out the content of my article and then he will just start attacking my person. Because you are a Muslim, you are an Arab you think this way particularly if you are critical with anything related to American foreign policies. But obviously the editor noticed that. He blocked him and he deleted his comments.

Participant Five recounted he has good relationship with faculty from various countries in his department, including United States, Germany, Armenia, and Bolivia. He felt lucky working with one of the top international leading scholars in southern colonialism, Dr. [name], who is a faculty in his department. Throughout the interview, I noticed Participant Five's passion for his work. He shared his future plans and places he would like to work because of their relevance to his research interests. 
Participant Six. Participant Six is a male student from Burkina Faso, West Africa, pursuing a dual doctorate degree in economics and statistics. He is 38 years old and had been living in the U.S for more than nine years. When he arrived in the U.S, he first studied English and then continued his studies in a community college. He earned a Master's degree in economics from his home country. He describes himself as a motivated and hard-working student. Participant Six noted that he did not have to go through many challenges in his doctorate program because he had already been in the U.S. for a while and had adjusted. Participant Six wrote in his diary: "Growing up in Burkina was great. I came from a modest family, and went to a good private school. After high school, I went to college where learning is very brutal; and a lot of brilliant people fail to graduate."

During the interview, Participant Six complained about African students' modesty and lack of promotion of themselves. He explained: "We don't know how to sell ourselves and in the U.S. knowing how to sell yourself is a big deal. People from our culture, you don't expose what you know or what you can do. You let people see what you can do."

Participant Seven. Participant Seven is a 35-year-old male major in statistics from Cameroon, Central Africa. He describes himself as a hardworking and dedicated person. He was single at the time of the study and had lived in the U.S. for over seven years. Participant Seven did not seem motivated during the interview, and I had to prompt him several times to get him talking. Participant Seven explained he wanted to get his degree and return to his home country to share his knowledge and skills with people from Cameroon. Similar to other participants, Participant Seven discussed his experience with social relationships in the U.S. Participant Six reported in his diary entry: "People are not too sociable here, or maybe I am not sociable but in my current office, there are some students since the first day that they get into the office, when I 
say hi to them they have never responded maybe that's how they are." However, he admitted that he had good interactions with other students. When discussing his experience back in Cameroon, Participant Seven wrote in his diary: “Growing up in my country has been difficult from beginning to the end. There is nothing that is easy to have. You have to fight every day." He shared that he never thought about coming in the U.S. He wrote: "I come from a French speaking country. So coming to America was not an option for me. I had never dreamt about America." His plans later changed mainly because of the advice he received from one of his aunts. He explained: "My aunt who lived in France for more than a decade told me that there is [are] more opportunity [opportunities] in America than most of the countries in Europe. So going to America will better improve your welfare (education as well)."

\section{Findings}

Data analysis were conducted in two-folds. Several themes emerged from the data and are described below. The themes presented in Table 4.1 describe the lived experiences of seven African Francophone doctoral students. They provide insight into their worlds, values, resiliency, and dreams. The results showed that African Francophone doctoral students encountered challenges in their relationships with faculty. They have to adjust to the complexity of the new relationship tainted by the language and cultural differences. Findings are categorized from the research questions aspects: What are the relationships? How do African Francophone students perceive these relationships? And what factors influence these relationships?

Table 4.1

Emergent Themes

\begin{tabular}{ll}
\hline Research Questions & Themes \\
\hline $\begin{array}{l}\text { (1) What are the } \\
\text { relationships? }\end{array}$ & Advisor Relationships \\
\hline
\end{tabular}




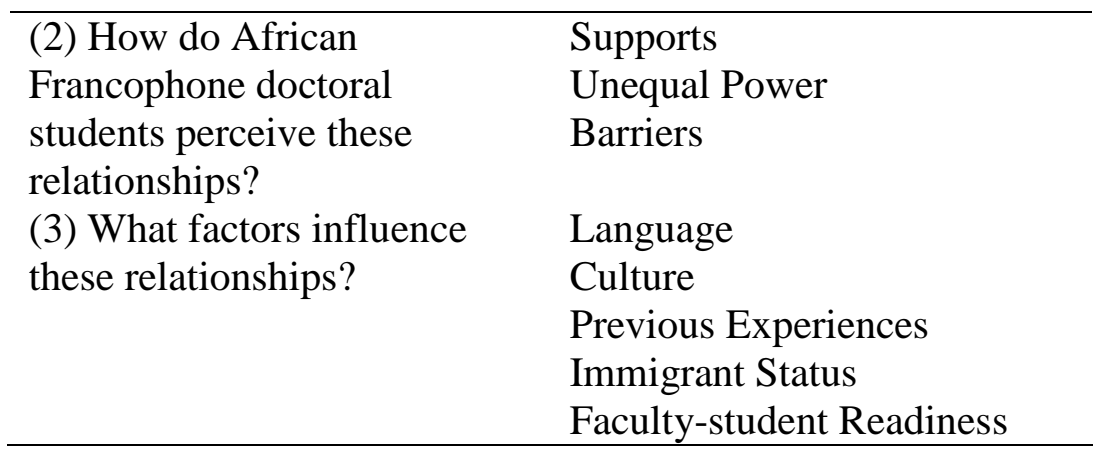

\section{Relationships}

In the diaries and during the interviews, participants discussed their experiences with faculty in the U.S., with a greater focus on advisor relationships.

Advisor Relationships. Previous studies stressed the importance of an advisor on doctoral student experience, program completion, and attrition rate (Adu, 2011; Gardner, 2007; Golde, 2000). When discussing academic relationships, participants described positive experiences with American faculty. Participant One shared her positive perceptions during the interview:

I believe I have some sort of collegial interactions with both faculty and my faculty advisor, because they do not consider me just as a student like a faculty in my home country would do. But they value me (...) by recognizing that I have skills and ideas to bring into our interactions rather than just someone receiving directives from top down high knowledge owner faculty.

Likewise, Participant Six reported: “(...) Interacting with faculties here is great. The faculty are most of the time available and willing to help."

In the diary entries and throughout the interviews most participants discussed the positive relationships they had with their faculty advisors on top of the faculty with whom they interacted in courses and departments. Participants unanimously recognized that the advisor is the most 
important person in their life. For these participants, an advisor is an instructor, a guide, mentor, resource person, and/or counselor. For example, Participant Three said: "Your advisor is the first person who is going to give you the feeling you are family. If he or she shows that your presence matters, your contribution matters you will give the best." He illustrated his statement by describing the welcoming and caring attitudes of his advisor. He reported: "When I feel stress[ed] out this is the person I talk [to]. She is not just my academic advisor she is also my mentor, she is also my psychologist, she is my everything." In the same vein, Participant Five shared: "I'm happy to be working now with a great advisor who shows care in everything." While most participants were happy with their relationship with faculty advisors, two participants reported their dissatisfaction with their advisors. Participant Six commented: "I wish my advisor took a leading role in my research. They could have pushed me more. They could have suggested conferences for me to attend. The coaching part of advising seems missing." Despite Participant Six's hope for his advisor to challenge him more, he reported in his diary entry and interview his will to do things on his own. He described: "Even though my professors are accessible, I still feel like I should do things on my own. I grew up in a school system where you rely on yourself or your classmates." Participant Two described a more negative experience with her advisor. She explained: "I wish I had a better relationship with my advisor. A lot of time, I felt looked down upon, berated, humiliated, denied credibility for what I achieved prior to my doctoral studies, and often not asked for what I think." She thought she had a better relationship with the faculty members in her department compared to her advisor. "Other members of the faculty often showed a lot more respect and valued my input on many things." She believes an advisor can impact international student funding and assistantship renewal. She declared: "Advisors of international graduate students have the scary power to influence a 
student's immigration status or funding renewal if they want to retaliate. This places the students in a vulnerable situation that does not give them much room to voice any disagreement or to complain when treated unfairly." She continued:

I would have appreciated interactions with my advisor that did not constantly instill fear or stress with a top-down approach; and placed me in a "de facto" deficit position; but rather inquired about what I can contribute, and how that is different from the academic practices in this part of the world.

Poor relationships influence satisfaction (Adrian-Taylor, Noels, \& Tischler, 2007; Barnes, Williams, \& Archer, 2010; Ferrer de Valero, 2001; Golde, 2000; Rice et al., 2009) and this particular participant mentioned she arrived at a stage of distrust of her advisor. Conflict in advising relationships is not new. Adrian-Taylor, Noels, and Tischler (2007) reported similar interpersonal conflicts between faculty supervisors and students.

All participants shared qualities they want to see in an advisor. When I also asked them about the type of faculty they wanted to become they described similar qualities they are looking for in a faculty advisor. These qualities align with Rice et al.'s (2009) proposed model of an ideal advisor, and included empathy, personable, respectful, guidance, open to communication, collaboration, feedback, and matching interests. Additional features participants reported are mentoring, coaching, and professionalism.

It is clear that participants who have a satisfactory relationship with their advisors appreciate the collaborative conversation and any types of help they get from the advisor, while participants who are dissatisfied reported a bitter experience and lack of meaningful collaboration with their advisors. The choice or assignment of an advisor varies across departments and schools. Most participants had been assigned an advisor and their expectations 
of the advisor may fall short because neither one got to choose the other based on common interests, personality, and fit. Some participants noted they wished they had access to important information regarding the education system, faculty expectations, and requirements so they did not have to learn the hard way. Participants provided varied recommendations for any African student planning to pursue a doctoral degree in the U.S. Participant Five proposed:

(1) Pick a good advisor who's going to help you through different challenges in the academe. (2) First meeting set up a timetable for your courses, exams, and dissertation. (3) Above all, make sure all topics of your class papers should serve your dissertation topic — don't waste time working on other topics—you'll have time after graduation to work on any field of interest. (4) Create a balanced life.

Participant Four also recommended: "Do not hesitate to approach your teachers. They will always respond favorably to your requests for appointments. Go and discuss with your professors during office hours. They love it."

The relationships described by African Francophone doctoral students are complex, and marked by unequal power in some instances, and by support and encouragement in others.

\section{African Francophone Doctoral Students' Perceptions of Relationships}

African Francophone doctoral students spent a good amount of the time in the diaries and interviews discussing the support they receive, unequal power between an advisor and an advisee, and barriers in the relationships. Unanimously, participants claimed that faculty in their specific departments supported them. When further questioned, the researcher noticed that the amount of support varied from one participant to another and from one advisor to another.

Supports. International student support in the host institution has been extensively examined (He, 2011). Researchers agree that social and academic support can make a difference 
in an international student's success and experience. Participants in this study claimed that faculty, their individual departments, and the institution as a whole supported them. All participants discussed the financial support they received from the departments. For example, Participant Two shared that the department of education: "provides funding every year. They renew as needed and they do check on the students' progress on my progress as a student. And when I go to somebody with concerns or questions I always get feedback and people are usually very nice.” Participant One, who was also from the Department of Education added: "my department offers fellowships every semester and you try and if you are lucky enough you can get a fellowship in addition to your assistantship which is very helpful because if you remember I mentioned financial difficulties like one of the difficulties international students encountered here." When discussing the support provided by the institution, participants believed their institution was very supportive through the presence of an office of international students and in terms of orientation for new comers, and student organizations.

In terms of academics most participants affirmed that they felt valued, and respected by faculty. Participants appreciated being able to take initiatives, share opinions freely, and being listened to. For example, Participant Six wrote in his diary entry: "In the U.S. you always seem like you are somebody because people will make you feel like what you say matter." Likewise, Participant Three reported: "I strongly feel at home in my department. Peers, faculty, and staff always listen and they value my point of view. When people can remember what I tell them about my culture and experience back home, it means they value what I say." Participant One pointed out: "I feel much freedom in my interaction with faculty now because they are available and offer support during class and their service hours to students." Yet, not all participants felt 
supported. Participant Two described her experience with her advisor in terms of power relations.

Unequal Power. "Human beings live out their daily lives and socially construct their reality through the negotiations, contestations and resistances of the rules and resources within which their lives are entwined. Through this ongoing dialectic people both influence and are influenced by the structures in which they find themselves" (Watkins, 1989, p. 16). The advisor role puts the faculty member in a position of power, complicating the advising relationship. Participant Two commented:

There is another aspect in academia especially graduate school that can be a lot of passive aggressive relationship[s] between faculty and students. It can be situations where power is at play and if respect is not prevailing then it is easy for the person in the position of power to restrict the person who is not so much in the position of power.

For this reason, Participant Two argued the importance of mutual respect between faculty and students. She believes without respect it is easy to suppress the voice of the person with less power, which is the student.

Agreeing with Gordon (2000) and Petersen (2007), Adu (2011) affirmed: "advisors are literally charged to police the academic boundaries as doctoral students are conducting their studies" (p. 23). Because of the role invested in advisors and the limits within a department, this partnership between advisor and advisee can create tensions in terms of advisee's dependency. Participant Seven also commented that working with an advisor can have some limitations. He believes that even though he can do what he wants, because of the authority invested in the faculty advisor he still cannot impose his choices and he is constrained to work within the boundaries defined by the advisor and the department. Participant Two added that for fear of 
retaliation she had never contradicted some of her advisor's judgments, which she thought could have been challenged. If Participants Two and Seven perceived the impact of power relations in the academic rapport, other participants discussed the existing barriers influencing their interpersonal relationships with faculty.

Barriers. Coming from a culture different from the United States, participants encountered barriers in their rapport with faculty. Participants discussed these barriers in relation to their culture, education, and previous experiences in home country. Several participants in the study discussed their expectations of their advisors. Participants tended to expect the advisor or faculty to clearly explain their expectations. When talking about her advisor, Participant One said:

Everything I said seemed ok for him as long as I wanted it. He would just make little suggestions. This gave me the feeling that he did not want to influence too much my decision. I did want him sometimes to do that [influence my decision] because I am not sure if everything I decided was great.

Along the lines, Participant Two shared her frustration in not always understanding the directions. She affirmed: "I don't always know what is appropriate and what is not and in a lot of time it seems like everybody knows exactly what to do in what situation and those are unwritten or unspoken rules that when I realized it later it makes me feel like I am dumb."

Other participants thought that it was the advisor's role to challenge them and tell them when to go to conferences. Participant Six wrote: “They [advisor, department] could have pushed me more. They could have suggested conferences for me to attend. (...).” Participant Three believed this type of expectations are rooted in his previous experience in his country of origin. He was accustomed to receiving his directives from his faculty and he explained: "here 
(...) you are on your own and you may miss a lot of opportunities to demonstrate that, in reality, you are a good student.”

\section{Influences on Student-Faculty Relationships}

Participants discussed the factors impacting their relationships with faculty in term of language, culture, previous experiences (education system), immigrant status, and facultystudent readiness.

Language. A common and recurrent challenge most international students experience is the language barrier and communication difficulties (Antwi \& Ziyati, 1993; Crosson, 2010; Liu, 2011; Trice, 2001; Vukeh, 1985; Wu, Garza, \& Guzman, 2015). The participants in this study are not an exception. Participants were divided in their challenges of language difficulties. All participants had previously studied English in their home countries before coming in the U.S. They also met the TOEFL and GRE requirements. Yet, the differences between participants who were still struggling with the language and those who were confident were attributed to time spent in the U.S., understanding others, being cognizant of one's own accent, and limited vocabulary. Three of the seven participants earned a master's degree from the U.S. These participants shared they were better prepared in their doctoral program compared to when they first arrived. Participant Six wrote in his diary: "I spent a lot of time studying English before being in the PhD program so I came with a different understanding of the language." Participant Three also reported he had little difficulties with the English language because of his previous exposure to the language and his degree in American Literature and Civilization.

While some participants described having a smoother transition, other participants talked about the challenges of the language related to limited vocabulary, American accent, and colloquial English. Participant One explained: "when I want to express an idea I sometimes lack 
words - the appropriate words - to make meaningful sentences the way I want to be understood." Similarly, Participant Two described: "I still struggle with how to phrase things, how to word things and I often find myself either checking with a native speaker or going on the internet to check if this is the right way to say something." Despite the difficulties to express ideas in English, Participant One did not give up. She shared in the interview the strategies used to get her ideas across. She stated: "I use a lot of gestures also. Sometimes I try to describe when I feel like the person doesn't get what I mean, I try to describe the thing so that it becomes easier to get what my idea is."

Participant Four discussed the difficulties understanding American accents. He wrote in his diary entry: "Even though I was an English major, I would find it hard to fully understand people due to their unfamiliar accent." Similarly, Participant One reported: "I had a hard time understanding what they will tell me, because they speak so fast and it takes me some times to kind of decode what they are saying, and also their accent, to be able to understand what they are telling me."

In terms of informal English, Participant Five recognized it was not easy transitioning from the formal English to informal English in the U.S. He reported American students use informal English in the classroom, which he found odd. He believed formal English should be used in academia. Though he admitted this formality may come from his French background. He said: "French is more sophisticated."

One participant talked about the language challenges beyond the classroom. In terms of public speaking, Participant One pointed out her anxiety presenting in front of a large audience. She affirmed: "I am thinking about starting attending conferences but I am so scared of my language level that I am almost paralyzed when I think about the idea of presenting in front of 
people.” If Participant One admitted, she still needs to improve her English; another reason slowing her to present at conferences could be her accent. She confessed: "I was very ashamed of my accent when I speak because everybody else has a different accent and they have this easiness to put their ideas while speaking." Despite her fear, she acknowledged she would have to do it, as it is necessary for her professional development. The findings in this study varied from Antwi and Ziyati's (1993) findings. Interestingly, participants in this study claimed that their peers and faculty understand English is not their first language and show them empathy. Participant Six explained: "The good thing here that a lot of people understand that international students don't speak American English or perfect English so because they understand communication is often smooth because they will sometimes try to complete sentences if you are struggling to say or express your idea."

One point on which all participants were unanimous was the difficult transition from French writing style to English writing style.

Transition from French Style to English Style. All participants agreed it was not easy transitioning from French writing style to English writing style. Learning is contextual (Bandura, 1997) and the language utilization goes beyond the only use of words. Language is connected to socio-cultural context (Ochs \& Schieffelin, 2011). Participant Five shared during the interview:

In the beginning you know I got used to thinking in French back home, writing in French style and when I got here obviously one of the professors he actually spent some time in France he does more than French history and he noticed in my essays that I use that French style and he urged me to kind of switch thinking in English rather than French because if you think in French and write in English I think sometimes your sentences get really awkward so yeah I think that helps me. 
Along that line, Participant One reported: “[my] writing is sort of, uhm, colored by my French background, so when I write in English uhm, it is like I am translating French into English.” When prompted to elaborate more on their understanding of French style versus English style, participants talked about the different writing requirements and structure of sentences. Participant Two explained: "In French, complex sentences are considered very good sentences and a piece of writing that has a lot of complex sentences is what is appreciated." She reported her observation of English writing style, which seemed the opposite of French. She continued: I had a hard time adjusting to the fact that I need to state my ideas in short straightforward sentences and also the style of writing in French that is held in high importance is the inductive style and that too I had to let go of and learn how to write in the deductive manner which means I need to state my point first and then bring supporting points and arguments whereas in French I should start with the least important and lead my reader gradually through my more and more important points and only at the conclusion I would reveal what I am trying to say.

Despite the challenges of learning to think and write in academic English, participants explained that writing in the new language style come with practice. Participant Five positively revealed that he writes much better in English compared to when he was pursuing his master's degree a few years ago.

Participants who struggled with oral expression in the English language experienced barriers between them and faculty.

Miscommunication related to language barriers. Because language is considered a tool of beliefs, values, norms, and attitudes, some participants reported miscommunications caused by language and culture differences. Participant Two explained: 
A professor I was assisting in a class. And we had a meeting with a student because there was a problem with grades and the professor really handled the situation very well and I meant to give him a compliment and said that it was very well handled. I wanted to say that was smart but I said that was clever.

The different meaning given to the word clever in French and English, she shared, created an awkward situation for her. She explained that the faculty member was offended and she could not understand the reason. To better understand the situation, she reported she had to verify the definition of clever. She continued: "I realized that being clever may have a slightly negative connotation of somebody wanted to deceive others whereas being smart is smart and it has a positive connotation."

Participant One also reported her advisor's frustration with her. She described: "I wanted to take one class and I was trying to explain to him that I really need to take this class because I am interested in it, and he wouldn't want me to take this class.” Despite her advisor's refusal, Participant One reported she could not understand the gravity of the conversation or the advisor body language. She said "He had to shout and then well he apologized after raising his voice over me before I realize that he was really serious, he was talking seriously."

Student language proficiency is crucial particularly at the graduate level where students are called to engage in classroom discussion, academic writing, including theses and dissertations, and interpersonal relationships with faculty and peers. The literature stresses the importance of language proficiency in student communication skills, interpersonal interactions, and success (Antwi \& Ziyati, 1993; Lipson, 2008).

Culture. Culture plays an important role in people's lives, and this role is more enhanced in a cross-cultural interaction (Crosson, 2010). Previous research (Lee \& Rice, 2007) reported 
negative experiences related to international students' culture. The findings of this study are not consistent with some of Lee and Rice's (2007) findings. While participants shared their challenges of adjusting to a new culture they recognized that this is common for any newcomer in a new environment. Participant Five wrote: "At the beginning, it was a bit challenging as I came from a very different cultural experience. For example, a few jokes in class didn't make sense to me because I didn't live those moments.” Participant Three pointed out his peers' curiosity to know him and his culture, which he saw as a good thing.

Several sub-themes emerged from the data: the meaning of respect in African student experience and gender matters. These findings are consistent with what Hofstede (1981) and Crosson (2010) reported in their works.

Meaning of respect. Participants described their understanding of respect and how it may sometimes clash with the academic culture in the U.S. Participants mostly talked about their difficulties interacting with faculty, and calling them by their first names. They shared that this is related to their previous experiences in home countries. Participants admitted that the reverence given to faculty in their home countries, the distance between student-faculty, and the respect of elders may undermine the relationship dynamic with U.S. faculty. Participant Three recounted: "I always feel that I need to keep some distance because they are my professors." Although she had been in the U.S. for several years, Participant Two reported having a difficult time calling faculty by their first names. She shared:

I was raised to show lot of respect and somewhat I will call it even reverence to my teachers in general so that is still present in the way I interact with every faculty member. I keep calling them doctor so and so and they insist that I should just call them on first 
name basis but I see that as very disrespectful and I think that some people think that I am being a snob.

Furthermore, Participant One also reported: "I am still not used to calling them by their first names. I always use Dr. or Professor plus their last names."

In the diary entries and throughout the interview I noticed the importance my participants gave to respect. When prompted to elaborate, Participant Three explained in these terms:

Just last week one of my professors said 'just sit on my chair and read on the computer.' In my culture, in my family, in my education you don't sit in somebody's chair when this person is older than you socially, higher than you. Based on this criterion you don't sit on this person's chair. I won't sit on my father's chair for example. I won't sit on my boss' chair for example. So I will just kneel on the floor or whatever but I won't sit on this person's chair.

This education difference, he clarified, guided his refusal to sit. He continued:

My father is chief of our village. I am suppose for example to become a chief one day so this is not the kind of stuff in our education. You don't sit in your father's chair or the chief chair so to my mind even if you are younger than me you are a professor I can't use your chair.

Despite the potential for close academic relationships in the U.S. several participants reported in the diaries and interviews, they intentionally or unintentionally put distance between faculty and them. These barriers can undermine the quality of interaction and collaboration like Participant One described:

When I go to his [advisor] office for meetings, I feel like, maybe because of his age also, he was older and I somehow consider him like a, if not a dad, like an uncle, you know 
how we consider elderly people in Africa. There is this kind of respect that I owe him, that make me stand a little bit away from him, somehow I am putting some barriers, some distance, physical distance and also even intellectual distance between us so, these are the reasons why I wouldn't ask him some of the things I have in mind.

Gender matters. Another sub-theme discussed by participants and related to cultural differences is gender matters. Participant One intentionally distanced herself from faculty, mostly older male faculty. She explained:

Right now I have a very cool advisor she is a lady and I feel like she is like a more like an aunty and the relationship is different compared to when I had this former advisor who looks like well he reminded me more a dad and an uncle so I wasn't really at ease with him.

Schroeder and Mynatt (1993) also found that female graduate students prefer and are more pleased with a supervisor of the same gender. A couple of elements that were not discussed in the literature and this study found are the preferences working with older female faculty and the self-limitation when working with older male faculty.

Participant Three shared his experience working with faculty from the opposite or same gender. He reported his preference for interacting with older female faculty. He explained:

I come from a community where space is... I am aware of gender differences like even my friends' wives I am very careful with what I say to them, my physical interaction with them. When I come in an environment where they have women I am okay when the women are much older than me for example I have one professor who is like my mother so this is the person I can give a hug greet she gives me hug I don't have a problem with that. 
He said he was very careful and cautious around younger women because of his education. He continued: "you don't go spend time at a certain time or a day of the night with women okay even if they offer. You have to be careful you go there for very very specific reason okay.”

Previous experiences. Participants consistently discussed the role of their primary education system and its impact on their learning and success in the U.S. To describe these differences participants pointed out the large amount of reading and writing in the U.S.

Participant Four noted: "In my home country, I was not used to writing long papers as there were assessments rather than assignments, and these assessments would be held in class. Another issue was the large amount of reading to do on a weekly basis at [institution name]." Participant Five also shared: "I underestimated the pace and volume of reading." Participant One affirmed: "My educational culture did not teach me to read a lot, so I am experiencing this difficulty until now." Confirming the previous statements, Participant Two shared in the interview: "The readings here is another component that is different because coming from an African country I was very much accustomed to having lectures and taking my own notes from lectures. And although I did read outside of class the volume of assigned readings was not as much as what is usually given out here."

Another major point discussed and similarly shared by most participants is the experience in the home country's university. Comparing their previous education system to the current one, participants discussed the class size, faculty availability, resources disposal, which gave them a different type of experience from one system to another. Participant Seven was very vocal about his challenging experience in his home country. He wrote in his diary entry:

I really have a bad experience. Firstly, there is a big gap between university and high school. When you are in high school, the class size is pretty small (45-100 first four 
years, and $<30$ thereafter). At university, the first year, there are 1500 students in the classroom, so professors cannot control the trouble. Everybody does want he wants. On top of this challenge, Participant Seven pointed out the difficulty taking notes. To access class notes, he affirmed: "you have to buy your notes from the professors and he will keep your name on his record so that he will grade your exam or homework."

In terms of faculty accessibility, Participant Four reported: In my previous university, students had very rarely the opportunity to meet their professors outside class time. Given high Student/teacher ratio, and the too formal student-teacher relationship common to Francophone countries, I felt there was too much distance between my teacher and me.

Along those lines, Participant Six described the absenteeism of some of his faculty when he was studying in his country. In terms of teaching format, Participant One pointed out:

My educational system is very teacher-centered. It affected me a lot in terms of independence and also decision making and even like self, self-direction speaking. It made me become really dependent on the professor in certain ways because back home you get all the directions form the teacher and all you have to do is just perform the activities, the academic assignments and everything the way he asked you do it.

Because of their past experiences, participants had positively appreciated the small class sizes and available resources and the academic relationship format offered in the U.S. Participant Seven explained: "When I was just starting classes here [U.S.] I never think one moment that I can do and ask something to the professor for me it was impossible so when I found out I can do that I start interacting with the professors." 
Despite faculty accessibility and available resources, two participants felt confused studying in a new education system. Participant Two reported in the diary entry and during the interview:

Taking classes in the U.S. can be confusing. Usually, the professors treat students with a high level of respect. However, a hand-off approach often prevails in interactions with faculty that often leaves me wondering how much help I can ask for before I am perceived as needy.

Participant Six also noted:

Here people would not tell you, you cannot do this or you can do this they will always hint what you can do what you cannot do and for us it is sometimes challenging because we are not use to taking those hints we want to be told what you can do or what you cannot do so that can be a challenge.

If participants described positive experiences with faculty and in their departments, they also admitted to their limited knowledge of the new education system, which can impact their academic relationships and learning. In terms of classroom discussion, Participant Two shared her frustrations. She explained:

I feel like I do not have the freedom to express myself in classes most of the time because a lot of people feel offended when you contradict their ideas and it feels like they are married to their ideas and they would rather not be contradicted so people keep quiet and people do not challenge some ideas that can obviously be challenged and I think that that lack of freedom is just everybody agrees not to use their freedom to challenge ideas or to go to a higher level of discussion just because they do not want to offend. 
Reflecting back on her experiences with classroom discussions in her country of origin, she continued:

I came to perceive the word 'argument' differently because in French when you say 'argument' it means just arguing a point not orally with people and people can have 'an argument' and it can go on for a long time but they don't have any hard feelings whereas here the word itself 'argument' is seen negatively.

Participant Two shared that because of this difference it has been hard for her to voice objectively her opinions for fear of offending faculty and her peers. Contrary to Participant Two, Participant Three recounted:

Americans do want to see things from other people perspectives. I remember writing a paper last semester to critique a book by one of my professors. She came back to me and thanked me for looking at her work with an African's eyes. She said that everything in my paper is scholarly inspirational to her as an American. I was the only international student in the class. So imagine the gains for research if all international students become more active.

This inconsistency in experiences between these two students may be explained by Participant Two frustrations with advisor and the feeling of undervalued and lack of consideration of her previous experience and knowledge as she described in the diary and interview. Compared to Participant Two, Participant Three acceptance and appreciation of the American language and culture may explain his enthusiasm and more positive tone.

Immigrant status. Like most international students, African Francophone students' positive sojourn in the U.S. requires a strict adherence to the immigration regulations. Any violation could compromise their immigrant status. If the U.S. Citizenship and Immigration 
Services (USCIS) provide opportunities for international students to work in the U.S. under the Optional Practical Training (OPT), participants discussed the constraints that come with this act.

Participant Five believed one contemporary challenge for African students or any international students is the 'after Ph.D.' Participant Five commented: "Once you finish your Ph.D. you have the pressure to find a job within six months through the OPT program, the optional practical training or you will be under pressure to leave the country." He added that this requirement defines the experiences of international students and limits those who finish their studies in the U.S. According to USCIS, the "Optional Practical Training (OPT) is temporary employment that is directly related to an F-1 student's major area of study" (USCIS.gov). USCIS distinguishes between the pre-completion OPT and post-completion OPT. The post-completion OPT discussed by Participant Five states that:

An F-1 student may be authorized to participate in post-completion OPT upon completion of studies.

- Employment must be directly related to the student's major area of study.

- Only full-time (more than 20 hours per week) OPT is available for post-completion OPT.

- Application for post-completion OPT must be received by USCIS prior to the end of the 60-day grace period following the completion of the student's academic program.

- Students must attend a mandatory information session before applying for OPT.

- Students earning a degree in a STEM field may qualify for an extension of OPT. Please see the Options After OPT section below for more information.

- Students must report employment to their respective offices of international students and scholars or risk automatic SEVIS termination after 90 days (international.nd.edu). 
Participants Two believes advisors can influence international students' immigration status. This complicates the relationship dynamic and limit students' complaints even if they want. She shared: "Advisor of international graduate students have the scary power to influence a student's immigration status or funding renewal if they want to retaliate."

Faculty-student readiness. To better support students, the literature suggests faculty learn about their students' culture and experiences (Constantine et al., 2005; Omotosho, 2005; Tompson \& Tompson, 1996). Faculty preparedness to work and support African students has been noted by most participants throughout the interviews and in the diaries. Participants believe it is important for American institutions welcoming international students to be prepared. Participant Two described her perceptions of faculty who have been abroad as interculturally competent to work and assist international students. She shared:

Some faculty members who spent time abroad even though they did not go to Africa were better at interacting with all international students than those who never left the country. And I am not saying that everybody should leave the country or live abroad before they can become a faculty member but I think it would be nice that the university gives them some sort of sensitivity training that would help interact with international students.

She added:

It seems like people know a lot about international students from Asia because we have big numbers and I hear a lot of people throw out sentences like okay Asian students will not always look you in the face Asian students will not always say no and that's good that they are trying to understand international students from Asia and trying to accommodate them but it would be nice to do so for everybody. 
Participant Three also reported: "I would advise universities to prepare their faculty to deal with international students. They are people from different cultures, so their behaviors are most likely to be different from American students."

Though there is still more work to do in that sense, participants in Glass et al.'s (2015) study on 'the impact of student-faculty interactions on international students' sense of belonging' reported the efforts U.S. faculty make to assist and accommodate international students.

Participants also discussed African students' preparedness to embark on the American education journey. Many African students' knowledge of American classrooms and faculty is based on other African or international students' experiences, books, or documentaries. This is not always enough to cover the meanings each person gives or brings to a student-faculty relationship or what their expectations are of this relationship. Further Nebedum-Ezeh (1997) found that the lack of preparation of African students before coming in the U.S. causes expectations and adjustments difficulties. When discussing cultural difference and student preparedness, Participant One commented:

The way we relate to our teachers and professors in the Francophone world is not always the same as what happens here and it always come as a chock to us when we see our fellow students here call their professors on the first name basis or just show a degree of freedom that would not have happened in our world.

This similar shock has been reported by participants in Crosson's (2010) study. Participant Two continued:

I think it would be good when preparing students coming from the Francophone world to tell them about the differences in the way we relate but also beyond that I think it's really 
important to tell them that just because it's your professor it doesn't mean you need to agree with everything they are saying.

Participant One also described in the interview student identification with faculty. She explained: The relationship between a teacher and a student (...) is different in Africa we look at our teachers in a different way we owe them respect and we don't disagree with what they say usually maybe now it is changing but I know at my time really you don't disagree with your teacher unless you want to be in trouble so you just obey what he says. You follow instructions and then you do your best to make the teacher requirements.

Students coming with such perceptions of faculty may experience difficulties because of how they relate to faculty. Participants agreed such preparedness on both sides is valuable for their adjustment and success.

\section{Summary}

All participants experienced the academic relationship with U.S. faculty in a unique way. Overall participants described positive experiences with faculty advisors in the U.S. This study adds knowledge to African student research and academic relationship research about how these students view their relationships and why they view them the way they do. The study revealed language can create barriers between students and faculty or acceptance of these students by faculty. The study also found that participants in the study intentionally construct barriers between themselves and faculty based on home country culture, complicating the relationship dynamic. In their relationships with faculty, participants experienced and negotiated new (and sometimes conflicting) meanings of freedom in these relationships to direct their own learning. 


\section{Chapter Five. Discussion, Implications, and Conclusion}

There is a large amount of research about African student experiences in the U.S., though most existing research on African students focuses on African Anglophone students and undergraduate students. (Adelegan \& Parks, 1985; Antwi \& Ziyati, 1993; Blake, 2012; Crosson, 2010; Lee \& Opio, 2011; Omotosho, 2005; Vukeh, 1985). Limited studies have examined student-faculty relationship dynamics from African Francophone doctoral student perspectives. This study aimed to advance knowledge of these relationships using African Francophone doctoral student voices. The study sought to answer one overarching question-What are African Francophone doctoral students' relationship experiences with faculty in a United States research institution? - and two subsidiary questions: (1) How do African Francophone doctoral students at a Midwestern research institution perceive their relationships with faculty? (2) What factors influence these relationship experiences? This single case study took part during Spring 2017.

\section{Interpretation of Findings}

African Francophone doctoral student relationships with faculty are shaped not only by the academic environment, but also by student experiences, which are connected to the language, culture, and understanding of teaching and learning. The findings of this study revealed several remarkable tendencies, which are related to the larger literature on academic and advising relationship, and African student experiences in the U.S.

Several themes did not fit neatly into the framework. Participants discussed the influence of social life experiences, like finding child care for children, on academic experiences. Participant Three commented that most of his difficulties came from his social life more than his 
academic life. Immigrant status was also another theme that did not fit into the current framework. However, these themes matter to the doctoral experiences of the participants.

Advisor Relationships. Participants had varied perceptions of their relationships with faculty—some positive and others negative. Participants described these relationships as accepting or distrustful, feeling valued or undervalued, and feeling empowered or disempowered.

The data analysis showed that a good relationship (including collaboration, mutual respect, and acceptance) was related to participants' positive perceptions of themselves, opinions of faculty, and overall experience. Participants discussed self-acceptance and sense of freedom while engaged with faculty, peers, and staff. Exceptionally, one participant reported feeling undervalued, scolded, and had difficulty bonding with her advisor. Rice et al. (2009) found similar frustrations with their participants. Schlosser et al. (2003) also reported that satisfied students tended to describe a positive and better relationship with faculty advisors while unsatisfied students described a negative relationship. Webber (2001) observed that issues that occurred between student and faculty advisor is linked to the lack of understanding of supervising/advising relationship. This study showed that the lack of consideration of student previous experiences, and knowledge could cause frustration and influence the relationship dynamic.

Participants believed an advisor has a detrimental role in their academic lives. Najjar (2015) affirmed that:

For many international doctoral students, the most important relationship they are able to develop outside of their own national group will be the relationship they create with their faculty advisor. The faculty advisor not only guides academic studies, supervises research or teaching, has the power to provide or deny funding, but may also serve as a 
professional gatekeeper who advises on publications and conferences. The advisor may also act as a mentor or a vital connection to future employment. (p. 14)

The apprenticeship model is widely used in American doctoral education. The advisors described in this study can be categorized in two groups: passive and active advisors. If some faculty have helped their advisees with funding to go to conferences others have not encouraged their advisees to participate to conferences. One participant felt he was not challenged enough and he thought this affected his employability. Yet the different priorities of faculty advisors may influence this activeness or passiveness in their advisees' academic lives.

Participant One, Two, and Six wanted more structured and explicit guidance. Gardner (2008) found that faculty advisors want their advisees to take initiatives and be independent. African students come from a more structured system, and the preference for structured instructions and advising may be based on a question of practice and routine. Because of their previous experiences in their home countries' higher education systems, participants were used to receiving directions and expected the same in their new relationships with the U.S. advisors. Most participants have been exposed to lecture style all their life and have developed a great passiveness throughout the years. This may become a problem when they are expected to take initiatives, share their knowledge and opinions.

Differences in culture. The findings clearly revealed that culture played an important role in student-faculty relationships. There is a great difference between the meaning given to respect and authority in both African and American cultures. Most students in the study were uncomfortable calling faculty by their first names. While this has been mentioned several times by different participants, using the title Dr. for a faculty or an advisor did not really influence the relationship dynamic of my participants. Participants reported that faculty understood where they 
were coming from and therefore sympathized. Nevertheless, this understanding does not address the important information students miss because they are too scared to ask questions or distance themselves intellectually from the faculty advisor. The study showed that the cultural barriers and previous experiences in home countries influence African Francophone doctoral student relationships with faculty. Antwi and Ziyati (1993) revealed West African students' feeling of isolation in their study. Yet, in this study, several participants intentionally distanced themselves from faculty because of age or gender. There were some inconsistencies in participants' needs. While some participants complained about their lack of interactions with faculty in home countries, they fail to take advantage of faculty's availability.

African students are aware of the challenges and differences (language, culture, education system) influencing their learning and daily interactions with faculty and faculty advisors. Most participants agreed faculty, staff, and peers are tolerant and accepting. The two students in the Humanities went further discussing the understanding people in their department exhibited. These findings are different from some of Antwi and Ziyati's (1993) participants'stories. Participants in Antwi and Ziyati's (1993) felt neglected because of their accent or origin. Several reasons can explain this difference: institution, student level, English proficiency, faculty, and classmates. Even in the same institution, like in this specific one, participants shared different stories ranging from very positive to bad.

Education System. The difference in education system influences student learning and interactions with faculty in this study. If the teaching and learning style has been researched in previous studies, participants in this study provided further evidence lacking in the literature. Writing is a complex mental process, and writing in a foreign language requires a mastering of the language to use it. To succeed, students need to understand the rules and requirements in 
reading and writing mostly at this stage where students are required to produce long papers and a dissertation as a final product of their doctoral study (Lipson, 2008). The findings in this study showed that students had limited experiences of the type of writing required in American colleges and universities. Participants admitted to the difficulty of learning to think and demonstrate their ideas in English.

Omar et al. (2016) found that academic writing was the most highly rated challenge faculty advisors reported while working with international students, while students rated faculty busyness as the top challenge. Faculty stressed the poor writing skills of international students (Omar et al., 2016), which required faculty to double their time when assisting an international student compared to an American student. The present study showed that language can cause misunderstanding and complicate student-faculty relationships. Several participants were frustrated because they did not always understand what was expected from them. In addition, they claimed faculty assumed they should know what was asked from them.

Language competence in relation to international students' adjustment has been extensively explored (Antwi \& Ziyati, 1993; Crosson, 2010). While language has been mentioned as barrier in understanding and interacting with faculty and peers, most participants in this study reported they did not experience language difficulties as much as coping with English writing.

\section{Theoretical Implications}

The cultural dimensions theory, language socialization, and socialization theory contributed to explaining the relationship dynamic, particularly the ways in which African Francophone doctoral students define and perceive their relationships with faculty. The findings supported Hofstede's (1981) assertions on student acceptance and respect of authority, 
preference for structured guidance, and understanding of gender and age matters. Many of the participants see faculty as authority figures. This causes students to expect faculty to take control of their learning and success, creating conflicting meaning in student-faculty roles. Because of their previous experiences and education in their home countries, some participants were not comfortable engaging with older male faculty or younger female faculty limiting the quality of intellectual collaboration and exchange with faculty.

The findings also revealed that the lack of knowledge of American campuses and education system influenced the students' relationships with their advisors. Participants did not always have a clear understanding of their roles as doctoral students and the advisor role. This implies a greater need to emphasize on African students and international students' socialization (Weidman, Twale \& Stein, 2001) in American universities. An important element that Weidman, Twale, and Stein (2001) overlooked is international students come already socialized. How can American institutions better support these students, recognizing their previous education and experiences, while socializing them in the new institution?

Language is more than words and sentences. It carries the culture, values, and worldview of individuals. While these students exhibit an acceptable language proficiency to deal with courses and interact with faculty, the language socialization model confirms that the lack, or absence of knowledge of American academic culture and custom left many participants confused and not always knowing the appropriate course of action to take. Indeed, the unspoken rules in one language and culture, which may carry individuals' values, means acceptable attitudes may not be always obvious for newcomers. The two incidents reported by Participants One and Two revealed that what is acceptable in one context may be improper in a different context. 
Cultural dimensions theory (Hofstede, 1980); language socialization (Ochs \& Schieffelin, 2011); and socialization of graduate and professional students (Weidman, Twale, \& Stein, 2001) are interconnected and help analyzed the social, cultural, and linguistic factors that influence African Francophone doctoral students' relationship experiences with faculty. Because of faculty and students' cultural differences, the graduate socialization process is challenging for both faculty and students and contributes to creating larger barriers between students and faculty advisors. The findings revealed that culture really affects African Francophone doctoral student socialization. African Francophone doctoral students need to change from a top-down transmission model to adapt to an apprenticeship/junior colleague model in the United States. Because of previous experiences in their home countries, participants tended to expect faculty to tell them what to do as opposed to contributing to the interaction.

The language barrier causes translation issues that complicate or mediate these relationships. African Francophone doctoral students are expected to understand the English written language as well as the norms of doctoral level writing and also the meaning and translation of the language in context.

\section{Limitations}

While there were interesting results from this study, there were also some limitations, which included the context, the small size of the sample, the target population, and the lack of voices of faculty and faculty advisors working daily with African Francophone doctoral students. With these limitations in mind, this study was intended to promote further research on African Francophone doctoral students. Research studies show that the student-faculty relationship is crucial and impacts the quality of the graduate experience (Gardner, 2007; Lechuga, 2011). With 
more diverse campuses, we would do well to continue our focus on African Francophone doctoral students, and international students in general.

\section{Practical Implications}

Because American higher education is increasingly diversified, and there is a greater chance for African students being advised by American faculty, the need for interculturally competent faculty is more crucial than ever. The study's findings have important implications for three main groups: faculty, African Francophone doctoral students in the U.S., and American higher education institutions.

Several participants pointed out the lack of preparedness of faculty to assist and support international students. Faculty, especially advisors of African Francophone doctoral students could gain insights into practice from the findings by recognizing the complexity of international students, and challenges each group and each individual brings. The exemplary advisors described in the study by many participants had a willingness to leave their own comfort zones and learn from their students in order to better support them.

This study examined and described African Francophone doctoral student perceptions of student-faculty relationship from the students' points of view. Potential students' expectations may not always coincide with the reality of U.S. education. Knowledge gained from this research may help African students better prepare and evaluate their readiness to take on the journey in U.S. higher education.

American universities and colleges can benefit from these findings and provide professional development to faculty to bring meaning support and changes to both faculty and students. There is a disconnect between U.S. faculty training and the population of students they serve. Most faculty in the U.S. are primarily trained to work with American students. With the 
increase of international students, it is important that institutions enrolling a large number of international students support international students by providing better training for faculty.

International students in the U.S. are not a homogenous group. They come from all over the world and with different learning and teaching experiences. Faculty need to understand their students' backgrounds, experiences in teaching and learning, and previous relationship experiences with faculty in their home countries if they want to better work, advise, and support these students. Faculty and university administrators have also the responsibility to support these students in adjusting to the new environment and adjusting their attitudes to the new context. Institutions could and should also provide professional development that focuses on awareness of cultural and linguistic differences of these students. This helps support faculty and by extension students' success and experiences.

\section{Research Implications}

Because this qualitative single case study aimed to examine and describe African Francophone doctoral student experiences of student-faculty relationship, it adds to a small body of African student-faculty relationship research in an introductory way. Further research is needed to gain deeper understanding of student-faculty relationship dynamic in regards to African Francophone doctoral students' experiences. First, it is important to replicate this study in a similar bounded system that welcomes African Francophone doctoral students to consider the ways in which context might influence experiences. Second, it would be beneficial to examine how advising styles impact relationship dynamics and student experiences. Third, it is important to find out how faculty advisors working with African Francophone doctoral students perceive their advising relationships, including alignment of expectations between faculty and students. Fourth, unexpected themes outside the research question emerged from the study and 
could be further examined to understand how African Francophone doctoral student social lives influence their academic life (i.e., child care, family, extended family in home country) and how immigrant status influences African Francophone doctoral students' experiences in American universities and colleges. Fifth, research is needed to understand African Francophone doctoral students' writing experiences and the mechanisms these students use to cope with such challenges. African Francophone doctoral students come from a different education system and it is important to fully understand these students to be able to assist and provide necessary support for them to transition and succeed in American campuses. Sixth, participants in the study come from majors ranging from English and History to Economics and Statistics. The different cultures across different disciplines about research may influence relationships with advisors as well as expectations for doctoral students by their advisors, which may lead to very different doctoral experiences. A further study can include the discipline layer to examine doctoral students' relationship experiences with faculty across different disciplines. In addition, because of the time limitation and small number of represented disciplines, the researcher did not closely look at similarities and differences across and within academic disciplines. An additional research study can focus on differences in advising across disciplinary bounds. And seventh, it will be helpful to explore how faculty interact or think about working with doctoral students in general and international students in particular.

\section{Concluding Observations}

Student-faculty relationships demand that both student and faculty negotiate their relationships. Faculty must understand who the students are, while students must be mindful of the education system in which they are situated in. The use of qualitative methods provided an in-depth understanding of student experiences as they negotiate student-faculty relationships and 
challenge their own personal values and beliefs. Though the existing studies on international students and African students highlight the communication difficulties experienced by students coming from non-English speaking countries, participants, in general, in this study did not experience or rarely experienced challenges when talking with faculty or peers. Instead, participants discussed more the struggle they had with transitioning from French writing to English writing. The diaries and interview transcripts provided rich and thick data. The participants' stories offered a glimpse in their world and how each navigates within the American system. Although these findings are limited to seven participants in a single case study, faculty, African students, and similar institutions could gain from the implications. 


\section{References}

Adelegan, F. O., \& Parks, D. J. (1985). Problems of transition for African students in an American university. Journal of College Student Personnel, 26, 504-508.

Adler, P. S. (1975). The transitional experience: An alternative view of culture shock. Journal of Humanistic Psychology, 15, 13-23.

Adrian-Taylor, S. R., Noels, K. A., \& Tischler, K. (2007). Conflict between international graduate students and faculty supervisors: Toward effective conflict prevention and management strategies. Journal of Studies in International Education, 90-117.

Adu, P. K. (2011). Conceptualizing doctoral advising from professors' and doctoral students' perspectives using concept mapping (Unpublished doctoral dissertation). West Virginia University, Morgantown.

Agarwal, V. B., \& Winkler, D. R. (1985). Migration of foreign students to the United States. The Journal of Higher Education, 56, 509-522.

Al-Sharideh, K. A., \& Goe, W. R. (1998). Ethnic communities within the university: An examination of factors influencing the personal adjustment of international students. Research in Higher Education, 39(6), 699-725.

American College Personnel Association (ACPA)., \& National Association of Student Personnel Administrators (NASPA). (2004). Learning reconsidered: A campus-wide focus on the student experience. Washington, DC: Authors.

Anderson, J. F., \& Powell, R. (1991). Intercultural communication and the classroom. In L. A. Samovar \& R. W. Porter (eds.), Intercultural Communication: A Reader (pp. 208-214). Belmont, CA: Wadsworth.

Andrade, M. S., \& Evans, N.W. (2009). Keys to persistence: International students in higher 
education. In M. S. Andrade \& N. W. Evans (Eds.), International students: Strengthening a critical resource (pp. 43-71). Lanham, MD: Rowman \& Littlefield Education.

Antwi, R., \& Ziyati, A. (1993). Life experience of African graduate students in a multi-cultural setting: A case study. Paper presented at the joint meeting of the Southern States Communication and the Central States Communication Association.

Arthur, N., \& Nunes, S. (2014). Should I stay or should I go home? Career guidance with international students. In G. Arulmani et al. (eds.), Handbook of Career Development (pp. 587- 606). International and Cultural Psychology.

Astin, A. (1993). What matters in college? Four critical years revisited. San Francisco: JosseyBass.

Bagley, C., \& Young, L. (1988). Evaluation of color and ethnicity in young children in Jamaica, Ghana, England, and Canada. International Journal of Intercultural Relations, 12, 45-60.

Bain, S., Fedynich, L., \& Knight, M. (2011). The successful graduate student: A review of the factors for success. Journal of Academic and Business Ethics, 1-9.

Bargar, R. R., \& Mayo-Chamberlain, J. (1983). Advisor and advisee issues in doctoral education. The Journal of Higher Education, 54(4), 407-432.

Barker, M. (1981). New Racism: Conservatives and the Ideology of the tribes. Univ Pubns of Amer.

Barletta, J., \& Kobayashi, Y. (2007). Cross-cultural counselling with international students. Australian Journal of Guidance and Counselling, 17(2), 182-194.

Barnes, B., \& Austin, A. (2009). The role of doctoral advisors: A look at advising from the advisor's perspective. Innovative Higher Education, 33(5), 297-315.

Barnes, B. J., Williams, E. A., \& Archer, S. A. (2010). Characteristics that matter most: Doctoral 
students' perceptions of positive and negative advisor attributes. NACADA Journal, 30(1), 34-46.

Barry, S. (2011). Analyse sociopolitique de la crise de l'enseignement supérieur au Burkina Faso: Cas de l'université de Ouagadougou (Unpublished Online Thesis). Université de Ouagadougou: Ouagadougou, Burkina Faso.

Bista, K., \& Foster, C. (2011). Issues of International Student Retention in American Higher Education. The International Journal of Research and Review, 7(2), 1-10.

Blake, A. C. (2006). The experiences and adjustment problems of Africans at a historically Black institution. College Student Journal, 40, 808-813.

Blake, A. C. (2012). African students studying in America: Their experiences and adjustment problems at an HBCU: An abridged version. iUniverse.

Bollag, B. (2004). Foreign enrollments at American universities drop for the first time in 32 years. The Chronicle of Higher Education.

Boroditsky, L. (2011). How language shapes thought: The languages we speak affect our perceptions of the world. Scientific American, 63-65.

Bourke, B. (2014). Positionality: Reflecting on the research process. The Qualitative Report, 19(33), 1-9. Retrieved from http://nsuworks.nova.edu/tqr/vol19/iss33/3/

Bragg, A. K. (1976). The socialization process in higher education. Washington, DC: The George Washington University.

Bretag, T. (2013). Challenges in addressing plagiarism in education. PLOS Medicine, 10(12).

Britton, S., Chamberlain, T., Davis, C., Easley, D., Grunden, C., \& Williams, J. (2003). Assessing international student perceptions of the classroom environment at a U.S. business school. Journal of the Indiana University Student Personnel Association, 65-79. 
Carson, B. M. (2008). Research on the experiences of international graduate students: A selective literature review. DLPS Faculty Publications: Western Kentucky University, 132.

Chang, J. C. (2005). Faculty-student interaction at the community college: A focus on students of color. Research in Higher Education, 46(7).

Choudaha, R. (2015, November 17). Diversity of international students in the US. Retrieved from http://www.huffingtonpost.com/rahul-choudaha-phd/post_10471_b_8563904.html

Clark, S. M., \& Corcoran, M. (1986). Perspectives on the professional socialization of women faculty: A case of accumulative disadvantage? The Journal of Higher Education, 57, 20 43.

Chun-Mei, Z., Golde, C. M., \& McCormick, A. C. (2007). More than a signature: How advisor choice and advisor behavior affect doctoral student satisfaction. Journal of Further \& Higher Education, 31(3), 263.

Church, A. T. (1982). Sojourner adjustment. Psychological Bulletin, 91(3), 540-572.

Cole, D. (2004). Minority students' faculty contact and the impact on their GPA. Paper presented at the annual meeting of the Association for the Study of Higher Education, Kansas City, MO.

Constantine, M. G., Anderson, G. M., Berkel, L. A., Caldwell, L. D., \& Utsey, S. O. (2005). Examining the cultural adjustment experiences of African international college students: A qualitative analysis. Journal of Counseling Psychology, 52(1), 57-66.

Council of Graduate Schools. (2004). Ph.D. completion and attrition: Policy, numbers, leadership, and next steps. Washington, DC.

Cox, B. E., \& Orehovec, E. (2007). Faculty-student interaction outside of class: A typology from 
a residential college. The Review of Higher Education, 30(4), 343-362.

Creswell, J. W. (1998). Qualitative inquiry and research design: Choosing among five traditions. Sage Publications.

Creswell, J. W. (2007). Qualitative inquiry and research design: Choosing among five approaches $\left(2^{\text {nd }}\right.$ ed.). Thousand Oaks, CA: Sage Publications.

Creswell, J. W. (2009). Research design: Qualitative, quantitative, and mixed methods approaches. Sage Publications.

Creswell, J. W. (2013). Qualitative inquiry and research design: Choosing among five approaches (3rd ed.). Sage: Thousand Oaks, California.

Crosson, L. S. (2010). How culture influences the experiences of international West African students enrolled in a two-year college degree program (Unpublished doctoral dissertation). University of Georgia, Athens, Georgia.

Deutscher, G. (2010). Does language shape how you think? New York Times Magazine.

Dewey, J., Boydston, J. A., Cahn, S. M. (2008). The Later Works of John Dewey, Volume 13, 1925 - 1953: 1938-1939, Experience and Education, Freedom and Culture, Theory of Valuation, and Essays. Southern Illinois University Press.

Doughty, C. (2004). Effects of instruction on learning a second language: A critique of instructed SLA research. In B. VanPatten, J. Williams, S. Rott \& M. Overstreet (eds.), Formmeaning connections in second language acquisition (pp. 181-202). Mahwah, N. J.: Lawrence Erlbaum Associates.

Dunker, C. (2014). [Institution Name] enrollment crosses 25,000 mark, largest enrollment since 1982. Lincoln Journal Star.

DuPraw, M. E., \& Axner, M. (1997). Toward a more perfect union in an age of diversity: 
Working on common cross-cultural communication challenges. Retrieved from http://www.pbs.org/ampu/crosscult.html.

Einarson, M. K., \& Clarkberg, M. E. (2010). Race differences in the impact of students' out of class interactions with faculty. Journal of the Professoriate, 3(2), 101-136.

Ejiofo, L. O. (2010). The experiences of international students in a predominantly White American university (Unpublished thesis). University of Nebraska-Lincoln, Lincoln.

Endo, J. J., \& Harpel, R. L. (1982). The effect of student-faculty interaction on students' educational outcomes. Research in Higher Education, 16(2), 115-138.

England, K. V. L (1994). Getting personal: Reflexivity, positionality, and feminist research. The Professional Geographer, 46(1), 80-89

Essandoh, P. K. (1995). Counseling issues with African college students in U.S. colleges and universities. The Counseling Psychologist, 23, 348-360.

Fairchild, H. P. (1967). Dictionary of sociology and related sciences. Totawa, NY: Littlefield, Adams \& Co.

Ferrer de Valero, Y. (2001). Departmental factors affecting time-to-degree and completion rates of doctoral students at one land-grant research institution. Journal of Higher Education, 72(3), 341-67.

Foreman, K., \& Monger, R. (2014). Nonimmigrant admissions to the United States: 2013. Washington, DC: Office of Immigration Statistics.

Fram, S. M. (2013). The constant comparative analysis method outside of grounded theory. The Qualitative Report, 18, 1-25.

Furnham, A., \& Bochner, S. (1982). Social difficulty in a foreign culture: An empirical analysis of culture shock. In S. Bochner (ed.), Cultures in contact. Oxford: Pergamon Press. 
Galloway, F., \& Jenkins, J. (2005). The adjustment problems faced by international students in the United States: A comparison of international students and administrative perceptions at two private, religiously affiliated universities. NASPA Journal, 42(2), 175-187.

Gardner, S.K. (2007). "I heard it through the grapevine": Doctoral student socialization in chemistry and history. Higher Education, 54, 723-740.

Gardner, S. K. (2008). What's too much and what's too little?: The process of becoming an independent researcher in doctoral education. The Journal of Higher Education, 79(3), 327-349.

Gardner, S. K. (2010). Faculty perspectives on doctoral student socialization in five disciplines. International Journal of Doctoral Studies, (5), 39-52.

Gardner, R. C., \& Lambert, W. E. (1972). Attitudes and motivation in second language learning. Newbury House: Rowley, MA.

Gardner, S. K., \& Barnes, B. J. (2007). Graduate student involvement: Socialization for the professional role. Journal of College Student Development, 48(4), 1-19.

Gardner, S., \& Mendoza, P. (2010). On becoming a scholar: Socialization and development in doctoral education. Sterling, VA: Stylus.

Gay, G. (1994). A Synthesis of Scholarship in Multicultural Education: Urban monograph series. North Central Regional Educational Laboratory. Eric. Retrieved from http://files.eric.ed.gov/fulltext/ED378287.pdf.

Gay, L. R., Geoffry, E. M., \& Peter, W. A. (2009). Educational research: Competencies for analysis and Applications. London, Pearson, 366- 375.

Giacchino-Baker, R., \& Baker, F. J. (1995). Institutional response of US colleges and 
universities to the linguistic and cultural needs of foreign students. 39-48. Retrieved from http://www.cpp.edu/ jis/1995/baker.pdf.

Giorgi, A. (1985). Phenomenology and psychological research (Ed). Pittsburgh, PA: Duquesne University Press.

Girves, J. E., \& Wemmerus, V. (1988). Developing models of graduate student degree progress. The Journal of Higher Education, 59(2), 163-189.

Glass, C. R., \& Braskamp, L. A. (2012, October, 26). Foreign students and tolerance. Inside Higher Ed. Retrieved from https://www.insidehighered.com/views/2012/10/26/essayhow-colleges-should-respond-racism-against-international-students.

Glass, C. R., Kociolek, E., Wongtrirat, R., Lynch, R. J., \& Cong, S. (2015). Uneven experiences: The impact of student-faculty interactions on international students' sense of belonging. Journal of International Students, 5(4), 353-367.

Glasser, S. P., \& Hook III, E. W. (2008). Mentoring and advising. Essentials of Clinical Research, 335-340.

Glaser, B. G., \& Strauss, A. L. (1967). The discovery of grounded theory: Strategies for qualitative research. New York, NY: Aldine De Gruyter.

Golde, C. M. (1998). Beginning graduate school: Explaining first-year doctoral attrition. In M. S. Anderson (Ed.), The experience of being in graduate school: An exploration (pp. 55-64). San Francisco, CA: Jossey-Bass.

Golde, C. M. (2000). Should I stay or should I go: Student descriptions of the doctoral attrition process. Review of Higher Education, 23(2), 199-227.

Goodwin, L. D., \& Stevens, E. A. (1993). The influence of gender on university faculty members' perceptions of "good" teaching. Journal of Higher Education, 64, 166-185. 
Institute of International Education. (2015). “International Students by Academic Level, 2013/14 - 2014/15.” Open Doors Report on International Educational Exchange. Retrieved from http://www.iie.org/opendoors.

Irizarry, J. G. (2011). Buscando la Libertad: Latino youths in search of freedom in school. Democracy \& Education.

Irwin, R. (2007). Culture shock: Negotiating feelings in the field. Anthropology Matters, 9(1). Retrieved from http://www.anthropologymatters.com/index.php/anth_matters/article/view/64/123

Habu, T. (2000) The Irony of Globalization: The Experience of Japanese Women in British Higher Education. Higher Education, 39, 43-66.

Han, X., Han, X., Luo, Q., Jacobs, S., \& Jean-Baptiste, M. (2013). Report of a mental health survey among Chinese international students at Yale University. Journal of American College Health, 61(1), 1-8.

Hanassah, S. (2006). Diversity, international students, and perceived discrimination: Implications for educators and counselors. Journal of Studies in International Education, 10(2), 157172.

Hartnett, R. T. (1976). Environments for Advanced Learning. In Scholars in the Making, edited by J. Katz and R. T. Hartnett, pp. 49-84. Cambridge: Ballinger.

Hindrawan, J. J. (2003, March 1). International student recruitment since 9/11. World Education News \& Reviews-WENR. Retrieved from http://wenr.wes.org/2003/03/wenr-marchapril2003-international-student-recruitment-since-911.

He, P. (2012). The social support for international graduate students to obtain academic success (Unpublished doctoral dissertation). West Virginia University, Morgantown. 
Hofstede, G. (1980). Culture's consequences: International differences in work-related values. Beverly Hills: Sage.

Hofstede, G. (1981). Culture and organizations. International Studies of Management \& Organizations, (4), 15-41.

Hofstede, G. (1985). The interaction between national and organizational value systems. Journal of Management Studies, 22(4), 347-357.

Hofstede, G. (2001). Culture's consequences: Comparing values, behaviors, institutions, and organizations across nations ( $2^{\text {nd }}$ ed.). Thousand Oaks CA: Sage.

Hull, W. (1978). Foreign students in the United States of America. New York: Praeger Publishers.

Huntley, H. S. (1993). Adult international students: Problems of adjustment. ERIC. Retrieved from https://archive.org/stream/ERIC_ED355886/ERIC_ED355886_djvu.txt.

Huxur, G., Mansfield, E., Nnazor, R., Schuetze, H., \& Segwa, M. (1996). Learning needs and adaptation problems of foreign graduate students. CSSHE Professional File, 15, 1-16. Retrieved from http://files.eric.ed.gov/fulltext/ED421025.pdf

Jenkins, H. M. (1983). Growth and impact of educational interchanges. In H. M. Jenkins (Ed.). Educating students from other nations. San Francisco: Jossey-Bass.

Jones, M. (2008). International Students' Cross-Cultural Experiences of Learning. International Journal of Asia-Pacific Studies, 4(2), 1-45.

Karakaya, I., \& Ülper, H. (2011). Developing a writing anxiety scale and examining anxiety based on various variables. Educational Sciences: Theory \& Practice, 11(2), 703-707.

Kezar, A. (2002). Reconstructing static images of leadership: An application of positionality theory. Journal of Leadership Studies, 8(3), 94-109. 
Kigotho, W. (2015, September 18). A profile of Sub-Saharan African students in America. University World News: The global window of higher education, (382). Retrieved from http://www.universityworldnews.com/article.php?story=20150917132859939

Kim, Y. Y. (2001). Becoming intercultural: An integrative theory of communication and crosscultural adaptation. Sage Publications.

Kingston, E., \& Forland, H. (2008). Bridging the gap in the expectations between international students and academic staff. Journal of Studies in International Education, 12(2), 204221.

Kluckhohn, C. K. (1951). Values and value orientations in the theory of action. In T. Parsons and E. A. Shils (Eds.), Toward a general theory of action. Cambridge, MA: Harvard University Press.

Kluckhohn, F. R., \& Strodtbeck, F. (1961). Variations in value orientations. New York: Row, Peterson.

Knowles, M. H. (2007). A narrative analysis of educators' lived experiences of motherhood and teaching (Unpublished doctoral dissertation).

Kumi-Yeboah, A. (2014). Transformative learning experiences of international graduate students from Africa. Journal of International Students, 4(2), 109-125.

Kuo, Y-H. (2011). International graduate students' challenges in Auburn university. LAP LAMBERT.

Kvale, S., \& Brinkmann, S. (2009). Interviews: Learning the craft of qualitative research interviewing. Sage Publications.

Lamport, M. A. (1993). Student-faculty informal interaction and the effect on college student outcomes: A review of the literature. Adolescence, 28(112), 971-990. 
Landsford, J. E., Antonucci, T. C., Akiyama, H., \& Takahashi, K. (2005). A quantitative and qualitative approach to social relationships and well-being in the United States and Japan. Journal of Comparative Family Studies, 36(1), 1-22.

Le, A. T., LaCost, B. Y., \& Wismer, M. (2016). International female graduate students' experience at a Midwestern university: Sense of belonging and identity development. Journal of International Students, 6(1), 128-152.

Lechuga, V. (2011). Faculty-graduate student mentoring relationships: Mentors' perceived roles and responsibilities. Higher Education, 62(6), 757-771.

Lee, J., \& Opio, T. (2011). Coming to America: Challenges and difficulties faced by African student athletes. Sport, Education and Society, 16(5), 629-644.

Lee, J. J., \& Rice, C. (2007). Welcome to America? International students' perceptions of discrimination and neo-racism. Higher Education, 53, 381-409.

Lipson, C. (2008). Succeeding as an international student in the United States and Canada. The University of Chicago Press.

Liu, L. (2011). An international graduate student's ESL learning experience beyond the classroom. TESL Canada Journal, 29(1), 77-92.

Lobnibe, J-F. Y. (2013). Different worlds, mutual expectations: African graduate student mothers and the burden of U.S. higher education. Journal of Education and Learning, 2(2), 201-209.

Mamiseishvili, K. (2012). International student persistence in U.S. postsecondary institutions. The International Journal of Higher Education and Educational Planning, 64(1), 1-17. Manning, P. (1999). Francophone Sub-Saharan Africa, 1880-1995. Cambridge University Press. Manyika, S. (2001). Negotiating identities: African students in British and American 
universities. Dissertation Abstracts International, 62(1-A), 97.

March, N., Zeman, J., \& Adrian, M. (2005). The effect of post 9-11 policy on foreign students: A critical analysis. Presentation at the 26th National Conference on Law and Higher Education Clearwater Beach, Florida.

Marginson, S., \& Sawir, E. (2011). Ideas for intercultural education. New York: Palgrave Macmillan.

Maringe, F., \& Carter, S. (2007). International students' motivations for studying in UK HE: Insights into the choice and decision making of African students. International Journal of Educational Management, 21(6), 459-475.

Mason, M. (2010). Sample size and saturation in PhD studies using qualitative interviews. Forum: Qualitative Social Research, 11(3). Retrieved from http://nbnresolving.de/urn:nbn:de:0114-fqs100387

Maxwell, J. A. (2005). Qualitative research design: An interactive approach (2nd ed.). Thousand Oaks, CA: Sage.

McMahon, M. (1992). Higher education in a world market: An historical look at the global context of international study. Higher Education, 24(4), 465-482.

Merriam, S. B. (1998). Qualitative research and case study applications in education. San Francisco, CA: Jossey-Bass

Merriam, S. B. (2009). Qualitative research: A guide to design and implementation ( $3^{\text {rd }}$ ed.). Jossey-Bass.

Mehta, S., Ruby, E., \& Letts, S. (1996). They're all alike to me: Student acceptance of foreign students. Paper presented at the American Psychological Association, Toronto, Canada.

Miller, A. M., Birman, D., Zenk, S., Wang, E., Sorokin, O., \& Connor, J. (2009). Neighborhood 
immigrant concentration, acculturation, and cultural alienation in former Soviet immigrant women. Journal of Community Psychology, 37, 88-105.

Mkhize, N. J., \& Frizelle, K. (2000). Hermeneutic-dialogical approaches to career development: An exploration. South African Journal of Psychology, 30, 1-8.

Najjar, K. (2015). International doctoral students, their advising relationships and adaptation experiences: A qualitative case study (Unpublished Dissertation). University of Nrebraska-Lincoln, Nebraska.

Nebedum-Ezeh, G. C. (1997). An examination of the experiences and coping strategies of African students at predominantly White institutions of higher education in the United States (Unpublished MS thesis). Michigan.

Nettles, M., \& Millett, M. (2006). Three magic letters: Getting to Ph.D. John Hopkins University Press.

Newsome, L. K., \& Cooper, P. (2016). International students' cultural and social experiences in a British university: Such a hard life [it] is here. Journal of International Students, 6(1), $195-215$.

Nieuwenhuis, J. (2007). Analyzing qualitative data. In K. Maree, J. W. Creswell, L. Ebersohn, I. Eloff, R. Ferreira, N. V. Ivankova, J. D. Jansen, J. Niewenhuis, J. Pietersen, V. L. Plano Clark \& C. Van der Westhuizen, First steps in research. Pretoria: Van Schaik.

Ngara, E. (1995). The African University and its Mission. Lesotho: Morija Printers.

Nguyen, H. M. (2013). Faculty advisors' experiences with international graduate students. Journal of International Students, 3(2), 102-116.

Nwadiora, E. (1996). Therapy with African Families. The Western Journal of Black Studies, 20(3), 117-124. 
Oberg, K. (1960). Culture shock: Adjustment to new cultural environments. Practical Anthropology, 7, 177-182.

Ochs, E., \& Schieffelin, B. B. (2011). The theory of language socialization. The Handbook of Language Socialization, 1-21.

Ogom, R. O. (2007). Tertiary education and development in Sub-Saharan Africa at the dawn of the twenty first century: A lost hope, or present opportunity? National Social Science Association, 29(1), 1-18. Retrieved from http://www.nssa.us/journals/2007-29-1/200729-1-18.htm\#_edn1

Omotosho, S. A. (2005). Being an African student: Stories of opportunity and determination. University Press of America.

Park, G., Rinke, C., \& Mawhinney, L. (2011, April). A critical look at international students in higher education contexts: Understanding critical and post-method pedagogy in two West African pre-service teachers. Paper presented at the Second Language Research SIG at the AERA 2011 Convention in New Orleans, LA.

Pascarella, E. T., \& Terenzini, P. T. (1977). Patterns of student-faculty informal interaction beyond the classroom and voluntary freshman attrition. Journal of Higher Education, 48, $540-552$.

Pascarella, E. T., \& Terenzini, P. T. (1991). How college affects students: Findings and insights from twenty years of research. San Francisco: Jossey-Bass.

Pascarella, E. T., \& Terenzini, P. T. (2005). How college affects students: A third decade of research. San Francisco: Jossey-Bass.

Patton, L. D. (2009). My sister's keeper: A qualitative examination of mentoring experiences 
among African American women in graduate and professional schools. Journal of Higher Education, 80(5), 510-537.

Patton, M. Q. (1985). Quality in qualitative research: Methodological principles and recent developments. Invited address to Division $\mathrm{J}$ of the American Educational Research Association, Chicago.

Patton, M. Q. (2002). Qualitative research and evaluation methods (3rd ed.). Thousand Oaks, CA: Sage.

Patton, M. Q. (2015). Qualitative research and evaluation methods $\left(4^{\text {th }}\right.$ ed.). Sage Publications, Inc.

Pedersen, P. B. (1991). Multiculturalism as a generic approach to counseling. Journal of Counseling \& Development, 70, 6-12.

Peluso, D. L., Carleton, R. N., \& Asmundson, G. J. G. (2011). Depression symptoms in Canadian psychology graduate students: Do research productivity, funding, and the academic advisory relationship play a role? Canadian Journal of Behavioral Science, 43(2), 119-127.

Pruitt, F. J. (1978). The adaptation of African students to American society. International Journal of Intercultural Relations, 2, 90-118.

Qin, D., \& Lykes, M. B. (2006). Reweaving a fragmented web of self: A grounded theory of self-understanding among Chinese women students in USA. International Journal of Qualitative Research in Education, 19(2), 177-200.

Reis, H. T., Collins, A., \& Berscheid, E. (2000). The relationship context of human behavior and development. The American Psychological Associations, 126(6), 844-872.

Reisberg, L. (2012). Why do we want international students? Inside Higher Ed. Retrieved from 
https://www.insidehighered.com/blogs/world-view/why-do-we-want-internationalstudents.

Resetarits, M. (2012). Graduate students' journey to the US. Chemical Engineering, 119(2), 21.

Rice, G. R., Choi, C., Zhang, Y., Villegas, J., Ye, H. J., Anderson, D., Nesic, A., \& Bigler, M. (2009). International student perspectives on graduate advising relationships. Journal of Counseling Psychology, 56(3), 376-391.

Roberts, A. (2010). The thinking student's guide to college: 75 tips for getting a better education. University of Chicago Press.

Robinson, C., \& Clardy, P. (2011). It ain't what you say, it's how you say it: Linguistic and cultural diversity in the classroom. Journal of Cultural Diversity, 18(3), 101-110.

Ruben, A. (2010). Surviving your stupid, stupid decision to go to grad school. Three Rivers Press.

Sahasrabudhe, U. (2007). International student mobility: A perspective of graduate engineering students from India (Thesis). California State University: Long Beach, California.

Saldana, J. (2009). The coding manual for qualitative researchers. Sage Publications.

Sam, D. L. (2001). Satisfaction with life among international students: An exploratory study. Social Indicators Research, 53(3), 315-318.

Sanchez, C. M., \& Curtis, D. M. (2000). Different minds and commons problems: Geert Hofstede's research on national cultures. Performance Improvement Quarterly, 13(2), 919.

Saul, S. (2016). Recruiting students overseas to fill seats, not to meet standards. The New York Times.

Sax, L. J., Bryant, A. N., \& Harper, C. E. (2005). The differential effects of student-faculty 
interaction on college outcomes for women and men. Journal of College Student Development, 46(6), 642-659.

Schieffelin, B. B., \& Ochs, E. (1986). Language socialization. Annual Review of Anthropology, 15, 163-191.

Schlosser, L. Z., Knox, S., Moskovitz, A. R., \& Hill, C. E. (2003). A qualitative examination of the graduate advising relationships: The advisee perspective. Journal of Counseling Psychology, 50, 178-188.

Schroeder, D. S., \& Mynatt, C. R. (1993). Female graduate students' perceptions of their interactions with male and female major professors. The Journal of Higher Education, $64,555-573$.

Seligman, A. (2012). Is graduate school really for you?: The whos, whats, hows, and whys of pursuing a Master's or Ph.D. Johns Hopkins University Press.

Silbernagel, E. (2015). Investigating the linguistic identity development of dual language Learners (Thesis). University of Northern Iowa, UNI ScholarWorks.

Shelley, F. (2013). Nation shapes: The story behind the world's borders. ABC-CLIO.

Smith, D. k. (nd). Cross-cultural adjustment. University of California Education Abroad Program, 1-2.

Stake, R. E. (1995). The art of case study research. Thousand Oaks, CA: Sage Publications.

Summer, S., Poyrazli, S., \& Grahame, K. (2008). Predictors of depression and anxiety among international students. Journal of Counseling \& Development, 86, 429-437.

Takougang, J. (1995). Recent African immigrants to the United States: A historical perspective. Western Journal of Black Studies, 19(1).

Takougang, J., \& Tidjani, B. (2009). Settlement patterns and organizations among African 
immigrants in the United States. Journal of Third World Studies, 26, 31-40.

Telli, S., Brok, P., \& Çakiroglu. (2008). Teachers' and students' perceptions of the ideal teacher. Education and Science, 33(149), 118-128.

Terenzini, P. T., \& Pascarella, E. T. (1980). Student-faculty relationships and freshman year educational outcomes: A further investigation. Journal of College Student Personnel, 21, $521-528$.

Thomas, G. (2009). How to do your research project: a guide for students in education and applied social sciences. London: Sage

Thomas, G (2011). How to do your case study: a guide for students and researchers. London: Sage

Thomas, K. M., Willis, L. A., \& Davis, J. (2007). Mentoring minority graduate students: Issues and strategies for institutions, faculty, and students. Equal Opportunities International, 26(3), 178-192.

Thornton, R., \& Nardi, P. M. (1975). The dynamics of role acquisition. American Journal of Sociology, 80(4), 870-885.

Tinto, V. (1987). Leaving college: Rethinking the causes and cures for student attrition ( $1^{\text {st }}$ ed.). Chicago: University of Chicago Press.

Tinto, V. (1993). Leaving college: Rethinking the causes and cures of student attrition ( $2^{\text {nd }}$ ed.). Chicago: University of Chicago Press.

Tompson, H., \& Tompson, G. (1996). Confronting diversity issues in the classroom with strategies to improve satisfaction and retention of international students. Journal of Education for Business, 72(1), 53-57.

Triandis, H. C. (1995). Individualism and collectivism. Boulder, CO: Westview Press. 
Triandis, H. C., \& Berry, J. W. (2004). Cross-cultural psychology, overview. In C. D. Spielberger (ed.), Encyclopedia of applied psychology. Oxford, United Kingdom: Elsevier Science \& Technology.

Trice, A. G. (2000, May). Navigating in a global learning community: Academic departments' responses to graduate international students. Paper presented at the annual forum of the Association for Institutional Research, Cincinnati, Oh.

Trice, A. G. (2001). Faculty perceptions of graduate international students: The benefits and challenges. Paper presented at the annual meeting of the Association for the Study of Higher Education, Richmond, VA.

Trice, A. G. (2003). Faculty perceptions of graduate international students: The benefits and challenges. Journal of Studies in International Education, 7(4), 379-403.

Tsang, E. K. (2001). Adjustment by mainland Chinese students and academics to Singapore. International Journal of Intercultural Relations, 25, 347-372.

Ushioda, E. (2010). L2 motivation, self and identity: Current theoretical perspectives. Antwerp CALL paper. Centre for Applied Linguistics, University of Warwick, Coventry, UK, 119.

Valenzuela, A. (1999). Subtractive schooling: U.S.-Mexican youth and the politics of caring. Albany, NY: State University of New York Press.

Vogt, W. P. (1999). Dictionary of statistics \& methodology: a nontechnical guide for the social sciences. Sage Publications.

Vukeh, E. N. (1985). Communication problems of West African students at the university of Minnesota (Unpublished doctoral dissertation). University of Minnesota.

Walker, G. E., Golde, C. M., Jones, L., Conklin Bueschel, A., \& Hutchings, P. (2008). The 
formation of scholars: Rethinking doctoral education for the twenty-first century. San Francisco, CA: Jossey-Bass.

Wang, H. (2006). How cultural values shape Chinese students' online learning experience in American universities (Unpublished doctoral dissertation). University of Georgia, Athens.

Wang, T. (2008). Chinese educational leaders' conceptions of learning and leadership: An interpretative study in an international education context. VDM Verlag.

Wang, T., \& Li, L. Y. (2011). Tell me what to do vs. guide me through it: Feedback experiences of international doctoral students. Active Learning in Higher Education, 12(2), 101-112.

Wang, Z. (2007). Key factors that influence recruiting young Chinese students. International Education Journal, 8(2), 37-48.

Warren, K. A., \& Constantine, M. G. (2007). Counseling African international students. In D. H. Singaravelu \& M. Pope (Eds.), A handbook for counseling international students in the United States (pp. 221-222). Alexandria, VA: American Counseling Association.

Watkins, P. (1989). Leadership, power and symbols in educational administration: Deakin Studies in Education Series 3. In J. Smyth (Ed.), Critical perspectives on educational leadership (pp. 7-26). RoutledgeFalmer: Taylor \& Francis Group.

Weaver, G. R. (1986). Understanding and coping with cross-cultural adjustment Stress. In R. M. Paige (Ed), Cross-cultural orientation: New conceptualizations and applications. Lanham MD: University Press of America.

Webber, R. (2001). Bungee jumping and supervision of higher degree students. Melbourne Studies in Education, 42(2), 89-104.

Weidman, J. C., Twale, D. J., \& Stein, E. L. (2001). Socialization of graduate and professional 
students in higher education: A perilous passage? New York: John Wiley \& Sons.

Wilson, R. C., Gaff, J. G., Dienst, E. R., Wood, L., \& Bavry, J. L. (1975). College professors and their impact on students. New York: Wiley.

Woldegiorgis, E. T., \& Doevenspeck, M. (2013). The Changing role of higher education in Africa: A historical reflection. Higher Education Studies, 3(6), 35-45.

World Bank (2016). "World Development Indicators 2016.” Washington, DC.

Wu, H-p., Garza, E., \& Guzman, N. (2015). International student's challenge and adjustment to college. Educational Research International, 1-9.

Yang, S., Salzman, M., \& Yang, C-H. (2015). Exploring the adjustment problems among international graduate students in Hawaii. Universal Journal of Educational Research, 3(3), 214-219.

Yin, R. K. (1994). Case study research: Design and methods (2 ${ }^{\text {nd }}$ ed.). Thousand Oaks, CA: Sage.

Yin, R.K. (2009). Case study research: Design and methods ( $4^{\text {th }}$ ed.). Thousand Oaks, CA: Sage Publications.

Zhao, C., Golde, C. M., \& McCormick, A. C. (2007). More than a signature: How advisor choice and advisor behavior affect doctoral student satisfaction. Journal of Further and Higher Education, 31(3), 263-281.

Zhou, Y., Frey, C., \& Bang, H. (2011). Understanding of international graduate students' academic adaptation to a U.S. graduate school. International Education, 41(1), 76-94. 
Appendixes A, B, C, D, E 


\section{Appendix A. Cover Letter}

\section{West VirginiaUniversity. \\ COLLEGE OF EDUCATION AND \\ HUMAN SERVICES}

\section{Dear participant,}

You are invited to take part in a research project to explore African Francophone graduate students' experiences interacting with faculty in a Midwestern institution and understand the factors influencing African Francophone graduate students' socialization and success in the institution and different programs. This project is being conducted by Nathalie H. Rouamba a doctoral candidate at the College of Education and Human Services, West Virginia University, under the supervision of Dr. Erin McHenry-Sorber, Assistant Professor of Higher Education.

Your involvement in this project will be kept as confidential as legally possible. You must be 21 years of age or older to participate and be a doctoral student from a Francophone country in Africa. Your name will not be published in any of my reports. Your responses will be audio recorded, but all recordings, diary entries, and identities will be kept confidential. The diary entries, recordings, and their respective transcriptions will be saved on my password-protected personal computer. The information obtained in this study may be published in scientific journals or presented at scientific meetings. There are no known risks or discomforts associated with this research.

Your participation is completely voluntary, and there is no compensation for participating in this research study. You may skip any question that you do not wish to answer, and you may discontinue at any time. The diary entry will last two weeks. The initial interview will last no more than 60 minutes. If you choose to participate in a follow-up interview, this will last no more than 30 minutes. West Virginia University's Institutional Review Board (IRB) has acknowledgement of this project is on file.

I hope that you will participate in this research project, as it could be beneficial in understanding African Francophone doctoral student experiences in the U.S. and providing ways for increasing international student retention, improving student support services and encouraging student success, and establishing an overall positive experience. Should you have any questions about this letter or the research project, please feel free to contact Dr. Erin McHenry-Sorber at 304293-2090 or by e-mail at ecmchenrysorber@mail.wvu.edu or Nathalie H. Rouamba by e-mail at nrouamba@mix.wvu.edu.

The study's title is Exploring African Francophone Doctoral Student Experiences of StudentFaculty Relationship and the IRB Protocol Number is 1611366815.

Thank you for your time and help with this project.

Sincerely,

Nathalie H. Rouamba 


\section{Appendix B. Diary Entry}

\section{WestVirginiaUniversity。 \\ COLLEGE OF EDUCATION AND \\ HUMAN SERVICES}

\section{Diary Entry}

Greetings my fellow African Francophone graduate students! I would like to know more about your experience interacting with faculty in the United States and home countries. Below are the instructions to complete a diary entry. Thank you.

Instructions: Please complete a diary entry based on your experience interacting with faculty and taking courses. Write your responses down in the word document or you can use a paper and pencil. Please provide as much information as you feel comfortable. The diary has to be completed in English. You will receive 2 to 3 questions every other day. You have two weeks to complete the diary. An extension will be given if needed. Thank you.

\section{Experience with Faculty Diary Entry}

\section{Participant name}

\section{Participant country of origin}

\section{Participant Discipline/Department}

\section{Day I}

Question 1: Tell me about what it was like growing up in your home country. Give me some examples.

Question 2: What motivated you to study in the United States? Give me an example. Question 3: Why did you choose this specific institution?

\section{Day II}

Question 4: What was your experience taking courses and interacting with faculty in your previous university (country of origin)? Give me an example.

Question 5: What is your experience taking courses and interacting with faculty in your current university? Give me an example.

Question 6: Have you experienced some barriers when interacting with faculty in your current department? Give me an example.

\section{Day III}

Question 7: Do you feel you belong to your current department? Give me an example.

Question 8: Do you feel you had a voice in the courses you have taken? Give me an example.

\section{Day IV}

Question 9: What were your expectations before coming to the department? Provide an example.

Question 10: Are your expectations met? Please explain. 


Day V
Question 11: How would you describe your interaction with faculty, faculty advisor?
Question 12: What are your expectations of your faculty advisor? Give some examples.
Day VI
Question 13: What kind of obstacles have you experienced when interacting with your
advisor? Please explain.
Day VII
Question 14: If you have to be a faculty, what kind of faculty do you want to be?
Question 15: What piece of advice would you give to a fellow student starting a doctoral
program in the U.S.?
Thank you for your time.




\section{Appendix C. Interview Questions}

\section{WestVirginiaUniversity.}

\section{COLLEGE OF EDUCATION AND}

HUMAN SERVICES

\section{Interview Questions}

\section{Introduction}

How would you describe yourself?

What kind of student are you?

\section{Question on language}

1. Language has been mentioned by several participants as a barrier, does it resonate with your personal experience? (follow-up question)

2. What is your experience interacting daily with faculty and your peers in English?

3. Tell me about a time language has been a barrier in communicating with faculty, or your faculty advisor?

4. Tell me about a time language has been a barrier in understanding lectures and assignments?

5. What has been your experience writing papers in English? Give me an example.

6. What has been your experience reading in English? Give me an example.

\section{Question on culture}

1. Several participants mentioned in their diaries they feel more freedom in the U.S.; do you feel the same way? (follow-up question)

2. Have you experienced cultural challenges in the U.S.?

3. How these challenges influence your learning and success? Give me an example.

4. Tell me about a time your previous culture influences your relationship with faculty? Give me an example.

5. Have you ever felt discriminated? What was the occasion?

\section{Question on socialization}

1. What do you hope to gain personally and professionally at the end of your program?

2. What are the obstacles for your success as an African Francophone doctoral student in your program?

3. What does student-faculty relationship mean for you?

4. What a successful student-faculty relationship looks like for you?

5. How your interaction with faculty influence your integration and success in the program? Give me an example.

6. How does your department support your success? Give me an example.

7. How does your institution support your success? Give me an example.

8. In the diaries, participants discussed U.S. faculty preparedness. How would you describe faculty preparedness to manage international students, specifically African students?

Final thought: Is there anything you want to add that I haven't addressed? 


\title{
Appendix D. IRB Protocol Exemption
}

\section{W. WestVirginiaUniversity. \\ Office of Research Integrity and Compliance \\ se6 CHESNUT RIDCE ROAD MORGANTOWN, WV 26506}

\section{Acknowledgement Letter Exempt Initial Protocol Review}

\author{
Action Date \\ 01/20/2017 \\ To \\ Erin McHenry-Sorber \\ From \\ WVU Office of Research Integrity and Compliance \\ Approval Date \\ 01/20/2017 \\ Expiration Date \\ $01 / 19 / 2020$ \\ Subject \\ Acknowledgement Letter Exempt Initial Protocol Review \\ Protocol Number \\ 1611366815 \\ Title \\ Exploring African Francophone Doctoral Students Perceptions of Student-Faculty \\ Relationship
}

The above-referenced study was reviewed by the West Virginia University Institutional Review Board IRB and was granted exemption in accordance with 45 CFR 46.101.

- This research study was granted an exemption because the Research involves educational tests, survey procedures, interview procedures or observation of public behavior and (i) information obtained is recorded in such a manner that human subjects cannot be identified, directly or through identifiers linked to the subjects; and (ii) any disclosure of the human subjects responses outside the research could not reasonably place the subjects at risk of criminal or civil liability or be damaging to the subjects financial standing, employability, or reputation [45 CFR 46.101(2)]. All exemptions are only good for three years. If this research extends more than three years beyond the approved date, then the researcher will have to request another exemption. The following documents have been acknowledged for use in this study and are available in the WVU+kc system:

Documents reviewed and/or approved as part of this submission:

Rouamba Letter Of Permission 12.22.16.pdf: 2016-12-22-05:00

DiaryEntryProtocol.pdf: 2016-12-21-05:00

CoverLetterResearchProject.pdf: 2016-12-21-05:00

InterviewProtocol.pdf: 2016-12-21-05:00 
Documents for use in this study have been acknowledged and are available in the WVUkc system in the Notes and Attachments section of your protocol.

The Office of Research Integrity and Compliance is here to provide assistance to you from the initial submission of an IRB protocol and all subsequent activity. Please feel free to contact us by phone at 304.293 .7073 with any question you may have. Thank you.

WVU Office of Research Integrity and Compliance

Date:01/20/2017

Signed: 
Appendix E. Letter of permission to conduct research

\section{Letter of Permission to Conduct Research}

Director of Research Compliance, give my permission for Dr. Erin McHenry-Sorber and Nathalie Rouamba, to conduct his or her study entitied "Exploring African Francophone Doctoral Students Perceptions of Student-Faculty Relationship," at the

Signąture of Location Administrator

Date
Printed Location Administrator Name
Dat $22 / 2016$

